RAFAEL WALTER DE ALBUQUERQUE

\title{
MONITORAMENTO DA COBERTURA DO SOLO NO ENTORNO DE HIDRELÉTRICAS UTILIZANDO O CLASSIFICADOR SVM (SUPPORT VECTOR MACHINES)
}




\section{MONITORAMENTO DA COBERTURA DO SOLO NO ENTORNO DE HIDRELÉTRICAS UTILIZANDO O \\ CLASSIFICADOR SVM (SUPPORT VECTOR MACHINES)}

Dissertação de Mestrado apresentada à Escola Politécnica da Universidade de São Paulo para obtenção do título de Mestre em Engenharia de Transportes

Área de Concentração:

Engenharia de Transportes

Orientador: Professor Livre Docente José Alberto Quintanilha 
Este exemplar foi revisado e alterado em relação à versão original, sob responsabilidade única do autor e com a anuência de seu orientador.

São Paulo, de janeiro de 2012.

Assinatura do autor

Assinatura do orientador

FICHA CATALOGRÁFICA

Albuquerque, Rafael Walter de

Monitoramento da cobertura do solo no entorno de hidrelétricas utilizando o classificador SVM (Support Vector Machine) / R.W. de Albuquerque. - ed.rev. -- São Paulo, 2012.

$95 \mathrm{p}$.

Dissertação (Mestrado) - Escola Politécnica da Universidade de São Paulo. Departamento de Engenharia de Transportes.

1.Imagem de satélite 2.Classificação 3.SVM (Support Vectors Machine) 4.Represa 5.Hidrelétrica 6.Sensoriamento remoto I.Universidade de São Paulo. Escola Politécnica. Departamento de Engenharia de Transportes II. t. 


\section{AGRADECIMENTOS}

A toda minha família e amigos, especialmente meus pais, que sempre apoiaram e estimularam meus estudos e crescimento profissional.

A José Alberto Quintanilha, Mariana Giannotti, Eduardo Jun Shinohara, Mauricio George Miguel Jardini, Manoel Cláudio da Silva Junior, Bruno Machado Telles Walter, Marcelo Brilhante Medeiros, Sérgio Eustáquio Noronha, Henrique Marinho Leite Chaves e Marcelo Hiromiti Matsumoto pela convivência e experiência profissional que proporcionaram ao longo da minha carreira acadêmica.

À FDTE (Fundação para o Desenvolvimento Tecnológico da Engenharia), pelo apoio profissional e concessão de material de trabalho.

À INVESTCO SA, pelo apoio financeiro ao desenvolvimento do projeto que derivou esta Dissertação.

Ao Prof. Dr. Teodoro Isnard Ribeiro de Almeida, pelo auxílio do LIG e suas ferramentas de trabalho, que possibilitaram o desenvolvimento desta Dissertação.

À Escola Politécnica da Universidade de São Paulo (EPUSP), pelo apoio institucional no desenvolvimento acadêmico-científico.

Ao Laboratório de Geoprocessamento da Escola Politécnica, pela estrutura e ambiente de trabalho que possibilitaram o desenvolvimento deste trabalho.

À ENGESAT, pelo fornecimento das imagens brutas da área de estudo quando as mesmas foram solicitadas.

À CAPES, pela concessão de bolsa de pós-graduação que permitiu o desenvolvimento desta Dissertação.

A Reinaldo Correa Cardoso Junior, pelo auxílio prestado nas atividades de campo. 


\section{RESUMO}

A classificação de imagens de satélite é muito utilizada para elaborar mapas de cobertura do solo. O objetivo principal deste trabalho consistiu no mapeamento automático da cobertura do solo no entorno da Usina de Lajeado (TO) utilizando-se o classificador SVM. Buscou-se avaliar a dimensão de áreas antropizadas presentes na represa e a acurácia da classificação gerada pelo algoritmo, que foi comparada com a acurácia da classificação obtida pelo tradicional classificador MAXVER. Esta dissertação apresentou sugestões de calibração do algoritmo SVM para a otimização do seu resultado. Verificou-se uma alta acurácia na classificação SVM, que mostrou o entorno da represa hidrelétrica em uma situação ambientalmente favorável. Os resultados obtidos pela classificação SVM foram similares aos obtidos pelo MAXVER, porém este último contextualizou espacialmente as classes de cobertura do solo com uma acurácia considerada um pouco menor. Apesar do bom estado de preservação ambiental apresentado, a represa deve ter seu entorno devidamente monitorado, pois foi diagnosticada uma grande quantidade de incêndios gerados pela população local, sendo que as ferramentas discutidas nesta dissertação auxiliam esta atividade de monitoramento.

Palavras-chave: Imagem de Satélite. Classificação. SVM (Support Vector Machines). Represa. Hidrelétrica. Sensoriamento Remoto. 


\begin{abstract}
Satellite Image Classification are very useful for building land cover maps. The aim of this study consists on an automatic land cover mapping in the domain area of Lajeado's dam, at Tocantins state, using the SVM classifier. The aim of this work was to evaluate anthropic dimension areas near the dam and also to verify the algorithm's classification accuracy, which was compared to the results of the standard ML (Maximum Likelihood) classifier. This work presents calibration suggestions to the SVM algorithm for optimizing it's results. SVM classification presented high accuracy, suggesting a good environmental situation along Lajeado's dam region. Classification results comparison between SVM and ML were quite similar, but SVM's spatial contextual mapping areas were slightly better. Although environmental situation of the study area was considered good, monitoring ecosystem is important because a significant quantity of burnt areas was noticed due to local communities activities. This fact emphasized the importance of the tools discussed in this work, which helps environmental monitoring.
\end{abstract}

Keywords: Satellite Images. Classification. SVM (Support Vector Machines). Dam. Hydroeletric. Remote Sensing. 


\section{LISTA DE ILUSTRAÇÕES}

Figura 3.1 - Exemplos de classificação SVM, que separou a classe verde da classe azul.

Figura 3.2 - Dois separadores de classes e suas margens, que são associadas aos support vectors.

Figura 3.3 - Espaço amostral em ambiente 3D possui função de separação 2D. A função de separação também é chamada de hiperplano de separação, ou separating hyperplane.

Figura 3.4 - Redistribuição dos dados de entrada, que coletados em espaço 2D foram redistribuídos em espaço 3D por aplicação de uma função Kernel.

Figura 3.5 - Espaço amostral inicial, em que as classes se distribuem de maneira não-linear.

Figura 3.6 - Exemplo da influência do parâmetro C em uma classificação SVM. .....37

Figura 3.7 - Métodos de resolução do problema multi-classe.

Figura 4.1 - Localização do município de Lajeado - TO.

Figura 4.2 - Cidade de Lajeado

Figura 4.3 - Imagem GEOEYE utilizada para os processos de classificação aqui ilustradas pelas bandas RGB.

Figura 4.4 - Hierarquia de classes utilizada, que tem como base a proposta do IBGE (2006) e possui adaptações de CORINE (2000).

Figura 4.5 - Exemplo da classe Água na imagem (a), ilustrada em nível de campo pelo reservatório da hidrelétrica (b) e por um curso d'água (c).

Figura 4.6 - Exemplo das classes Florestal e Campestre na imagem (a), que mostradas em campo são vegetação arbórea (b) e rasteira (c), respectivamente....50

Figura 4.7 - Exemplo da classe Edificações na imagem (a) e em campo (b), consistindo basicamente em casas não situadas em aglomerados urbanos.

Figura 4.8 - Exemplo da classe Rochas na imagem (a) e em campo (b).

Figura 4.9 - Exemplo da classe Solo Exposto na imagem GEOEYE (a) e em nível de campo como área desprovida de vegetação (b) e rodovia não-pavimentada (c), consistindo em áreas antrópicas não cobertas por vegetação. 
Figura 4.10 - Exemplo da classe Queimadas na imagem (a) e em campo (b); (c), representando locais desprovidos de vegetação mas com coloração mais escura devido à ocorrência de queimadas.

Figura 4.11 - Exemplos da classe Concreto na área de estudo, que englobam este material sobre a construções (a) e rodovias (b), sendo mostrada sua ocorrência em campo (c).

Figura 4.12 - Fluxograma do processo de classificação utilizando algoritmo SVM. ..56

Figura 4.13 - Metodologia geral do trabalho. .57

Figura 5.1 - Resultado da classificação SVM para a área de estudo. 60

Figura 5.2 - Confusão entre as classes Edificações e Solo Exposto. Exemplo de acerto na identificação de casas (a) e de erro de comissão para Edificações e omissão para Solo Exposto (b).

Figura 5.3 - Exemplo de erro de comissão para a classe Concreto e omissão para a classe Rochas.

Figura 5.4 - Exemplo de confusão entre as classes Rochas (erro de comissão) e Concreto (erro de omissão), que são facilmente notáveis.

Figura 5.5 - Exemplo de amostra de teste da classe Solo Exposto que sobrepôs pequenas áreas classificadas como Rochas.

Figura 5.6 - Exemplo de confusão não detectada pela Matriz de Confusão, envolvendo as classes Rochas e Queimadas. Neste caso, as áreas classificadas como Rochas (Comissão) deveriam ter sido rotuladas como Queimadas (Omissão).

Figura 5.7 - Confusão entre as classes Queimadas e Campestre, que não são facilmente notáveis. Neste exemplo, as áreas da classe Queimadas deveriam pertencer à classe Campestre

Figura 5.8 - Áreas da classe Queimadas que erroneamente foram classificadas como Campestre.

Figura 5.9 - Habitantes locais praticando a queimada em um local próximo à rodovia que liga Palmas a Lajeado. 69

Figura 5.10 - A presença de queimadas mostradas pela imagem GEOEYE de 2010

(a) e o mesmo local como pastagem em 2011 (b). .70

Figura 5.11 - Falsa presença de um corpo d'água próximo à regiões de Queimadas (a); Incorreta indicação de antropismo próximo ou no domínio cursos d'água (b). ...71 
Figura 5.12 - Resultado da classificação MAXVER para a área amostrada. .73

Figura 5.13 - Confusões envolvendo a classe Rochas, que são facilmente notáveis.

Figura 5.14 - Confusão entre as classes Campestre e Queimadas, sendo que elas apresentaram, respectivamente, erros de comissão e de omissão. 75

Figura 5.15 - Comparativamente, o MAXVER classificou maior quantidade de árvores (Florestal) e o SVM maior quantidade de vegetação rasteira (Campestre).. 77

Figura 5.16 - Exemplo de uma maior acurácia na classificação de Campestre e Solo Exposto pelo classificador SVM visto pela imagem e seus mapas temáticos (a) e comprovado em nível de campo (b).

Figura 5.17 - Classificador MAXVER obteve maior acurácia no mapeamento da classe Queimadas. Neste exemplo, a classe Queimadas está mais superestimada nos resultados do SVM do que nos resultados do MAXVER.

Figura 5.18 - Erros de comissão para a classe Edificações foi menor nos resultados do SVM que nos resultados do MAXVER.

Figura 5.19 (a) e (b) - A classe Campestre obteve maior acurácia quando classificada pelo SVM.

Figura 5.20 - A classe Concreto obteve maior acurácia quando classificada pelo SVM.

Figura 5.21 - As classes Campestre e Rochas obtiveram maior acurácia e apresentaram melhor contextualização quando classificadas pelo SVM.

Figura 5.22 - Locais classificados como Rochas são, na verdade, gramíneas (a) que germinaram logo acima de uma camada de rochas (b). 


\section{LISTA DE TABELAS}

Tabela 1 - Matriz de confusão com $p_{m m}$ representando a proporção da categoria $m+$ da cobertura da terra da área mapeada e da categoria $+m$ da cobertura da terra de referência.

Tabela 2 - Principais classificadores Supervisionados e Não-supervisionados. 27

Tabela 3 - Dimensão das classes de cobertura do solo para o algoritmo SVM. .61

Tabela 4 - Matriz de Confusão por pixels (a) e em porcentagem (b) para a classificação obtida com o algoritmo SVM.

Tabela 5 - Matriz de Confusão em pixels (a) e em porcentagem (b) para a classificação obtida com o algoritmo MAXVER.

Tabela 6 - Dimensão das classes de cobertura do solo ao longo da região amostrada para o algoritmo MAXVER. .76 


\section{SUMÁRIO}

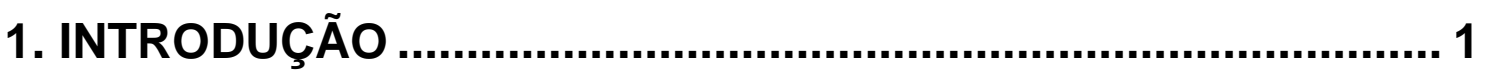

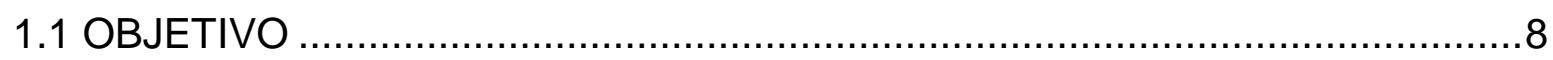

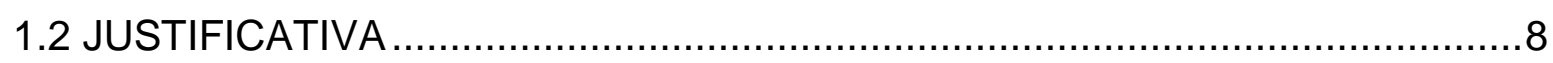

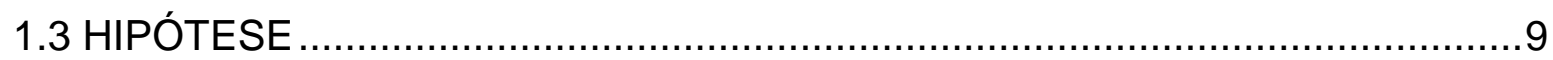

1.4 ESCOPO

2. PROCESSAMENTO DE IMAGENS ........................................11

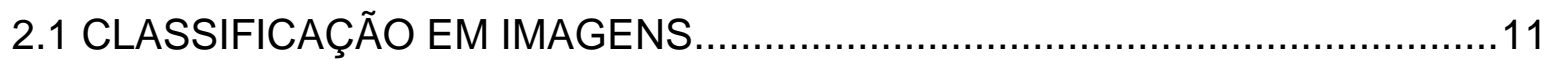

2.1.1 Classificação Supervisionada ..........................................................13

2.1.2 Classificação Não-supervisionada .......................................................14

2.1.3 Classificação por objetos ....................................................................15

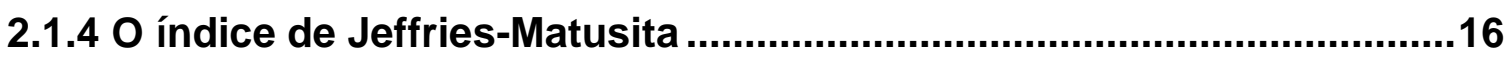

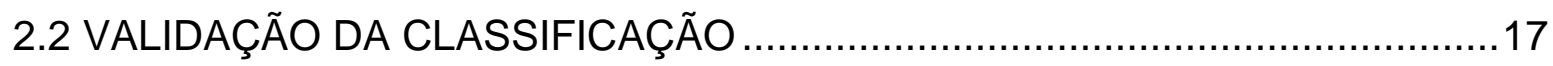

2.3 CLASSIFICAÇÃO E MAPEAMENTO DA COBERTURA DO SOLO ................21

2.3.1 Classificação de imagens para o gerenciamento de recursos hídricos e de Usinas Hidrelétricas .......................................................................21

2.3.2 Aplicações do algoritmo SVM (Support Vector Machine) .....................27

3. SUPPORT VECTOR MACHINES ........................................... 30

3.1 O ALGORITMO SVM E SUA APLICAÇÃO EM DADOS LINEARES ................30

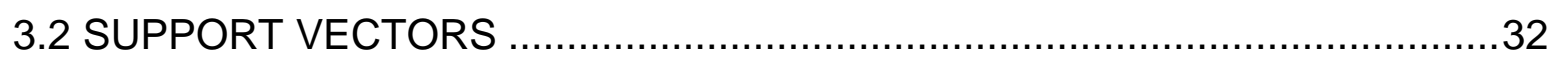

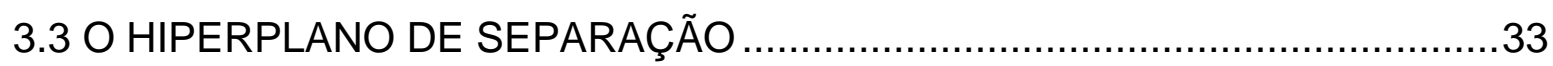

3.4 SVM E SUA APLICAÇÃO EM DADOS NÃO-LINEARES ...............................34

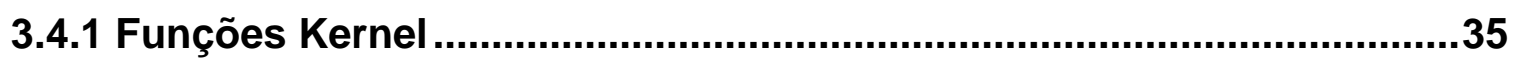

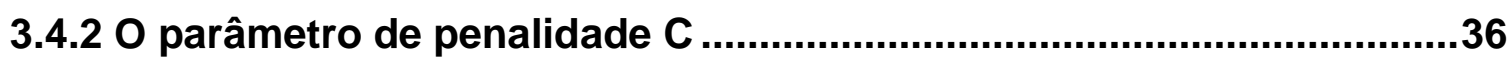




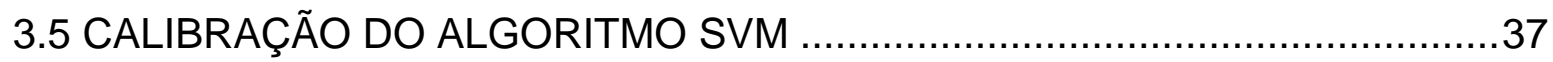

3.6 O PROBLEMA DE CLASSIFICAÇÃO MULTI-CLASSE................................38

4. MATERIAIS E MÉTODOS .................................................... 41

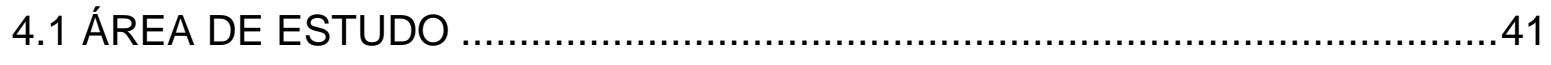

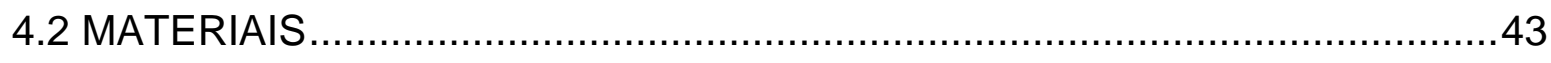

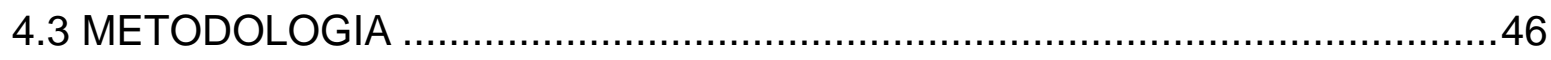

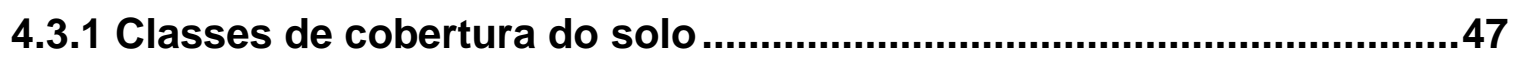

4.3.2 Processamento das imagens .............................................................56

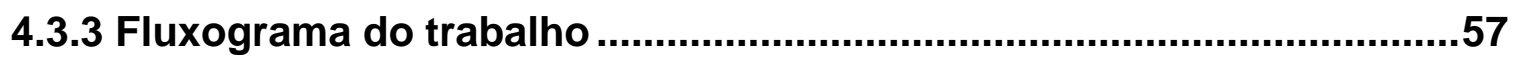

5. RESULTADOS E DISCUSSÃO ............................................. 59

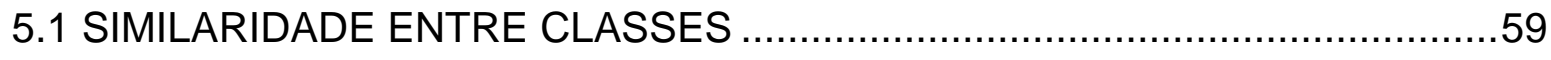

5.2 CALIBRAÇÃO DE PARÂMETROS DO CLASSIFICADOR SVM E SEUS

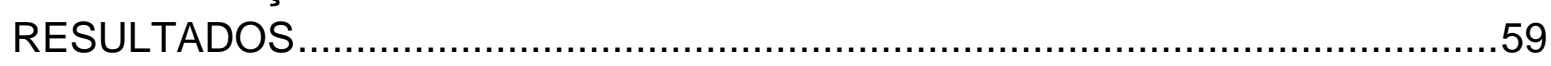

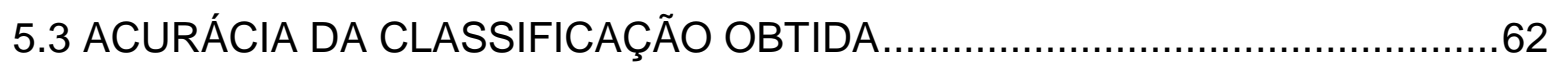

5.4 COMPARAÇÃO ENTRE OS CLASSIFICADORES SVM E MAXVER ..............72

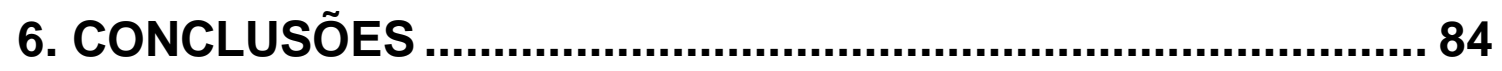

7. REFERÊNCIAS BIBLIOGRÁFICAS ..................................... 86 


\section{INTRODUÇÃO}

A cobertura do solo é uma questão que deve ser devidamente estudada, tanto para o seu monitoramento quanto para o seu planejamento. $O$ monitoramento da cobertura do solo é importante, por exemplo, para identificar ocupações desordenadas do meio urbano ou para verificar o desmatamento de uma determinada área de cobertura vegetal. O planejamento do uso do solo envolve, dentre outras, que seja providenciada uma ocupação ordenada dos conglomerados urbanos. Definem-se, por exemplo, as áreas mais aptas à expansão da cidade e a localização das vias de transporte que permitirão o acesso a um determinado Centro Gerador de Viagens (CGV) (KNEIB; SILVA, 2004).

O Sensoriamento Remoto é uma ferramenta cada vez mais utilizada em análises para determinação de cobertura e ocupação do solo. De acordo com Novo (2008) o sensoriamento remoto é o modo de obtenção de dados à distância, a partir da utilização conjunta de modernos sensores a bordo de aeronaves, espaçonaves ou outras plataformas. Tais sensores são equipamentos de processamento e de transmissão de dados, capazes de coletar a energia proveniente de um objeto que se deseja avaliar. O sensor coleta a energia, converte-a em sinal passível de ser registrado e apresenta-o em forma adequada à extração de informações. A finalidade da aquisição de tais informações consiste no estudo do ambiente terrestre, por meio do registro e da análise das interações entre a radiação eletromagnética e as substâncias componentes do planeta Terra em suas mais diversas manifestações.

Jensen (1986) enfatiza a diferença desta técnica de aquisição de dados pelo fato de o sensor coletar dados a distância, não estando o mesmo em contato físico direto com o seu alvo em questão. Os sensores medem a reflectância dos alvos da superfície terrestre. Ou seja, da radiação que atinge os sensores, são coletados os valores refletidos do espectro eletromagnético, pois de toda a energia que atinge a superfície terrestre, parte do que não sofre reflexão é absorvida ou sofre espalhamento. Os valores coletados do espectro transmitem sua informação em forma digital, de maneira que a composição de vários destes valores constituem os pixels uma imagem. 
O emprego de dados coletados por sistemas sensores orbitais a bordo de satélites tem-se mostrado uma ferramenta muito valiosa para auxiliar o homem a obter informações da cobertura do solo em grandes áreas. Os produtos de sensoriamento remoto, segundo Padilha e Kurkdjian (1996), foram utilizados para estudar o planejamento e reestruturação de cidades ao identificar e analisar as áreas que são desprovidas de edificações. Já Loch e Kirchner (1988) afirmaram que os produtos de sensoriamento remoto, ao possibilitarem a extração de informações acerca da cobertura do solo, permitem a identificação de interferências que o homem realiza sobre a superfície terrestre, além de permitirem o mapeamento e a verificação da extensão e da intensidade das alterações por ele provocadas.

Imagens multitemporais consistem em imagens de um mesmo local obtidas em datas diferentes, retratando assim a situação desta área em distintos momentos, o que permite inferir sobre eventuais mudanças ali ocorridas. Para Rodriguez (2000), a análise do uso e cobertura do solo, através de informações obtidas pelo sensoriamento remoto em imagens multitemporais, é de grande utilidade ao planejamento e administração da ocupação ordenada e racional do meio físico. Segundo a autora, além de possibilitar avaliar e monitorar a preservação de áreas de vegetação natural, o sensoriamento remoto é uma ferramenta de grande valia para auxiliar o homem na caracterização do meio físico, biótico e de áreas submetidas ao processo de antropismo. Com base nesta idéia, Rodriguez (2000) chega a propor a implantação de um plano diretor baseado no Zoneamento Ecológico - Econômico da área que realizou seu estudo (município de São Sebastião-SP).

$O$ avanço das tecnologias de sensoriamento remoto e a maior disponibilidade de sistemas sensores com melhores resoluções espacial, temporal e radiométrica expandiram o leque de aplicações das imagens orbitais, permitindo que as análises não sejam restritas a pixels, mas sim ao contexto a qual os mesmos estão inseridos, que também são chamados de objetos (BLASCHKE, 2010). Entretanto, os atuais sensores de alta resolução espacial ainda possuem limitações em relação à resolução espectral (número, largura e posição de bandas no espectro eletromagnético) que dificultam a discriminação entre algumas classes de cobertura do solo no processo de classificação automática de áreas urbanas (HEROLD et al., 
2003). Estas limitações do processo de classificação automática ocorrem devido a uma maior variação dos valores dentro das classes e uma menor diferenciação entre as classes no espaço de atributos, que acabam confundindo o classificador. Em áreas urbanas, a dificuldade no mapeamento deve-se, principalmente, à grande quantidade e semelhança dos valores dos espectros dos elementos que compõem a mancha urbana e às limitações dos métodos de classificação usados.

Os sistemas de análise de imagens do tipo OBIA (Object-Based Image Analysis) têm sido largamente utilizados na classificação de uso e cobertura de áreas urbanas, analisando-se a variação acerca de densidade de ocupação e distinguindo-se também a presença de casas ou edificações (ALMEIDA et al., 2009). Entretanto, a maioria destes sistemas é comercial e caro. Além disso, eles não são facilmente adaptáveis às necessidades específicas de cada aplicação, pois "[...] operam, na sua grande maioria, apenas com informações estatísticas dos segmentos (média, variância e, eventualmente, métricas texturais) e exclusivamente com um único nível de segmentação."

Classificação em imagens permite também, caso haja material disponível, que um mesmo local seja devidamente analisado em diferentes datas ao longo do tempo. Segundo Mouat et al. (1993), quando se realiza uma análise de dados multitemporais, uma seqüência básica deve ser seguida para se obter um bom resultado sobre os dados em estudo. Inicialmente, adquirem-se os dados, provenientes dos sensores remotos, de uma cena particular envolvendo duas ou mais datas. Adquiridos os dados, as imagens são geometricamente corrigidas para poder ser feito o ajuste a fim de se obter similares condições atmosféricas e de aquisição de dados. Realizadas estas etapas, é feita a análise espectral das imagens propriamente ditas. O registro e o ajuste das adversidades atmosféricas são etapas necessárias ao estudo comparativo de dados obtidos em datas de aquisição diferentes, constituindo a fase denominada pré-processamento. $A$ análise espectral é relativa aos processos comparativos desses dados, representando a fase denominada de processamento. Todas essas partes constituem o tratamento digital de imagens orbitais.

Assim, antes da interpretação de imagens adquiridas e não devidamente processadas, temos apenas "dados de sensores remotos". Após a interpretação, 
esses dados são transformados em "informação útil" (LILLESAND; KIEFER, 1994; FLOPRENZANO, 2002). O Sensoriamento Remoto não fornece uma informação apenas ao mostrar seus dados, como a diversidade da gama de cores de uma imagem de satélite. Os mesmos devem ser devidamente interpretados para que a informação seja realmente transmitida. Por exemplo, em uma imagem de uma cidade litorânea, apenas os dados oriundos dos sensores, que armazenam o valor das reflectâncias em pixels, não indicam onde está o mar e onde está a cidade. Logo, estes dados devem sofrer algum tipo de interpretação para que esta distinção de classes se torne de fato uma informação.

Aplicações de assinaturas espectrais pelo Sensoriamento Remoto são utilizadas até mesmo em estudo de monoculturas. Assad e Sano (1998) afirmaram que a disponibilidade de informações confiáveis sobre a área, distribuição, tipos de culturas implantadas e expectativa de produção é fundamental para a tomada de decisões e o planejamento. Dados orbitais fornecidos pelo Sensoriamento Remoto podem fornecer informações atualizadas acerca da ocupação agrícola a um custo relativamente baixo. Estes planos abordam a definição de prioridades e projeções sobre o volume de recursos a ser liberado para o financiamento da produção, tanto por parte do setor público quanto do setor privado.

Para obter informações sobre alvos da superfície terrestre de um plantio (por exemplo, área plantada com determinada cultura e o tipo de estresse hídrico a qual a planta está submetida) através da análise de dados coletados por sensores orbitais, há duas abordagens passíveis de utilização: análise qualitativa por interpretação visual, utilizando produtos analógicos, e análise quantitativa por meio digital, feita através de métodos computacionais automáticos (MOREIRA, 1997), também chamados de classificação de imagens. Segundo Moreira (1997), a escolha de uma ou outra abordagem vai depender da disponibilidade de equipamentos e da finalidade da análise. Em muitos casos, as duas abordagens são empregadas, como por exemplo, a realização de estudos de ocupação de áreas agrícolas e testes que avaliam a eficiência de um determinado processo de classificação digital.

Até a década de 80, o uso de imagens de satélites para obter informações sobre a ocupação do solo baseava-se mais no método de interpretação visual (análise qualitativa), em particular, para a execução de projetos de mapeamento de 
grandes áreas, como a Floresta Amazônia (SKOLE et al., 1993). Essas técnicas fazem a digitalização de mapas a partir das imagens de satélite, a qual os mapas temáticos e suas informações são manualmente geradas a partir de um fotointérprete, que realiza a avaliação visual.

A citar outro exemplo, Murtha (1978) estudou aplicações do Sensoriamento Remoto na detecção de áreas de plantios florestais que apresentam certas patologias vegetais. Tais adversidades patogênicas alteram tanto a composição hídrica quanto a coloração das folhas, o que acaba por alterar a resposta espectral dos locais cujas árvores sofrem algum tipo de ataque.

Os elementos da interpretação visual de imagens, de acordo com Florenzano (2002), estão relacionados a alguns fatores básicos: tonalidade, que consiste nos tons de cinza que abrangem do preto ao branco; cor, que é a composição nos canais coloridos das bandas de um satélite; textura, que consiste na frequência de mudanças de níveis de cinza e confere aspecto liso (uniforme) ou rugoso; tamanho, que é dependente da escala da imagem e permite, por exemplo, distinguir casas de indústrias em conglomerados urbanos; forma, que é o delineamento de um objeto, geralmente mais linear para estradas e rios e mais retangular para casas e prédios; sombra, que pode ocorrer quando da presença de objetos como árvores e prédios; padrão, que é a organização e o arranjo dos objetos na superfície; e localização geográfica, que é o local a qual um determinado objeto ou feição de interesse se encontra em uma imagem. Florenzano (2002) destaca ainda que uma informação extremamente importante consiste na data de obtenção das imagens, pois ela indica se a imagem é antiga ou recente, se ela foi obtida em período de seca ou de chuva ou se antes ou depois da ocorrência de um fenômeno, como incêndios ou deslizamentos.

Apesar da fotointerpretação possuir nítida importância, a procura de objetividade na extração automática de informações por meio de classificação de imagens (análise quantitativa) vem ganhando importância operacional em nível mundial, permitindo a realização de estimativas com maior antecedência, com maior precisão e com menor custo quando comparadas com as técnicas tradicionais (DUTTA et al., 1994). 
A idéia de se criar procedimentos computacionais para a análise de dados coletados por sistemas sensores surgiu basicamente por duas razões: agilizar as tarefas manuais realizadas durante a interpretação visual (delimitação de áreas, confecção de mapas, cálculo de área, etc.) e possibilitar que o analista pudesse introduzir outros tipos de informações e cruzá-las com os padrões espectrais contidos nas imagens. Desta maneira a interpretação tornou-se mais fácil de ser realizada, podendo-se estabelecer a relação, por exemplo, que o estresse hídrico em plantas tem com o espectro, que é diferente da relação que as plantas têm com o espectro quando encontram-se devidamente hidratadas (Moreira, 1997).

O acompanhamento e distribuição espacial da cobertura do solo deve ser analisado constantemente para auxiliar os estudos de desenvolvimento e da dinâmica de uma determinada região. Muitos aspectos podem ser estudados acerca de um local a fim de se realizar diversos planejamentos futuros, como a identificação e propagação de reservas ecológicas, culturas agrícolas e florestais, áreas urbanas consolidadas e áreas urbanas em fase de consolidação (BEZERRA; SANO; FERREIRA, 2007).

Um exemplo encontra-se na avaliação da cobertura e ocupação do solo para fins de preservação e conservação dos mananciais hídricos. Segundo estimativas da ONU (Organização das Nações Unidas) apenas um quarto da humanidade terá disponibilidade de água para suas necessidades mínimas até o ano de 2050 (WRI, 2000). Nascimento et al. (2011) ressalta que a degradação de sistemas aquáticos, além de causar uma série de impactos ambientais, pode ser estudada e monitorada através de análises acerca do entorno a qual os locais emissores de poluentes da rede hídrica estão inseridos. Nascimento et al. (2011) ressalta também que deve-se compreender os ecossistemas aquáticos e suas respostas decorrentes de perturbações introduzidas pelas atividades humanas, de modo a prever o impacto dessas sobre suas condições de sustentabilidade em médio e longo prazo.

Diante de problemas como este, a utilização de recursos de Sensoriamento Remoto para auxiliar no monitoramento da qualidade das águas superficiais de mananciais de usos múltiplos desponta como instrumento de grande interesse por parte da sociedade como um todo, uma vez que permite monitorar e controlar a qualidade de um recurso natural de vital importância. Principalmente no caso de 
reservatórios hidrelétricos, que suprem cerca de $85 \%$ da energia elétrica do país e são possíveis de ter a qualidade da água avaliada pelo resultado das combinações dos tipos e quantidades das substâncias opticamente ativas presentes nas represas de hidrelétricas (NASCIMENTO et al., 2011). Losekann e Oliveira (2008) também destacam a importância do setor elétrico e sua manutenção no Brasil: as represas devem ser cuidadosamente manejadas, pois muitas das estações elétricas compartilham a mesma base de rios, tornando interdependentes as decisões tomadas acerca de uma determinada área.

O uso de sensores remotos hiperespectrais para identificar características a partir da energia refletida pelo corpo d'água propicia uma percepção ampliada (geograficamente) e momentânea (em um breve instante) do comportamento espectral de toda a área imageada. A comparação entre os sinais registrados pelo sensor e o comportamento espectral medido permite identificar características associadas à substâncias encontradas na água, tais como clorofila, material inorgânico suspenso e matéria orgânica dissolvida. Essas feições espectrais são dependentes do comprimento de onda e, portanto, influenciam a forma e a magnitude do espectro refletido a partir da água (KOPONEN et al., 2002).

As concentrações de substâncias na água variam tanto no espaço quanto ao longo do tempo. Associada a esta circunstância está o fato de que o sinal que atinge os sensores possui baixa intensidade, uma vez que a água possui baixa reflectância da radiação. Além disso, os corpos d'água estão sujeitos a outros fatores que afetam a atenuação da radiação captada pelos sensores, como a alteração da rugosidade da superfície pela ação dos ventos, reflexão especular da luz solar em função do ângulo de incidência, interferência da reflexão do fundo em águas transparentes e pouco profundas e a atenuação pela atmosfera (CHEN et al., 1992).

A avaliação da alteração da paisagem busca identificar diferenças no estado de um fenômeno pela observação de diferentes datas (SINGH, 1989). O autor alerta também para o fato de que nos últimos anos diversos processos de análises multitemporais, delineadoras de detecção de mudanças no uso do solo, foram desenvolvidos, fazendo com que os resultados obtidos sejam diferentes entre si até mesmo ao se utilizar a mesma base de dados. 
Uma área devidamente mapeada pode, portanto, auxiliar no monitoramento da cobertura do solo. A classificação em imagens mostrou-se uma ferramenta útil a ser implementada neste tipo de monitoramento, sendo que represas hidrelétricas podem fazer uso da mesma. O Sensoriamento Remoto, neste caso, pode apresentar grande utilidade ao ser implementado no monitoramento da superfície terrestre das áreas a qual o corpo hídrico se estende.

\subsection{OBJETIVO}

O objetivo principal deste trabalho consiste na validação do uso do classificador Support Vector Machine (SVM) no mapeamento da cobertura do solo no entorno da represa de Lajeado (TO). Buscou-se encontrar a calibração de uma classificação de imagens utilizando o algoritmo Support Vectors Machine (SVM) para gerar o mapeamento da cobertura do solo e identificar possíveis focos de antropização em represa hidrelétrica. Assim, o mapeamento da cobertura do solo partiu do uso de imagem de satélite de alta resolução, sendo a aplicação do classificador SVM avaliada pela acurácia dos seus resultados. Pretende-se ainda, especificamente:

- verificar a presença de áreas antropizadas no entorno da represa, que são potenciais agentes de degradação da qualidade tanto da água da represa quanto do meio ambiente a qual o reservatório está inserido;

- comparar a acurácia do classificador SVM com a acurácia obtida pelo MAXVER, que é o algoritmo mais conhecido e utilizado por analistas;

- validação do uso do SVM no mapeamento da cobertura do solo em imagens de alta resolução.

\subsection{JUSTIFICATIVA}

A classificação da imagem da represa visa à identificação dos principais alvos presentes na superfície terrestre imageados por um satélite de alta resolução 
espacial. O uso do algoritmo SVM no processo de classificação deve-se ao fato de que o mesmo tem apresentado resultados satisfatórios no meio acadêmico.

A pesquisa também objetiva propor uma metodologia que gere uma classificação SVM capaz de identificar os principais focos de degradação da qualidade do meio ambiente e das águas da represa. A classificação automática é um método que fornece agilidade na geração de um mapa temático, podendo-se identificar possíveis focos de degradação da represa, como invasões de terra e construção de pequenas propriedades em locais inadequados, focos estes que muitas vezes não são devidamente distinguidos por interpretação visual de imagens de satélite.

Logo, o gestor público, ao fazer uso do produto gerado pela classificação automática de imagens, depara-se com uma ferramenta que auxilia o monitoramento de represas hidrelétricas e reduz seus custos. O analista de imagens de satélite agiliza seu trabalho de identificar áreas antropizadas e/ou de invasão no entorno de uma represa, reduzindo assim os custos dos fiscais de campo no seu trabalho de inspeção de irregularidades ambientais.

Imagens de alta resolução, para o caso de gestão de represas de hidrelétricas, fornecem a possibilidade de identificação de pequenos conglomerados urbanos, que são potenciais degradadores da qualidade da represa. $O$ uso deste tipo de dado possibilita resultados mais interessantes para o processo de classificação em imagens, pois a identificação de pequenas manchas urbanas pode evitar que as mesmas se tornem uma área consolidada.

\subsection{HIPÓTESE}

É possível gerar o mapeamento da cobertura do solo a partir da classificação em imagens. Logo, o SVM, potencial classificador que vem ganhando notoriedade no meio científico (exemplos são mostrados no Capítulo 2), pode gerar resultados satisfatórios e até mesmo superiores aos algoritmos mais tradicionais para o processo de classificação.

No caso desta Dissertação, o gerenciamento de hidrelétricas pode ser beneficiado com a classificação em imagens de satélite para o mapeamento da 
cobertura do solo. Tal processo de classificação, além de reduzir custos de monitoramento e fiscalização de represas, pode ser aprimorado ao se fazer uso do algoritmo SVM.

\subsection{ESCOPO}

O trabalho foi dividido em 5 capítulos, sendo os capítulos 2 e 3 uma fundamentação teórica, o capítulo 4 os procedimentos metodológicos, o capítulo 5 as análises dos resultados da pesquisa e o capítulo 6 as conclusões obtidas.

O capítulo 2 consiste em uma revisão bibliográfica do tema processamento digital de imagens e algumas de suas aplicações.

O capítulo 3 fornece uma análise do algoritmo SVM, mostrando seus princípios e maneiras a qual o classificador realiza a definição de classes a partir de um grupo de amostras.

O capítulo 4 refere-se à metodologia utilizada, incluindo os materiais, área de estudo e validação dos resultados gerados pela classificação.

O capítulo 5 mostra os resultados obtidos, bem como uma análise dos mesmos acerca do contexto deste estudo e comparação com o classificador mais tradicional, o MAXVER.

O capítulo 6 trata das conclusões obtidas pelos resultados mostrados no capítulo 5. 


\section{PROCESSAMENTO DE IMAGENS}

As imagens digitais, como é o caso das imagens de satélite, possuem uma grande vantagem em relação às imagens analógicas, pois elas podem ser devidamente processadas a fim de se extrair informações específicas. Segundo Novo (2008), a extração destas informações pode ser organizada em três etapas diferentes, a saber: pré-processamento, realce e classificação. O pré-processamento consiste num tratamento inicial das imagens, onde são feitas correções nas distorções geométricas e são removidos os ruídos. O realce é uma espécie de manipulação dos dados radiométricos, espaciais e espectrais das imagens de maneira a realçar os objetos de interesse. Finalmente, a classificação consiste no processo de atribuir significado a um pixel em função de suas propriedades numéricas, rotulando o mesmo de acordo com suas características espaciais e/ou espectrais. Novo (2008), porém, não destacou que a etapa classificação pode ser feita de maneira qualitativa (visual) ou quantitativa (classificação). Neste caso, considera-se que o realce é uma etapa presente apenas quando o processamento da imagem for feito de maneira qualitativa.

Como o objetivo deste trabalho consiste em classificar imagens de satélite, este capítulo abordará apenas a etapa da classificação no processamento de imagens de Sensoriamento Remoto. Recomenda-se a leitura de Novo (2008) e Gonzales e Woods (2000) para maiores detalhes acerca das outras etapas que envolvem o processamento de imagens.

\subsection{CLASSIFICAÇÃO EM IMAGENS}

A classificação digital em imagens orbitais consiste no estabelecimento de um processo de decisão no qual um grupo de pixels é definido como pertencente a uma determinada classe ou um determinado tema que descreve um objeto. Segundo Lu e Weng (2007), o processo de classificação é dividido nas seguintes etapas: seleção de dados obtidos por Sensoriamento Remoto; pré-processamento dos dados; seleção de um sistema de classificação e, se for supervisionada, de amostras de 
treinamento; escolha de classificadores mais adequados; extração de atributos e seleção; pós-classificação; e avaliação da performance obtida na classificação.

No processo de classificação, deve-se atentar para a correção dos efeitos atmosféricos. Ao se trabalhar com uma única cena, tal correção não é necessária quando os fenômenos atmosféricos encontram-se dispostos de maneira uniforme, pois as distorções tornam-se homogêneas para a área imageada. Logo, caso a imagem a ser classificada apresente mais de uma cena, a correção atmosférica torna-se necessária (SCHOWENGERDT, 2007).

O processo de classificação em imagens consiste, basicamente, no reconhecimento de categorias pertencentes ao mundo real e na definição de rótulos (labelling process) às entidades a serem avaliadas, que normalmente são pixels (MATHER, 2004). Para se classificar uma imagem em categorias de interesse, o algoritmo de classificação necessita de treinamento para realizar as devidas distinções, treinamento este que define se a classificação é Supervisionada ou Nãosupervisionada (SCHOWENGERDT, 2007). O treinamento de algoritmos de classificação é Supervisionado, quando a coleta de amostras de pixels é considerada um dado referência, ou seja, pressupõe-se que o analista já possui um conhecimento prévio da área, ou Não-supervisionado, quando pixels não-rotulados são determinados e distinguidos conforme as características intrínsecas que possuem acerca da assinatura espectral dos elementos da superfície terrestre (SCHOWENGERDT, 2007).

$\mathrm{Na}$ classificação supervisionada, o usuário procura identificar pontos na imagem pertencentes a classes desejadas através de uma seleção de amostras. Em seguida, através de algoritmos pré-estabelecidos, o programa de classificação faz a identificação de todas as feições existentes na imagem a partir das amostras obtidas para cada classe. Já no processo de classificação não supervisionada, cada feição de uma imagem é atribuída a um grupo de classe, não existindo o processo de amostragem. A atribuição das feições a um grupo de classe é feita com base nas observações das suas propriedades em si e na sua vizinhança, bem como numa série de outras regras (PEREIRA, 1992). Mais detalhes acerca destes dois métodos encontram-se nas subseções 2.1.1 e 2.1.2 a seguir. 


\subsubsection{Classificação Supervisionada}

Neste método de classificação, os temas de interesse são determinados por pixels representativos de cada categoria estabelecida pelo analista. A representação destes pixels pode ser escolhida por interpretação visual (caso a imagem possua, por exemplo, uma resolução espacial que permita a distinção visual de objetos), dados de campo ou mapas já existentes (MATHER, 2004; SCHOWENGERDT, 2007).

Schowengerdt (2007) considera que no treinamento supervisionado é importante que cada categoria (ou classe) apresente amostras (pixels representativos) homogêneas de sua composição. Deve-se também tentar incluir a maior variabilidade intra-classe possível, apesar da impossibilidade de se ter certeza sobre a obtenção de uma quantidade significativa de amostras para cada classe. A separabilidade dos dados de treinamento deve, portanto, abordar não só a média dos valores de cada classe, mas também a variância da mesma.

As técnicas de classificação supervisionadas baseiam-se na disponibilidade de uma amostra representativa de cada classe identificada. Estas amostras são informações a respeito do comportamento médio das classes e podem ser denominadas como "pixels de treinamento" do sistema (NOVO, 2008). Tais pixels de treinamento são, portanto, exemplos de que o sistema de classificação os toma como referência para decidir a qual classe cada pixel da imagem deve ser designado.

Segundo Jensen (1986), o algoritmo mais conhecido de classificação supervisionada é o chamado máxima verossimilhança, ou MAXVER. Tal algoritmo pressupõe que os níveis de cinza de cada classe seguem uma distribuição normal multivariada. Analisada a distribuição normal de cada classe, o MAXVER avalia as probabilidades a qual um determinado pixel tem de pertencer às classes já avaliadas e o designa àquela cuja a probabilidade é maior. 


\subsubsection{Classificação Não-supervisionada}

No treinamento não-supervisionado 0 analista utiliza um algoritmo que localiza concentrações dos atributos de vetores heterogêneos de pixels e os agrupa de acordo com suas propriedades, consistindo uma espécie de análise exploratória (MATHER, 2004). Ao agrupamento, chamado de cluster, não se supõe a existência de conhecimentos prévios da distribuição de densidade de probabilidade dos dados, procurando-se agrupar regiões a partir de uma medida de similaridade entre elas (KÖRTING, 2006). Esta busca por agrupamentos deve representar as classes da imagem e suas respectivas assinaturas espectrais obtidas através dos cálculos para a distinção de temas. As classes estabelecidas devem, então, ser devidamente rotuladas após o agrupamento gerado pelo algoritmo. O agrupamento foi obtido analisando-se a estrutura inerente dos dados, sem a existência de conhecimento externo (SCHOWENGERDT, 2007).

$\mathrm{Na}$ classificação Não-supervisionada, o analista não precisa se atentar para a homogeneidade dos locais. Nos trechos mais heterogêneos de uma imagem, podese garantir que parte significativa das classes de interesse e suas respectivas variabilidades sejam incluídas, ficando para o analista a tarefa de rotular os dados agrupados após o treinamento ou a classificação de toda a imagem. Logo, este método de treinamento pode ser útil para a determinação de áreas homogêneas, pois não requer treinamento supervisionado e pode, portanto, auxiliar este processo (SCHOWENGERDT, 2007).

A classificação não supervisionada é uma opção quando a área investigada é desconhecida, ou quando suas características não são bem definidas e busca-se encontrar áreas homogêneas (NOVO, 2008; SCHOWENGERDT, 2007). Os padrões dominantes que ocorrem em uma imagem são extraídos e em seguida agrupados, definindo assim as classes existentes na imagem ou na área de estudo que é previamente desconhecida (NOVO, 2008).

O algoritmo de classificação não-supervisionado mais comum é o k-médias. Neste, em um primeiro passo, um vetor inicial de média é arbitrariamente especificado para $\mathrm{k}$ grupos. Cada vetor de pixel da imagem é associado à classe cuja média do vetor possui valor mais próximo, sendo em seguida calculada a 
distância Euclidiana entre cada pixel do grupo e a média calculada e formando-se então o primeiro conjunto das regras de decisão (ANDERBERG, 1973; SCHOWENGERDT, 2007). Um novo conjunto de média de vetores é então calculado a partir desta classificação, sendo os pixels da imagem re-classificados. A cada iteração, as $\mathrm{k}$ médias tenderão a se distribuir de acordo com o resultado da iteração anterior, continuando até que as mudanças dos resultados (diferença entre as médias) não sejam significativas. O critério de finalização de interações é mostrado na eq. (1), que define a magnitude da mudança das médias dos vetores da iteração $i-1$ para a iteração $i$, para os k grupos. (SCHOWENGERDT, 2007).

$$
\Delta \mu(i)=\sum_{k=1}^{K}=\left|\mu_{k}^{i}-\mu_{k}^{i-1}\right|
$$

Deste algoritmo surgiu o chamado Isodata, que difere do k-médias apenas por juntar dois grupos se a separação dos mesmos for menor que um determinado intervalo e transforma um grupo em dois se esta separação estiver muito acima deste intervalo (SCHOWENGERDT, 2007).

Outro algoritmo muito usado na classificação Não-supervisionada é o Isoseg, que utiliza vetores de média e matrizes de covariâncias para procurar regiões similares. Por estes parâmetros estatísticos estima-se o valor de cada classe em três etapas: limiar (percentagem) de aceitação; detecção de classes em ordem decrescente de área, seguindo o limiar de aceitação estabelecido; competição entre classes, que reclassifica os dados segundo os parâmetros estatísticos definidos na fase anterior, visando assim à eliminação de pontos isolados que acabam por evitar uma aparência mais ruidosa (KÖRTING, 2006).

\subsubsection{Classificação por objetos}

A classificação de imagens, tradicionalmente, consiste em associar cada pixel a uma determinada classe de interesse. Com a evolução das imagens de satélite, que são cada vez mais capazes de distinguir detalhes da superfície terrestre, outra 
abordagem de classificação de imagens surgiu: a classificação por regiões e a orientada a objeto.

A classificação por regiões faz uso da segmentação de imagens, que visa à captação de detalhes de cenas muito heterogêneas e com grande variação interna das classes, permitindo a utilização de parâmetros de cor, forma, textura e relações de vizinhança na classificação de imagens (Pinho et al., 2005). Cada grupo de pixels unidos pela segmentação é chamado de região.

Já a classificação orientada a objeto também faz uso da segmentação de imagens, porém insere outros conhecimentos na delimitação de alvos presentes nas imagens. Assim, uma região se torna um objeto quando as informações contidas nas regiões são devidamente avaliadas e interpretadas por um avaliador: o conteúdo dos alvos de interesse, portanto, fica organizado de maneira que a descrição de tais alvos de interesse se assemelhe à percepção humana (LANG, 2008). Autores como Gigandet et al. (2005) destacam que classificação orientada a objeto, quando se trabalha com imagens de alta resolução, é superior à classificação pixel a pixel, que é mais tradicional. Para maiores detalhes sobre o conceito de objetos e classificação orientada a objeto sugere-se a leitura de Lang (2008).

\subsubsection{O índice de Jeffries-Matusita}

Objetivando analisar a resposta espectral de cada classe e a separabilidade entre estas pelas bandas de um determinado satélite, o índice de Jeffries-Matusita, mostrado na eq. (2) por Gunal e Edizkan (2008), mostra a possibilidade de uma eventual separabilidade entre duas classes. Ou seja, a partir do valor gerado pelo índice, infere-se uma espécie de grau de similaridade entre duas classes, indicando se as mesmas podem ou não ser unificadas em uma só a partir do valor calculado pelo índice, valor este que é referente à semelhança espectral.

$$
\mathrm{JM}_{\mathrm{ij}}=\left[2^{*}\left(1-\mathrm{e}^{-\mathrm{B}}\right)\right]^{1 / 2}
$$

em que B é a distância de Bhattacharya $\left(B_{i j}\right)$ : 


$$
B_{i j}=\frac{1}{8}\left(M_{i}-M_{j}\right)^{T}\left(\frac{\Sigma_{i}+\Sigma_{j}}{2}\right)^{-1}\left(M_{i}-M_{j}\right)+\frac{1}{2}\left(\frac{\left|\frac{\Sigma_{i}+\Sigma_{j}}{2}\right|}{\sqrt{\left|\Sigma_{i}\right|\left|\Sigma_{j}\right|}}\right)
$$

Para o cálculo do índice de Jeffries-Matusita, os dados de entrada necessários são $M_{i}$ e $M_{j}$, que correspondem aos vetores de média das classes i e j, respectivamente, sendo $\Sigma_{i}$ e $\Sigma_{j}$ as matrizes de covariância destas classes. O software ENVI 4.8 dispõe de uma ferramenta que calcula este índice, cabendo ao usuário fornecer as amostras de treinamento utilizadas na classificação. $O$ índice Jeffries-Matusita assume que as classes apresentam comportamento normal padrão, sendo que a função que delimita seu valor apresenta comportamento exponencial em alguns trechos e uma curvatura assíntota para o valor 2, que indicaria que duas classes são iguais (RICHARDS; JIA, 1999). O valor 1,9 é considerado o limiar entre a separabilidade e não separabilidade entre as classes (ITT, 2010). Um detalhamento sobre o procedimento deste passo pode ser encontrado em ITT (2010). Para maiores detalhes do índice Jeffries-Matusita, ver Richards e Jia (1999).

\subsection{VALIDAÇÃO DA CLASSIFICAÇÃO}

Os processos de classificação automática de imagens, contudo, freqüentemente apresentam erros em seus resultados. Tal fato tornou necessária a existência de uma medição da acurácia de um processo de classificação, ou seja, a medição da quantidade de acertos e de erros que uma classificação automática gerou. Diante deste cenário, a comunidade científica desenvolveu alguns métodos que avaliam a acurácia dos resultados de um processo de classificação de imagens.

Bolfe et al. (2004) citam Story e Congalton (1986) ao afirmar que a Exatidão Global é a maneira mais comum para se verificar a porcentagem da área de um mapa que foi corretamente classificada. O mapa é comparado com os dados de referência e verifica-se o total da área, em porcentagem, que foi corretamente classificado. Assim, o trabalho de Bolfe et al. (2004) completa que a Exatidão Global 
"[...] normalmente é derivada de uma contraparte da classificação correta gerada por amostragem dos dados classificados, e expressa na forma de matriz de erro, algumas vezes denominada de matriz de confusão ou tabela de contingência."

A matriz de erro (também chamada de matriz de confusão) é apresentada na Tabela 2. A mesma é simétrica e apresenta uma visão tabulada da acurácia do mapa de classificação, uma vez que são mostrados todos os erros de omissão e comissão ocorridos entre todas as classes. A matriz de confusão permite também o cálculo de medidas específicas, tais como a exatidão global (ou acurácia geral), acurácia do usuário e acurácia do produtor (CONGALTON, 1991). A exatidão global é uma das medidas mais simples, sendo calculada pela soma do total dos pixels corretamente classificados (localizados na diagonal principal da matriz) dividida pelo número total de pixels da matriz de confusão.

Tabela 1 - Matriz de confusão com $p_{m m}$ representando a proporção da categoria $m+$ da cobertura da terra da área mapeada e da categoria $+m$ da cobertura da terra de referência.

\begin{tabular}{c|cccc|c}
\hline \multirow{2}{*}{ Classificada } & \multicolumn{5}{|c}{ Referência } \\
\cline { 2 - 6 } & 1 & 2 & $\ldots$ & $m$ & Total \\
\hline 1 & $p_{11}$ & $p_{12}$ & $\ldots$ & $p_{1 m}$ & $p_{1+}$ \\
2 & $p_{21}$ & $p_{22}$ & $\ldots$ & $p_{2 m}$ & $p_{2+}$ \\
$\ldots$ & $\ldots$ & $\ldots$ & $\ldots$ & $\ldots$ & $\ldots$ \\
$m$ & $p_{m 1}$ & $p_{m 1}$ & $\ldots$ & $p_{m m}$ & $p_{m+}$ \\
\hline Total & $p_{+1}$ & $p_{+2}$ & $\ldots$ & $p_{+m}$ & \\
\hline
\end{tabular}

Jensen (1986) considera que uma das características mais importantes da matriz de confusão encontra-se nos valores não localizados na sua diagonal principal, que são os erros de omissão e comissão presentes na classificação. Erros de comissão, localizados à esquerda e abaixo da diagonal principal, e erros de omissão, localizados à direita e acima da diagonal principal (JENSEN, 1986), são os pixels classificados incorretamente.

Os erros de omissão de uma determinada classe, por exemplo, uma classe $A$, referem-se aos pixels da classe $A$ que foram erroneamente classificados como $B$. Ou seja, uma determinada área $A$ que foi classificada como B apresenta erros de 
omissão para a classe $A$, pois os pixels são de fato pertencentes à classe $A$, mas o modelo gerado a omite.

Os erros de comissão ocorrem quando os pixels de uma determinada área, segundo os resultados de um modelo obtido, são classificados como pertencentes à uma determinada classe, porém, estes rótulos deveriam corresponder à uma outra classe. No caso do exemplo do parágrafo anterior, uma área que é de fato constatada como A, mas que foi erroneamente classificada como $B$, possui erros de comissão para a classe B. Ou seja, a classe B foi mapeada em locais onde ela não existe segundo os dados de referência.

Logo, pode-se notar que erros de comissão de uma determinada classe geram erros de omissão para uma outra. Ainda no exemplo dos dois parágrafos anteriores, os erros de comissão presentes na classe $B$, mapeada em lugares que de fato não existe, geraram erros de omissão para a classe $A$, que deixou de ser mapeada onde realmente existe. Outra explanação sobre erros de omissão e comissão pode ser verificada em Campbell (2008).

Outro conhecido método da avaliação da acurácia de uma classificação é o chamado índice Kappa. Tal índice vem sendo recomendado (CONG e HOWARTH, 1990) como uma medida apropriada da exatidão entre resultados de classificações por representar integralmente a matriz de erro com um único índice. O índice Kappa é, portanto, uma espécie de medida global de concordância que define o grau de dependência entre duas classificações, uma de referência e outra a ser comparada.

O índice de Kappa avalia a concordância entre a referência e o mapa temático gerado através de valores que variam de 0 a 1, correspondendo o valor 1 à similaridade total entre o modelo gerado e os dados considerados referência. $O$ índice de Kappa é calculado da seguinte maneira (IWAI; QUINTANILHA, 2005):

$$
K=\frac{N \sum_{i=1}^{n} x_{i i}-\sum_{i=1}^{n} x_{i+} x_{+i}}{N-\sum_{i=1}^{n} x_{i+1} x_{+i}}
$$

em que " $\mathrm{n}$ " é o número de linhas da matriz de confusão, "N" é o número total de células e $X_{i i}$ são os elementos da matriz de confusão. Segundo Iwai e Quintanilha (2005), dividindo-se o numerador e o denominador da eq. (4) por $\mathrm{N}^{2}$, tem-se que: 


$$
K=\frac{\theta_{1}-\theta_{2}}{1-\theta_{2}}
$$

sendo

$$
\begin{gathered}
\theta_{1}=\frac{\sum_{i=1}^{r} x_{i i}}{N} \\
\theta_{2}=\frac{\sum_{i=1}^{r} x_{i+} x_{i+}}{N^{2}}
\end{gathered}
$$

Considera-se uma classificação validada quando a mesma atinge um patamar mínimo de acurácia ou quando se obtém o maior valor de acurácia a partir de todos os modelos que podem ser obtidos. Após validada a classificação, os índices de acurácia são utilizados para avaliar os erros existentes no modelo gerado.

Autores como Bolfe et al. (2004) estudaram a comparação entre estes índices que consistem na etapa de validação da classificação em imagens de satélite. Além do índice de Kappa e da matriz de Exatidão Global como medidores de acurácia da classificação, existe também o índice Tau (T) (MA e REDMOND, 1995). Bolfe et al. (2004) compararam a avaliação destes três avaliadores. Assim, feitas as classificações temáticas dos sensores TM-Landsat e objetivando a distinção entre comunidades florestais nativas (florestas primárias, florestas secundárias, matas de galeria e capoeiras), Pinus sp. e Eucalyptus sp e definidos os pontos de controle, o total de acertos para a Exatidão Global, índice de Kappa e índice de Tau foi equivalente a, respectivamente, $85,23 \%, 84,9 \%$ e $77,74 \%$. Diante de tais resultados, o Bolfe et al. (2004) concluíram que:

[...] embora a Exatidão Global apresente um valor mais alto, os índices Kappa e Tau possuem mais consistência por envolver no valor final todas as células da matriz de erros. A determinação da matriz de erros permite verificar e analisar as confusões ocorridas entre as classes temáticas levantadas. (BOLFE et al., 2004) 


\subsection{CLASSIFICAÇÃO E MAPEAMENTO DA COBERTURA DO SOLO}

A classificação de imagens em Sensoriamento Remoto é, portanto, muito utilizada para se realizar o mapa de cobertura do solo, pois além de reduzir custos de avaliação e monitoramento em nível de campo devido à visão panorâmica oferecida pelas imagens de satélite, confere maior agilidade no processo de confecção do mapa temático através de sua automatização. Logo, aplicações de classificação de imagens em Sensoriamento Remoto são de grande utilidade. Dentre outras áreas do conhecimento, tamanha utilidade é notável na gestão ambiental, pois o monitoramento da cobertura do solo permite identificar focos de ocupação desordenada que geram deterioração do meio ambiente (BORGES e SILVA, 2008).

Segundo Rosa (1989), a expressão "uso do solo" pode ser entendida como sendo a forma pela qual o espaço está sendo ocupado pelo homem. O levantamento do uso do solo é de grande importância, na medida em que os efeitos do mau uso causam deterioração no ambiente. Os processos de erosão intensos, as inundações, os assoreamentos desenfreados de reservatórios e cursos d' água são ocasionados pelo mau uso deste solo, que degradam, dentre outras, a vegetação de margem de um corpo d'água. Neste quesito, Davide et al., (2000) coloca como inquestionável a necessidade da presença da vegetação ciliar, devido às suas funções que têm efeitos que não são apenas locais, mas refletem na qualidade de vida de toda a população sob influência de uma bacia hidrográfica.

\subsubsection{Classificação de imagens para o gerenciamento de recursos hídricos e de Usinas Hidrelétricas}

Uma bacia hidrográfica é importante como referencial para estudo de erosão e preservação dos solos. A ocupação intensiva de uma bacia, com seus usos múltiplos, muitas vezes tem provocado conflitos em termos de captação para irrigação, geração de energia, abastecimento público e industrial, apresentando riscos face aos processos de degradação das Áreas de Proteção Permanente 
(APP's), que exercem uma função essencial na preservação dos recursos hídricos (NASCIMENTO et al., 2005).

As descargas sólidas em águas de reservatórios diminuem a vida útil dos mesmos, pois o material arrastado gera uma diminuição do volume de água a ser utilizado para a movimentação das turbinas, prejudicando a geração de energia elétrica. Dentre os principais atores indiretamente envolvidos com a qualidade e quantidade de água disponível em uma bacia hidrográfica, destacam-se os agricultores. A forma com que fazem o uso do solo interfere diretamente na produção e na qualidade da água, pois seu processo produtivo em áreas marginais compromete o estado de conservação do solo e interfere diretamente na sustentabilidade dos sistemas hídricos (CALDERANO FILHO et al., 2009).

Diante de problemas como este, diversos estudos já foram produzidos no Brasil objetivando realizar o monitoramento de recursos hídricos através do emprego de recursos de sensoriamento remoto, sendo alguns deles voltados à compreensão da variação de parâmetros limnológicos em reservatórios de usinas hidrelétricas (REIS et al., 2003; CABRAL, 2003; PEREIRA FILHO et al., 2003; NOERNBERG et al., 1996; SILVA et al., 1996 entre outros).

Cabral (2003), por exemplo, estudou a concentração de sedimentos em suspensão no reservatório de Barra Bonita (SP). O autor aplicou algoritmos de segmentação, a fim de identificar diferentes massas d'água que compreendem regiões espectralmente distintas no reservatório e estudou a correlação entre dados in situ de concentração de sólidos totais em suspensão e dados obtidos pelos sensores de satélite, originais e processados. Verificou-se então que a segmentação foi útil para a identificação de diferentes massas d'água no Reservatório, detectando-se através da segmentação duas grandes classes espectrais homogêneas no reservatório: concentrações mais baixas e concentrações mais altas de CSS (Concentrações de Sólidos e Suspensão), estas últimas fortemente influenciadas pelos afluentes que carregam dejetos industriais e urbanos. A classificação digital não supervisionada por regiões (Isoseg) também foi útil, pois identificou diferentes massas d'água presentes no reservatório, sendo sugerido pelo autor que pesquisas similares de Sensoriamento Remoto sejam feitas antes de se realizar a coleta de dados em campo. 
Autores como Sousa Júnior (1998) fizeram uso do Sensoriamento Remoto para propor um esquema metodológico para a determinação da área e volume de alagamento de reservatórios. Seu trabalho aborda a questão das áreas inundadas por represas de hidrelétricas, podendo-se estimar a área que o reservatório ocupa e o seu volume a partir de mapas altimétricos da região estudada.

Políticas de conservação de represas devem estar voltadas também para o tipo de cobertura do solo existentes nas redondezas dos corpos d'água. Dutra et al. (2007) fizeram uso da classificação digital de imagens para analisar a área que abrange uma distância de 100 metros da margem de um reservatório. Neste caso, o algoritmo de classificação utilizado, o chamado árvore de decisão, buscou identificar nas áreas degradadas quais que a recuperação tem condições de ocorrer normalmente e quais que a implantação de vegetação é necessária. Segundo estes autores, a árvore de decisão se mostrou bastante eficiente, com o valor do coeficiente Kappa de 0,9357 e matriz de erro com uma exatidão global de 94,76\%.

Almeida et al. (2009) realizaram o mapeamento da cobertura do solo como parte de um trabalho que realiza a construção de uma carta geotécnica de susceptibilidade à erosão em uma área no entorno de uma usina hidrelétrica. Com o classificador Isoseg, os

[...] temas de uso e cobertura do solo foram agrupados nas seguintes classes temáticas, verificadas durante os trabalhos de campo: a) reservatório; b) açudes; c) cerradão; d) mata de galeria; e) campo sujo; f) solos expostos; g) solos preparados para cultura agrícola; $h$ ) cultura agrícola tipo I; i) cultura agrícola tipo II; j) cultura agrícola tipo III; I) área de queimada; m) área de pastagens; e, n) estradas;". Assim, o resultado da classificação do mapa de uso do solo, avaliado por trabalhos de campo, foi considerado adequado e forneceu "subsídios significativos para a compreensão das áreas que possuem maior potencial de susceptibilidade a processos erosivos. (ALMEIDA et al., 2009)

Sousa et al. (2009) fez uso dos classificadores MAXVER e método do paralelepípedo para realizar o mapeamento da cobertura do solo em área compreendida por uma bacia hidrográfica. Neste trabalho, o MAXVER definiu melhor as classes campo, campo/pastagem e mata ciliar, ocorrendo também erros de comissão para a classe agricultura. Já para o método do Paralelepípedo, o trabalho de Sousa et al. (2009) destacou que na "[...] classificação utilizando-se o método paralelepípedo obteve-se um resultado mais rápido, porém ocorreram resultados incoerentes." Neste trabalho, a medida de acurácia utilizada não fora devidamente 
explicitada, mas inferiu-se que a avaliação feita pelos autores acerca dos resultados das classificações foi realizada visualmente, onde o próprio analista qualitativamente percebe um erro no resultado da classificação. Por exemplo, o intérprete verifica visualmente se uma área que consiste em campo fora erroneamente classificada como campo/pastagem.

Ao avaliar a dinâmica da cobertura vegetal e da ocupação do uso do solo na planície aluvial do rio Paraná, Hayakawa et al. (2010) comparou dois classificadores: Isoseg (não-supervisionado) e MAXVER (supervisionado). Seu trabalho destaca:

O primeiro refere-se a um algoritmo de agrupamento de dados não-supervisionados aplicado sobre o conjunto de regiões, que por sua vez, foram caracterizadas por atributos estatísticos de média, matriz de covariância e também pela área na fase de extração de regiões (MOREIRA, 2003). O MAXVER é um método de classificação supervisionado que estima o vetor médio e a matriz de variância e covariância de cada classe, assumindo-se que a frequência de distribuição dos pixels de cada classe possua probabilidade de distribuição normal (MATHER, 1985). Nesse método, a fase de treinamento é essencial para fornecer um conjunto de pixels representativos de cada alvo na imagem. Os pixels escolhidos devem representar fielmente suas respectivas classes (MOREIRA, 2003). (HAYAKAWA et al., 2010)

Assim, ao avaliar a mudança de uso do solo entre os anos 1987 e 2007, os classificadores, segundo o Hayakawa et al. (2010), tiveram desempenho satisfatório e semelhante, mas com algumas ressalvas. Apesar da semelhança dos resultados obtidos, estes autores destacaram que "[...] o MAXVER é o mais indicado para o estudo do uso e ocupação da planície fluvial do rio Paraná, em especial para a classificação da vegetação arbustiva." O Isoseg fora, portanto, mais indicado para classificar áreas úmidas.

Avaliando uma área que compreende uma parte da bacia do Ribeirão Santa Cruz (MG), Bernardi et al. (2007) realizou uma comparação entre dois métodos de classificação de imagens: pixel a pixel, que é tradicionalmente o mais adotado, e orientada a objeto. Este trabalho de Bernardi et al. (2007) cita Gonçalves et al. (2001) para mostrar os motivos a qual uma classificação orientada a objeto deve ser adotada:

- O processamento de imagens aproxima-se mais dos processos cognitivos humanos que as análises baseadas em pixel;

- É mais fácil incorporar informação de contexto com significado numa abordagem orientada ao objeto do que numa abordagem apenas por pixel. (BERNARDI et al., 2007) 
Bernardi et al.(2007), citando Tanaka e Sugimura (2001), destacam ainda a atuação de alguns algoritmos utilizados na classificação de imagens. Neste caso, os não-supervisionados Kmédias e Isodata e os supervisionados MAXVER, Distância Mínima, Paralelepípedo e os que fazem uso da Distância de Mahalanobis, distância esta descrita por Schowengerdt (2007), utilizam a classificação "por ponto" ou "por pixels". Já os algoritmos Isoseg (não supervisionado) e o que faz uso da Distância de Bhattacharyya (supervisionado), distância esta também descrita por Schowengerdt (2007), realizam a classificação por regiões, ou seja, fazem uso de imagem segmentada para realizar o processamento.

Assim, ao comparar o classificador MAXVER (pixel a pixel) e o Nearest Neighbor (orientado a objetos) sobre uma imagem de alta resolução, Bernardi et al. (2007) destacaram que, "apesar de algumas classes terem ficado confusas", os resultados do orientado a objetos foram mais satisfatórios.

O estudo feito por Borges e Silva (2008) analisou a evolução temporal dos padrões de cobertura das terras no período de 1990 a 2005 no reservatório de Manso (MT). Utilizando-se imagens dos satélites LANDSAT e CBERS, o classificador MAXVER gerou um mapa prévio para esta última, que teve sua qualidade avaliada por pontos de controle avaliados a nível de campo. Ressaltou-se que interpretação da imagem de 1990 (LANDSAT) foi feita visualmente, pois por ser antiga estava impossibilitada de ser avaliada a nível de campo. Como resultado, verificou-se que a pastagem é muito presente no local, com $71 \%$ da área total, sendo a única classe que apresentou aumento (cerca de 10\%) em prol das classes de vegetação. Diante deste cenário, Borges e Silva (2008) salientaram o propósito econômico do agronegócio, que traz grandes retornos financeiros aliados à degradação do meio ambiente. Outros fatores que contribuíram para a redução da vegetação foram a construção de uma usina hidrelétrica no local estudado, que aumentou a extensão em termos de área dos corpos d'água, e a expansão de áreas urbanas, que apresentaram um crescimento oriundo da valorização imobiliária e turística do local devido à presença da usina.

A classificação de imagens também já foi usada para mapear e analisar as áreas de risco passíveis de desertificação. Este foi o objetivo de Freire e Pacheco (2005) na área delimitada para o entorno da Usina Hidrelétrica de Xingó, na divisa 
entre os Estado de Alagoas e Sergipe. Os autores citam Sachs (1993), que definiu a desertificação como sendo "a degradação da terra nas zonas áridas, semi-áridas e sub-úmidas secas, resultante de vários fatores, incluindo as variações climáticas e as atividades humanas." Assim o classificador MAXVER foi utilizado na distinção de seis classes: Área urbana, Corpos d’Água, Caatinga Arbórea, Caatinga Arbustiva, Pasto/cultivo e Solo exposto. Ao avaliar as imagens LANDSAT dos anos 1989, 1995 e 2003, Freire e Pacheco (2005) definiram as áreas como "Em processo de desertificação" aquelas áreas que sempre permaneceram como "Solo exposto" e como "Áreas degradadas" as áreas que eram cobertas por alguma forma de vegetação e passaram por perda de biomassa. A validação das classificações foi feita através de expedições de campo. Assim, "Numa visão geral, o estudo concluiu que no período observado, 1989 a 2003, a Região de Xingó sofreu uma contínua, sistemática e devastadora degradação ambiental", pois fora verificado na região um aumento de $91,3 \%$ de solo exposto. Nesse sentido, acerca do processo de desertificação, o Freire e Pacheco (2005) completaram que em sua área de estudo:

[...] cerca de $985,44 \mathrm{~km}^{2}$ têm problemas ambientais significativos relacionados à desertificação, ou seja, $22,37 \%$ da área de estudo estão relacionados com algum processo de desertificação, necessitando de atenção urgente por parte do Governo e da sociedade. (FREIRE; PACHECO, 2005)

Já Jardini et al. (2011) fizeram uso da classificação em imagens como proposta de um mecanismo que auxilia o monitoramento das redes hidrelétricas. Os autores classificaram duas imagens da represa de Jundiaí (SP), datadas de 2009 e 2010. Pelos resultados obtidos, foram detectados os pontos de invasão que ocorreram neste intervalo de tempo e os mesmos foram armazenados em um banco de dados da CESP (Companhia Energética de São Paulo).

A Tabela 2 abaixo mostra os principais classificadores (supervisionados e não-supervisionados) utilizados pelo meio acadêmico no processamento de imagens. Nesta tabela, o classificador SVM, cujos trabalhos que abordam sua utilização encontram-se citados na seção a seguir, está assinalado tanto como por pixel quanto por regiões porque autores como Tzotsos (2006) e Lizarazo (2008) mostraram que é possível realizar uma classificação SVM a partir de imagens 
segmentadas. Ressalta-se, contudo, que neste trabalho a classificação SVM foi implementada da sua maneira mais usual, ou seja, pixel a pixel.

Tabela 2 - Principais classificadores Supervisionados e Não-supervisionados.

\begin{tabular}{cccc}
\hline Algoritmo & $\begin{array}{c}\text { Tipo de } \\
\text { classificação }\end{array}$ & Por pixel & $\begin{array}{c}\text { Por } \\
\text { regiões }\end{array}$ \\
\hline K-médias & Não-Supervisionada & X & \\
Isodata & Não-Supervisionada & X & \\
Isoseg & Não-Supervisionada & & X \\
Battacharya & Supervisionada & & $\mathrm{X}$ \\
Maxver & Supervisionada & $\mathrm{X}$ & \\
Distância Mínima & Supervisionada & $\mathrm{X}$ & \\
Paralelepípedo & Supervisionada & $\mathrm{X}$ & \\
Redes Neurais & Supervisionada & $\mathrm{X}$ & \\
Distância de Mahalanobis & Supervisionada & $\mathrm{X}$ & \\
Vizinho mais Próximo & Supervisionada & & $\mathrm{X}$ \\
SVM & Supervisionada & $\mathrm{X}$ & $\mathrm{X}$ \\
\hline
\end{tabular}

\subsubsection{Aplicações do algoritmo SVM (Support Vector Machines)}

Apesar do algoritmo de classificação supervisionada MAXVER ser o mais usado pela comunidade científica, outro classificador vem ganhando notoriedade nos últimos anos: o Support Vector Machines (SVM) (GIGANDET et al., 2005). O sucesso deste algoritmo fora verificado por diversos autores, dentre eles Sousa et al. (2009), que comparou a acurácia dos resultados obtidos pelo SVM e pelo MAXVER. A autora, cuja área de estudo envolveu o bioma Caatinga, recomendou o uso do algoritmo SVM para se realizar a classificação de imagens deste bioma, pois o índice de Kappa e Exatidão Global apontaram maior acurácia deste classificador em relação ao MAXVER.

Outros que confirmaram a superioridade do algoritmo SVM sobre o MAXVER foram Song e Civco (2004), cujo objetivo de identificar estradas presentes nas imagens de satélite foi atingido. A conclusão de seu artigo, porém, sugere o desenvolvimento de algoritmos que sejam capazes de identificar os vazios presentes nas classificações e identificações das estradas, que são causados pelo sombreamento existente na imagem de estudo. 
Castano et al. (2005) realizaram uma comparação entre 4 classificações, sendo uma manual (interpretação visual) e três obtidas por algoritmos de classificação supervisionada: SVM, Árvore de Decisão e um classificador gerado pelos autores que é por eles chamado de Melhor Relação. Na busca pela identificação de 5 classes de cobertura do solo (água, gelo, terra, neve e nuvem) em nível continental, a acurácia das classificações obtidas pelo classificador manual, Melhor Relação, Árvore de Decisão e SVM foi equivalente a, respectivamente, $82,9 \%, 76,6 \%, 80,9 \%$ e $81,3 \%$. Este artigo, portanto, destacou o algoritmo SVM em termos de qualidade na automação do processo de classificação de imagens, pois o único processo que o superou em termos de acurácia foi manual, que fora aplicado por um especialista.

Wijaya (2007) buscou explorar o potencial do processo de classificação de imagens diante de algumas variações nas medidas da textura espacial de imagens LANDSAT. As diferenças de textura, que segundo o autor representam a variação de níveis de cinza na imagem, ocorrem em imagens que contém áreas de vegetação. Tais diferenças podem influenciar o processo de classificação devido aos seguintes quesitos: medidas de textura promovem informação extra; áreas que são visualmente semelhantes podem ser distinguidas a partir da adição de informações texturais; e os aspectos de textura de classes de cobertura do solo em áreas florestais possuem sutil diferença mesmo quando os valores espectrais são semelhantes. No trabalho de Wijaya (2007), a textura foi avaliada por Geoestatística e pela GLCM (Grey Level Co-ocurrence Matrix) e as áreas de vegetação, foco de seu estudo, foram avaliadas pelos classificadores SVM e Distância Mínima. Atingindo uma exatidão global de $81,44 \%$ e índice de Kappa igual a 0,78, o SVM obteve rendimento superior ao Distância Mínima quando utilizados os parâmetros texturais, resultado este já esperado por Wijaya (2007), que cita outros trabalhos (GUALTIERI e CROMP, 1999; PAL e MATHER, 2004, 2005) que têm comprovado o potencial deste algoritmo.

Oommen et al. (2008), comparou a acurácia dos classificadores SVM e MAXVER em diferentes situações: imagens multi-espectrais, hiper-espectrais e quantidade de amostras. O SVM obteve em todos os casos maior acurácia, sendo que o MAXVER não se mostrou adequado para classificação de imagens hiper- 
espectrais devido ao chamado Hughes Effect. Este efeito acontece quando os vetores amostrais apresentam considerável número de dimensões em seu espaço de atributos a ser avaliado, confundindo assim os parâmetros estatísticos utilizados no processo de classificação quando a quantidade de dados amostrados não é considerada suficiente (SHAHSHAHANI; LANDGREBE, 1994). Outra constatação de Oommen et al. (2008) foi que o SVM superou o MAXVER mesmo quando se utilizou uma grande quantidade de amostras, pois neste caso foi possível encontrar, mesmo que em uma quantidade proporcionalmente menor devido ao tamanho da amostra, os support vectors mais adequados para uma boa classificação.

Pal e Mather (2005) compararam os resultados das classificações obtidas pelo algoritmos SVM, MAXVER e redes neurais. Foi constatado neste estudo que o SVM apresentou resultados superiores ao redes neurais e similares ao MAXVER, mas quando o espaço amostral sofreu aumento no número de dimensões a acurácia do SVM foi maior que a dos demais classificadores. Este resultado fez jus aos encontrados e discutidos por Oomen et al. (2008), em que o MAXVER apresentou erros devido ao Hughes Effect, que também fora constatado no experimento de $\mathrm{Pal}$ e Mather (2005) quando as amostras possuem espaço de atributos com mais de dez dimensões. Logo, acurácia obtida pelo SVM tanto em espaços dimensionais menores quanto maiores confirmaram o potencial deste algoritmo na classificação de imagens. 


\section{SUPPORT VECTOR MACHINES}

Schowengerdt (1996), em contexto de Sensoriamento Remoto, definiu uma classe como um espaço de atributos específicos, em que os pixels podem ser agrupados de acordo com seu grau de similaridade em relação às classes existentes ou disponíveis.

Diversos algoritmos foram elaborados visando à delineação de uma função discriminante de classes, que agrupam dados de entrada em classes específicas, ou espaço de atributos específicos. Neste contexto, o algoritmo SVM (Support Vector Machines) surgiu como um potencial classificador passível de aplicação em imagens de satélite.

\subsection{O ALGORITMO SVM E SUA APLICAÇÃO EM DADOS LINEARES}

Support Vector Machines (SVM) é uma técnica para classificação binária, ou seja, realiza uma separação automática entre duas classes diferentes (Vapnik, 1995). Por exemplo, a classificação SVM, por ser binária, realiza uma separação automática entre duas classes que possuem características distintas, como uma população de pessoas altas e uma população de pessoas baixas. A partir de uma entrada de dados de treinamento, uma classificação SVM responde ao usuário a qual das duas classes o indivíduo selecionado pertence.

$\mathrm{Na}$ literatura, diversas aplicações foram feitas utilizando SVM. A citar a aplicação deste algoritmo em reconhecimento de padrões, foram feitas análises de reconhecimento de letras escritas à mão (CORTES e VAPNIK, 1995), reconhecimento de objetos (BLANZ et al., 1996) e detecção de rostos em imagens (OSUNA et al., 1997). A aplicação do SVM ocorre em uma gama diversa de trabalhos e dados a serem classificadas devido ao seu alto poder de generalização, que tem alta performance e é competitivo com outros métodos de classificação (BURGES, 1998).

SVM é um algoritmo de classificação supervisionada cujo objetivo consiste na separação ótima de classes (VAPNIK, 1995). Os primórdios de seu estudo provém de Vapnik e Chervonenkis (1971), mas somente a partir dos anos 90 suas aplicações começaram a ganhar notoriedade. A teoria a qual se baseia o SVM 
estabelece uma série de princípios que devem ser seguidos na obtenção de classificadores com boa capacidade de generalização. Tenta-se prever corretamente a classe a qual determinado dado de entrada pertence baseando-se nos seus próprios dados e nos dados do mesmo domínio em que o aprendizado ocorreu (LORENA e CARVALHO, 2007). Logo, diante de uma amostragem de duas classes distintas, a classificação SVM permite a obtenção de diversas funções de um separador das mesmas. A Figura 3.1 abaixo mostra dois possíveis separadores de classes que encontram-se distribuídas linearmente. Diante de diversas possibilidades para obtenção de uma função separadora de classes, deve-se avaliar qual é a função que faz a melhor distinção entre duas categorias diferentes de dados.

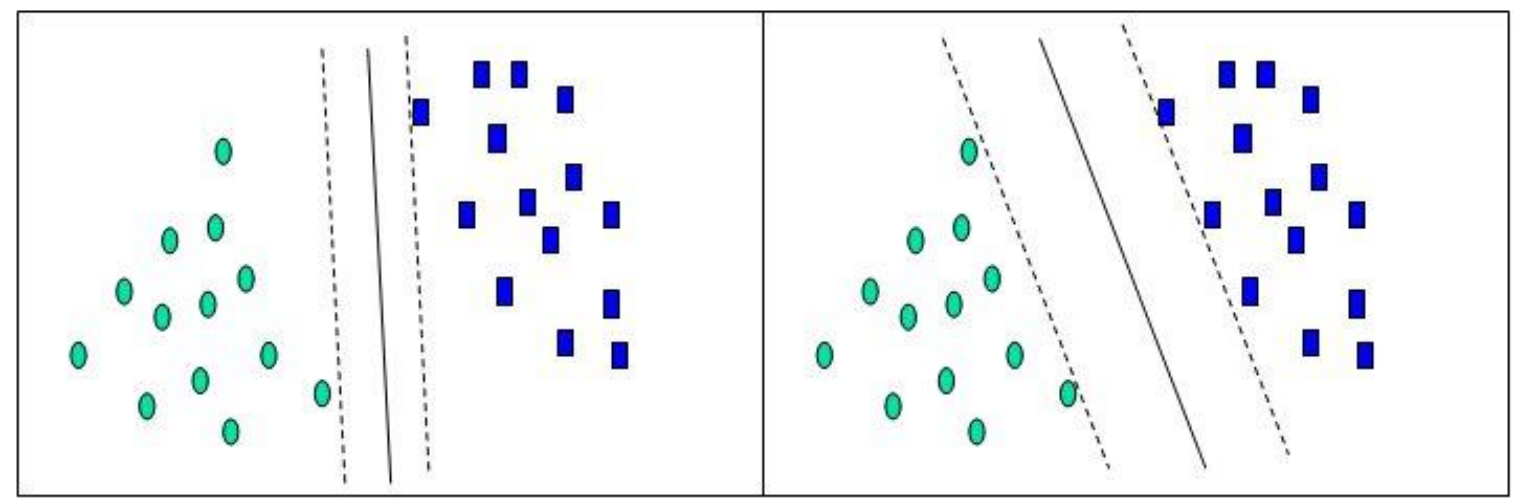

Figura 3.1 - Exemplos de classificação SVM, que separou a classe verde da classe azul. Fonte: DTREG <http://www.dtreg.com/svm.htm>. Acesso em: 6 de junho de 2011.

A função de decisão que faz a melhor separação é aquela que apresenta a maior margem entre as duas classes analisadas. A margem é definida como a soma das distâncias entre os pontos de ambas as classes que são os mais próximos à função de separação (VAPNIK, 1995). Para facilitar o entendimento do conceito de margem, introduz-se o conceito de Support Vectors, que dão o nome ao algoritmo. 


\subsection{SUPPORT VECTORS}

Support Vectors (ou Vetores de Suporte) nada mais são do que os pontos de ambas as classes que estão mais próximos do separador de classes. A determinação destes Support Vectors é crucial para o estabelecimento da função separadora de classes, pois o algoritmo faz uso destes dados para gerar a classificação. O número de Support Vectors é, conseqüentemente, menor que a quantidade total de amostras de cada classe (VAPNIK, 1995). A Figura 3.2 abaixo mostra dois exemplos de classificação SVM para os mesmos dados de entrada, evidenciando a margem e os Support Vectors de cada classe.

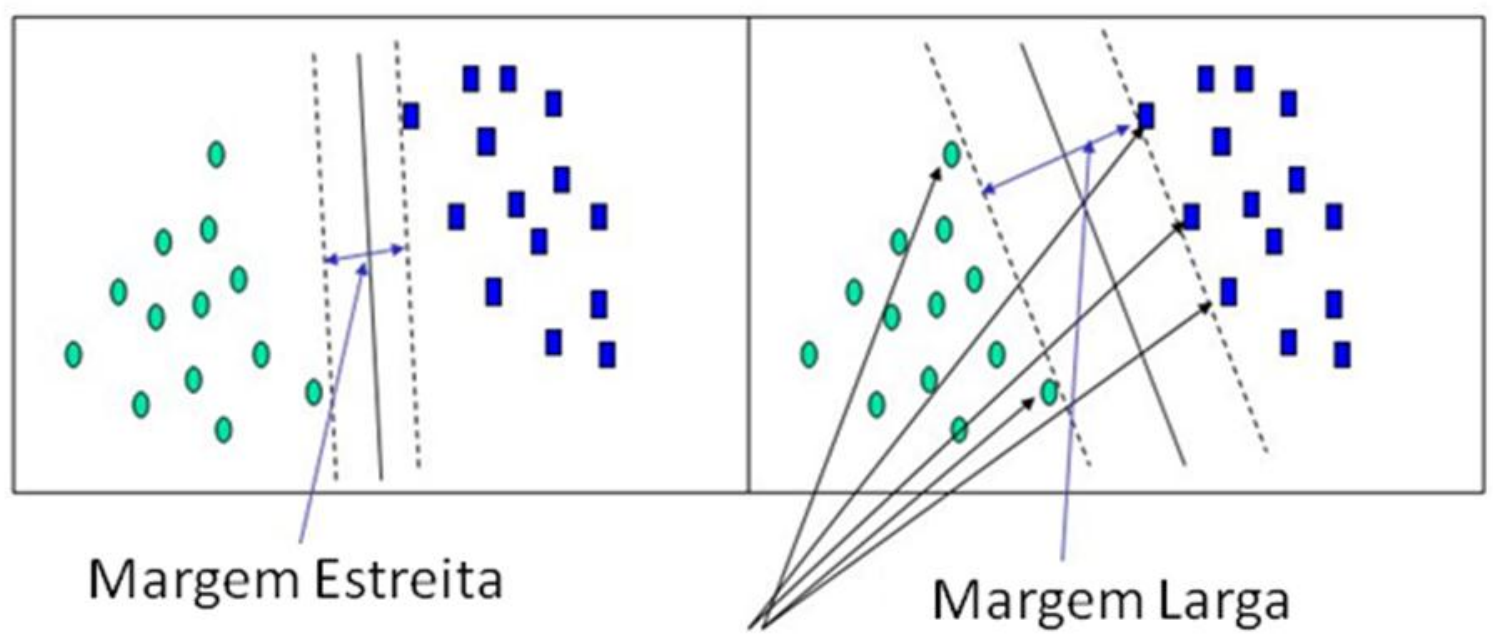

Support Vectors

Figura 3.2 - Dois separadores de classes e suas margens, que são associadas aos support vectors. Support vectors são os vetores do espaço amostral mais próximos da função de separação, sendo eles os únicos parâmetros utilizados no delineamento da função. Já a margem, que é a distância entre os support vectors e a função de separação, deve ser a maior possível para que o processo de classificação seja otimizado. Adaptado de: DTREG <http://www.dtreg.com/svm.htm>. Acesso em: 6 de junho de 2011.

Verifica-se, portanto, que o classificador da direita é o mais adequado, pois ele segue a premissa básica do SVM, em que o separador ótimo de classes deve apresentar a maior margem possível entre a função de separação e os Support Vectors (LORENA; CARVALHO, 2007). 


\subsection{O HIPERPLANO DE SEPARAÇÃO}

A função de separação também é chamada de hiperplano de separação (BURGES, 1998). No caso das Figuras 3.1 e 3.2, os atributos do espaço amostral estão distribuídos em um espaço bi-dimendional, o que faz com que o hiperplano de separação seja uma reta, de dimensão única. Para facilitar a visualização deste hiperplano de separação, um exemplo em dimensão maior é dado pela Figura 3.3, que possui um espaço amostral dos dados de entrada em ambiente 3D e faz com que a função de separação seja um plano (2D).
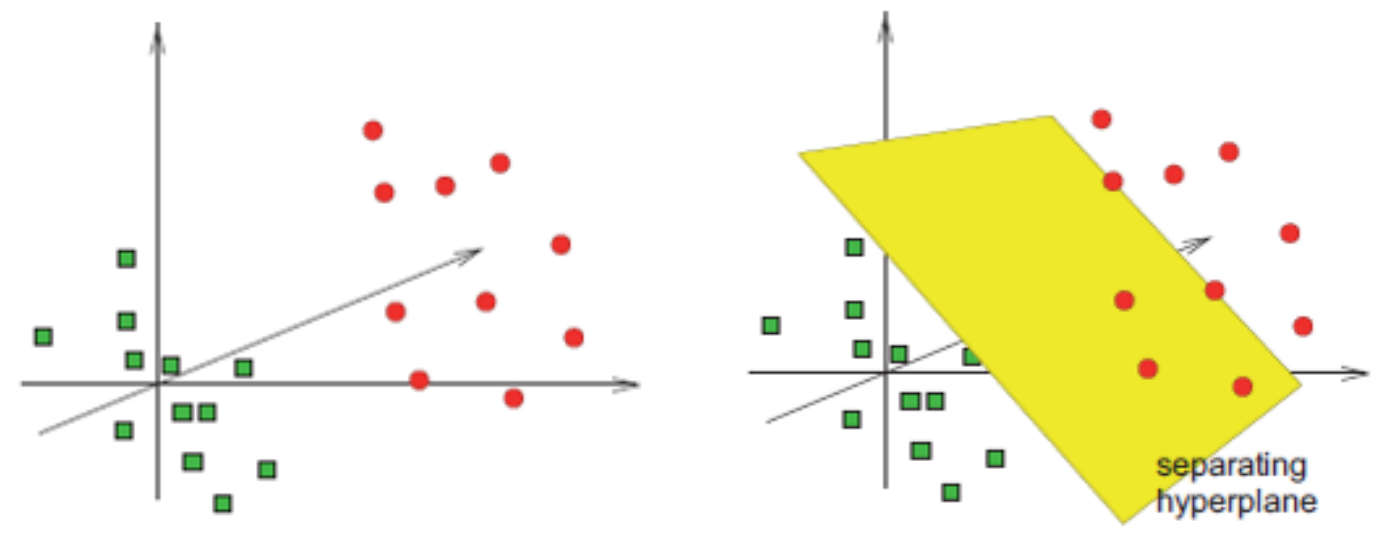

Figura 3.3 - Espaço amostral em ambiente 3D possui função de separação 2D. A função de separação também é chamada de hiperplano de separação, ou separating hyperplane.

Fonte: Huson (2007).

Assim, busca-se o hiperplano de separação que possuir a maior margem possível para se obter a melhor classificação possível, sendo este hiperplano chamado de hiper-plano de separação ótima, ou Optimal Separating Hyperplane (OSH) (BURGES, 1998). A eq. (7) mostra a margem a ser maximizada para obtenção do $\mathrm{OSH}$. Sua demonstração bem como os parâmetros matemáticos que demonstram as propriedades dos Support Vectors, não consistem o foco desta Dissertação, recomendando-se para tal a leitura de Burges (1998) e Lorena e Carvalho (2007). 


$$
\tilde{L}(\alpha)=\sum_{i=1}^{n} \alpha_{i}-\frac{1}{2} \sum_{i, j} \alpha_{i} \alpha_{j} y_{i} y_{j} \mathbf{x}_{i}^{T} \mathbf{x}_{j}
$$

em que $\mathbf{x}_{i}$ é um conjunto de treinamento, $y_{i}$ seus respectivos rótulos, $\mathbf{x}_{j}$ os dados não classificados, $y_{j}$ seus respectivos rótulos e a os multiplicadores de Lagrange dos dados de treinamento $i\left(\alpha_{i}\right)$ e dos dados a serem classificados $j\left(\alpha_{j}\right)$.

\subsection{SVM E SUA APLICAÇÃO EM DADOS NÃO-LINEARES}

Os exemplos mostrados acima, porém, são muito distantes dos dados coletados na vida real, pois freqüentemente as amostras ficam distribuídas de maneira não linear no espaço. Demonstrado por Hofmann, Scholkopf e Smola (2008), a fim de resolver o problema da não-linearidade do espaço amostral, foi proposta uma reprojeção dos dados amostrais em um espaço dimensional maior através de funções Kernel $(\Phi)$, sendo que a partir deste novo espaço amostral o algoritmo de classificação SVM de Vapnik (1995) é utilizado. Um exemplo de aplicação de função Kernel é mostrado na Figura 3.4.

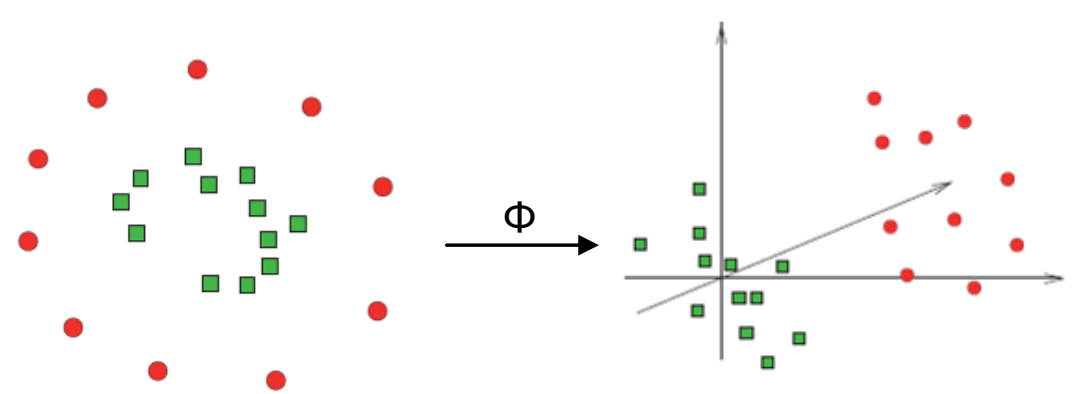

Figura 3.4 - Redistribuição dos dados de entrada, que coletados em espaço 2D foram redistribuídos em espaço 3D por aplicação de uma função Kernel.

Fonte: Huson (2007). 


\subsubsection{Funções Kernel}

De acordo com Hofmann, Scholkopf e Smola (2008), um Kernel corresponde a um produto escalar que normalmente encontra-se em espaço dimensional superior a qual os atributos foram inferidos. Neste novo espaço dimensional, os métodos de modelagem são lineares, sendo que os termos originais, quando tratados por relações envolvendo os Kernels, não são computacionalmente mostrados em dimensões superiores.

A aplicação de funções Kernel otimiza a atuação do separador de classes. A Figura 6 abaixo mostra esta situação. No caso, os dados coletados em espaço bidimensional necessitaram de ser reamostrados em espaço tri-dimensional, para que então a função separadora de classes pudesse ser obtida. Nesta situação da Figura 3.5, como o espaço é tri-dimensional, o hiperplano de separação tem o formato de um plano.

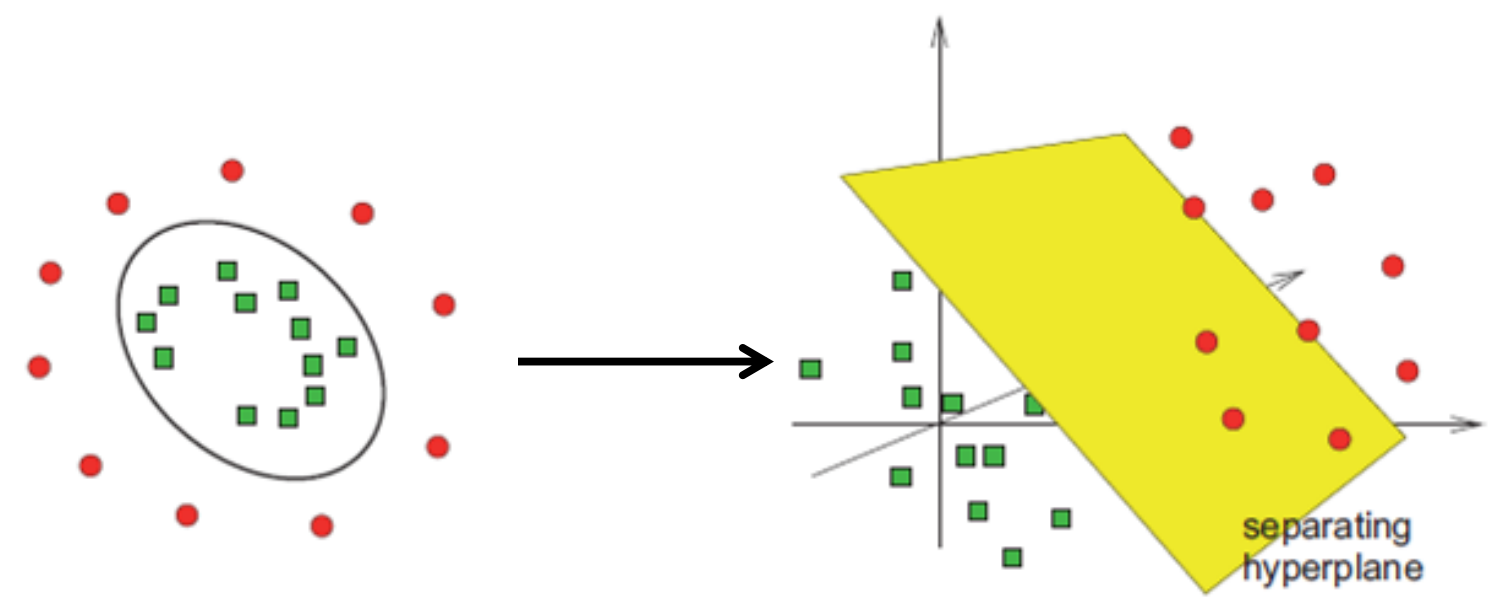

Figura 3.5 - Espaço amostral inicial, em que as classes se distribuem de maneira não-linear. Foi então aplicada uma função Kernel para se tornar possível a delimitação do hiperplano de separação. Fonte: Huson (2007).

Como a atuação do SVM não-linear depende da função Kernel, também expressa por $\mathrm{K}(\mathrm{xi} ; \mathrm{xj}) \equiv \Phi(\mathrm{xi})^{\top} \Phi(\mathrm{xj})$, a ser implementada, a correta aplicação da mesma é fundamental para se obter uma boa classificação. A literatura apresenta 
diversas funções Kernel, da qual Hsu et al.(2010) destaca as seguintes funções que são as mais utilizadas em um processo de classificação do algoritmo SVM:

$$
\begin{aligned}
& \text { linear: } \mathrm{K}\left(\mathrm{x}_{\mathrm{i}} ; \mathrm{x}_{\mathrm{j}}\right)=\mathrm{x}^{\top}{ }_{i} \mathrm{x}_{\mathrm{j}} . \\
& \text { polynomial: } \mathrm{K}\left(\mathrm{x}_{\mathrm{i}} ; \mathrm{x}_{\mathrm{j}}\right)=\left(\mathrm{Y} \mathrm{X}_{\mathrm{i}}^{\top} \mathrm{X}_{\mathrm{j}}+\mathrm{r}\right)^{\mathrm{d}}, \mathrm{Y}>0 \text {. } \\
& \text { radial basis function }(R B F): \mathrm{K}\left(\mathrm{x}_{\mathrm{i}} ; \mathrm{x}_{\mathrm{j}}\right)=\exp \left(-\mathrm{Y}\left\|\mathrm{x}_{\mathrm{i}}-\mathrm{x}_{\mathrm{j}}\right\|^{2}\right), \mathrm{Y}>0 \text {. } \\
& \text { sigmoid: } \mathrm{K}\left(\mathrm{x}_{\mathrm{i}} ; \mathrm{x}_{\mathrm{j}}\right)=\tanh \left(\mathrm{Y} \mathrm{X}_{\mathrm{i}}^{\top} \mathrm{x}_{\mathrm{j}}+\mathrm{r}\right) \text {. }
\end{aligned}
$$

Segundo Hsu et al.(2010), usuários do classificador SVM não necessitam conhecer toda a teoria por traz do algoritmo, mas sim algumas premissas básicas para realizar o procedimento da classificação. Assim, nos exemplos das funções Kernel acima, os coeficientes "Y", "r" e "d" são parâmetros Kernel: "Y" é um parâmetro de todas as quatro funções, à exceção da linear; "r" é um parâmetro da função sigmoidal; e "d" é o grau do polinômio na função da eq. (9). Tais parâmetros devem ser devidamente estabelecidos pelo usuário, a fim de calibrar ao máximo o classificador que gera a função de separação de classes. A seção 3.5 desta dissertação aborda um método de calibração do classificador SVM sugerido por Hsu et al., (2010).

\subsubsection{O parâmetro de penalidade C}

Além destes, outro parâmetro que deve ser calibrado na classificação SVM é o valor de $\mathrm{C}$, que deve ser maior que zero, por consistir no parâmetro de penalidade do algoritmo. Basicamente, o parâmetro $C$ é uma espécie de tolerância aos erros existentes em uma classificação. A demonstração matemática da presença do parâmetro $C$ na equação da margem a ser maximizada pode ser vista em Burges (1998) e Lorena e Carvalho (2007).

Para exemplificar, ao separar as classes "a" e "b", o valor do parâmetro C define uma espécie de permissão a erros existentes no modelo, que são a existência de muitas ou poucas amostras de "a" presentes no espaço classificado como "b" e vice-versa, ou seja, o grau de tolerância a erros na classificação gerada. A Figura 3.6 ilustra um exemplo da atuação do parâmetro $C$ em uma classificação SVM, 
mostrando o resultado da função de separação (a) tolerante a erros, (b) não tolerante a erros e (c) moderadamente tolerante.
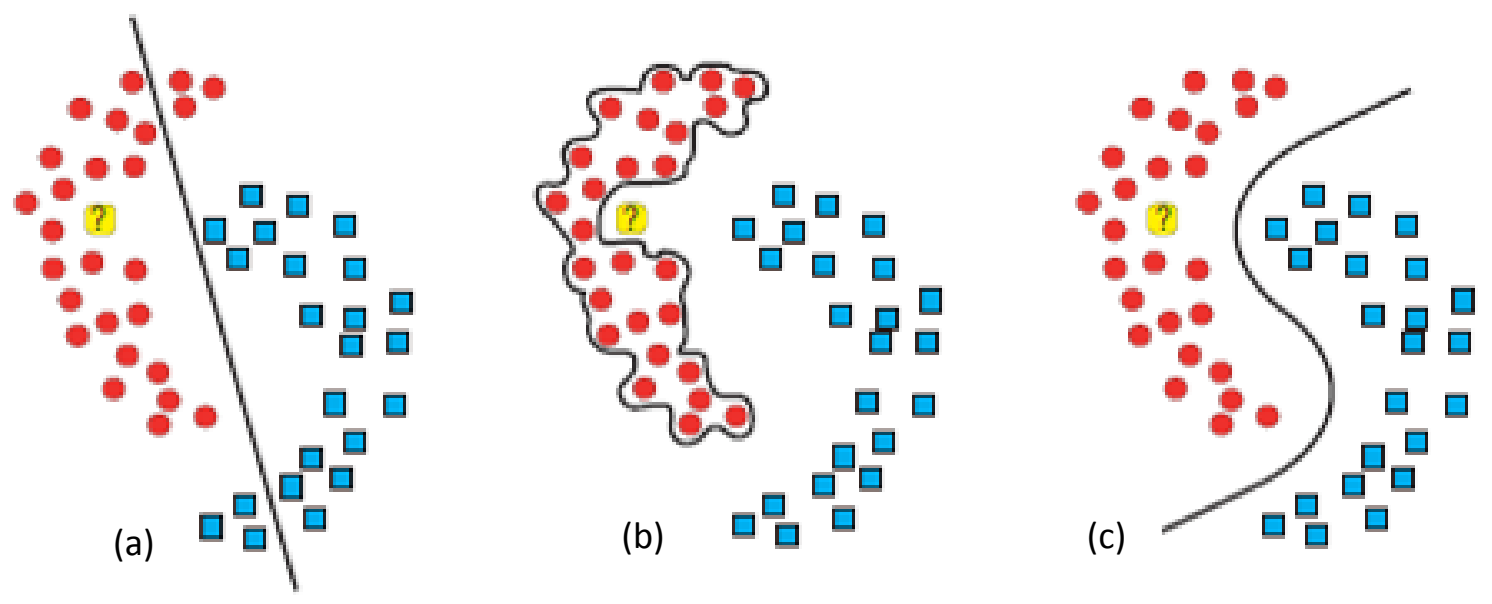

Figura 3.6 - Exemplo da influência do parâmetro $C$ em uma classificação SVM.

O modelo (a) é tolerante a erros, (b) é não tolerante a erros e (c) é moderadamente tolerante. Delimitadas as amostras da classe vermelha e da classe azul, deseja-se classificar o ponto amarelo. Neste caso, nota-se que o melhor classificador está em (c), pois em (a) existem erros de omissão e comissão e em (b) o ponto amarelo é erroneamente classificado. Adaptado de Huson (2007).

\subsection{CALIBRAÇÃO DO ALGORITMO SVM}

Para se calibrar uma classificação SVM e tentar otimizar seu processo, é comum aos novos usuários fazer testes aleatórios para verificar os resultados dos mesmos e assim conferir os parâmetros que geraram os melhores classificadores. Para evitar tal cenário, autores como Hsu et al.(2010) orientam os novos usuários a não realizarem testes aleatórios e procederem da seguinte maneira:

- Recalcular os dados de maneira a dispor todos eles em uma mesma escala;

- Considerar a função Kernel RBF, que tem gerado resultados satisfatórios para usuários do SVM; 
- Fazer uso da validação-cruzada para encontrar os melhores valores de C e $\mathrm{Y}$;

O primeiro passo consiste, basicamente, em colocar todos os atributos analisados em uma escala similar. Por exemplo, caso a abrangência de um atributo "a" possua valores que variam de 8 a 25 u.m. (unidades de medida) e de um atributo "b" variam de 11 a 21 u.m., ambos devem ser recalculados para se adequarem a uma mesma escala, que geralmente vai de 0 a 1 .

$O$ segundo passo consiste apenas em uma sugestão de primeira tentativa de classificação SVM utilizando a função Kernel RBF. A recomendação ocorre porque ela pode apresentar resultados similares tanto quanto à função Linear quanto à função Sigmoidal, grau de similaridade este que depende dos valores que serão estabelecidos para seus parâmetros $(\mathrm{C}, \mathrm{Y})$. Em relação à função polinomial, a RBF é recomendada pelo fato de possuir menos parâmetros a serem calibrados. Entretanto, quando a quantidade de atributos dos elementos a serem classificados é muito grande recomenda-se usar a função linear ao invés da RBF (HSU et al., 2010).

O terceiro passo consiste na calibração dos parâmetros $C$ e $Y$. O método de busca destes parâmetros chamado de validação-cruzada (ou cross-validation) basicamente separa seus dados em duas partes, sendo que um deles deve ter seu valor estabelecido e o outro valor são feitos testes. Desta maneira a performance da classificação pode ser considerada como feita sobre dados em que cada par (C, Y) é independente, o que permite avaliar melhor a influência dos parâmetros (HSU et al., 2010).

\subsection{O PROBLEMA DE CLASSIFICAÇÃO MULTI-CLASSE}

Os passos já mostrados neste Capítulo direcionaram o entendimento da atuação do algoritmo SVM e os passos para se realizar as classificações. Apesar de verificados tais passos, mais uma questão deve ser abordada: o problema multiclasse. 
Conforme mencionado neste trabalho e citando-se Vapnik (1995), o SVM é um classificador binário. Como na grande maioria dos trabalhos que envolvem aplicação do SVM são usadas mais de duas classes para serem identificadas, o uso de um classificador binário se depara com o problema multiclasse. Para contornar este problema, existem duas soluções possíveis de serem adotadas, que são baseadas na idéia de realizar uma série de classificações binárias para gerar um único resultado final: através do método "um contra todos" ou do método "um contra um".

No método "um contra todos", a separação binária faz com que uma classe seja separada de todas as demais. Por exemplo, para se obter uma classificação que envolva as classes "a", "b", "c" e "d", a condição para um dado pertencer à classe "a" vai depender dos seus valores de probabilidade dele se encontrar em "a" ou em "b, c, d", ou seja, "a" contra "b, c, d". Da mesma maneira, para saber se um objeto pertence à classe "b" depende da probabilidade dele pertencer à classe "b" ou ‘a classe “a, c, d", e assim por diante. Este método, apesar de ser computacionalmente mais rápido que o método "um contra um", apresenta maior quantidade de erros (ou menor acurácia) em seus resultados (HSU; LIN, 2002).

No método "um contra um", é gerada uma série de classificadores formada por todos os pares de classes, cada um contendo suas regras. Para um dado objeto, cada par de classes dá o seu voto acerca de qual classe ele pertence, sendo este objeto classificado segundo o maior número de votos recebido. Seguindo o mesmo exemplo das classes "a", "b", "c" e "d", geram-se os seguintes pares de classes:

"a, b" ; “a, c" ; "a, d" ; "b, c" ; "b, d" ; “c, d"

Cada dado a ser classificado recebe um voto de cada um destes pares de classes. Logo, um dado pertencente à classe "a", caso o algoritmo esteja bem calibrado, deve receber 3 votos para "a" (cada um destes três votos vêm de cada um dos três pares que contém a classe "a") e quaisquer outros votos, que poderiam ser, por exemplo, dois votos para "b" e um para "d". Neste caso o maior número de votos foi para a classe "a", fazendo com que este dado seja, portanto, classificado como "a". Apesar de o método "um contra um" demandar maior quantidade de tempo operacional para os computadores, ele gera menor quantidade de erros que o "um 
contra todos" (HSU; LIN, 2002). A Figura 3.7 ilustra as resoluções "um contra todos" e "um contra um" para o problema multi-classe.

\section{SVMs e o problema Multi-classe}

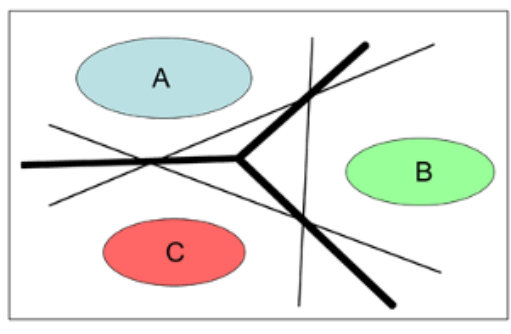

Um contra Todos

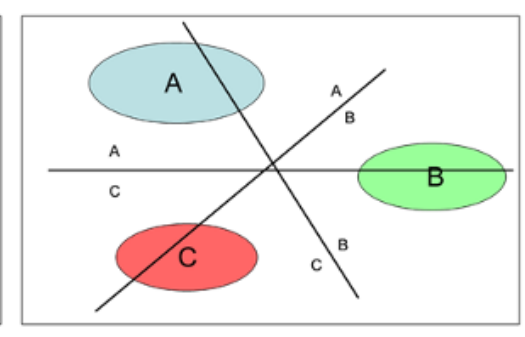

Um contra Um

Figura 3.7 - Métodos de resolução do problema multi-classe. Fonte: http://courses.media.mit.edu/2006fall/mas622j/Projects/aisen-project/index.html

Alguns softwares fazem a implementação do algoritmo SVM em processos de classificação em imagens de satélite. O software Envi 4.8 possui esta operação disponível. As análises feitas por este software permitem que a classificação seja feita pixel a pixel e o problema multiclasse seja contornado pelo método "um contra um" (ITT, 2010). Detalhes do software nos processos de classificação realizados nesta Dissertação são descritos no capítulo seguinte. 


\section{MATERIAIS E MÉTODOS}

Neste capítulo é detalhada a metodologia aplicada na abordagem proposta para classificação de imagens do satélite GEOEYE. São apresentadas as classes de interesse assim como a classificação pelo método SVM. Também são apresentados detalhes sobre a validação do algoritmo e a acurácia do mesmo.

\section{1 ÁREA DE ESTUDO}

A represa de Lajeado - Tocantins (TO), também chamada de UHE (Usina Hidrelétrica) Luis Eduardo Magalhães está localizada no município que leva o mesmo nome, onde o mapa da localização desta região é mostrado na Figura 4.1 abaixo.

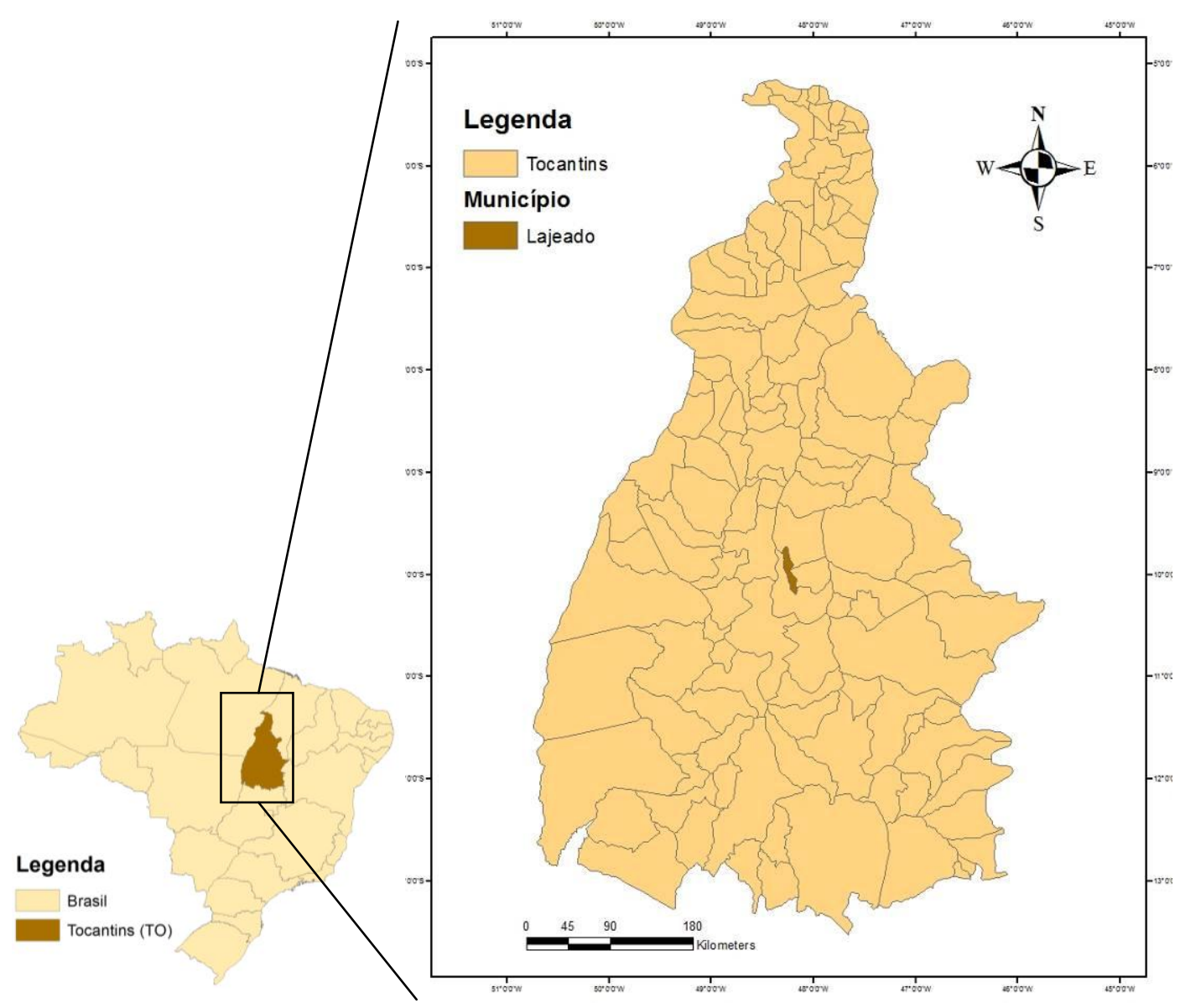

Figura 4.1 - Localização do município de Lajeado - TO. 
A menos de 53 kilômetros ao sul do município de Lajeado encontra-se a capital do estado de Tocantins (TO), Palmas. O estado do Tocantins encontra-se aproximadamente entre os paralelos $9^{\circ} 30^{\prime} \mathrm{S}$ e $11^{\circ} 30^{\prime} \mathrm{S}$ e os meridianos $48^{\circ} 15^{\prime} \mathrm{W}$ e $48^{\circ} 45^{\prime}$ S. A cidade de Lajeado é mostrada na Figura 4.2 abaixo.

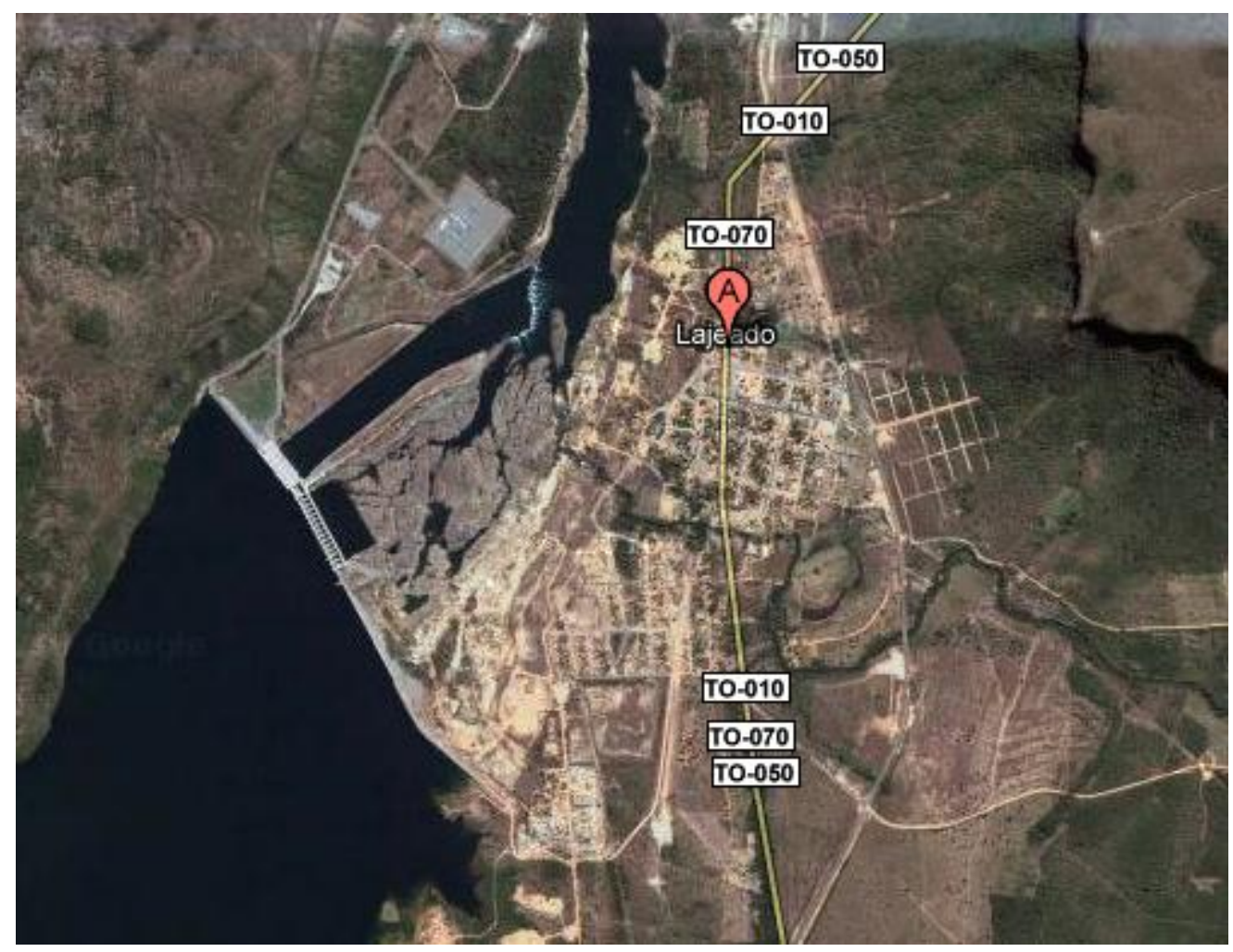

Figura 4.2 - Cidade de Lajeado.

Fonte:

http://www. microbeworld.org/index.php?ltemid=189\&id=53\&layout=blog\&limitstart=50\&option=com co ntent\&view=category

A temperatura da região tem média superior a $25{ }^{\circ} \mathrm{C}$ e possui certa homogeneidade climática, sendo as temperaturas mínimas de $12^{\circ} \mathrm{C}$ atingidas nos meses de junho e julho (TUNDISI, 2006). A classificação de Koppen (1948) mostra a represa de Lajeado inserida em Zona Tropical Chuvosa, cuja precipitação média mensal oscila entre $200 \mathrm{~mm}$ e $134 \mathrm{~mm}$ e a umidade relativa do ar possui média de $80 \%$ em períodos chuvosos e $55 \%$ em períodos de seca.

A UHE Luis Eduardo Magalhães foi construída pela INVESTCO S.A., consórcio formado pelo Grupo REDE, EDP, CEB e CMS Energy. A usina gera energia para o Estado do Tocantins e ainda envia o restante da energia produzida 
para o Centro Oeste e o Sudeste (EPE, 2005). Contudo, o empreendimento, apesar de ter possibilitado a implantação de programas ambientais e a criação de empregos diretos em uma área que era considerada atrasada, sofreu algumas críticas como a de Zitzke (2007), cuja análise infelizmente constatou que muitas famílias acabaram sendo indevidamente realocadas.

O reservatório foi construído para oferecer à população diversos tipos de uso da água, como pesca, piscicultura, navegação, irrigação, turismo e recreação. O enchimento da represa durou pouco menos de um ano, tendo início em setembro de 2001 e término em fevereiro de 2002. A área aproximada do reservatório é $704 \mathrm{~km}^{2}$ e o tempo de residência 24 dias (PEREIRA, 2002).

O cenário a qual a represa está inserida vem provocando poluição das águas, onde à montante das usinas os afluentes são fontes de degradação por transportarem material em suspensão, nitrogênio e fósforo, que estimulariam os processos de eutrofização e assoreamento (PEIXOTO, 2007; apud SILVA, 2009). Neste contexto a caracterização do uso e ocupação do solo é de evidente importância e já se encontra em uma das etapas do plano de conservação da bacia hidrográfica (TUNDISI, 2006).

\subsection{MATERIAIS}

A classificação em imagens consiste em um método automático de extração de informações da superfície terrestre e geração de um mapa temático. Para gerar uma classificação que defina os tipos de cobertura do solo, neste trabalho foi utilizada uma imagem GEOEYE, de setembro de 2010, que cobre a represa da hidrelétrica Luis Eduardo Magalhães em seu período de seca. A imagem é de alta resolução e foi adquirida pela FDTE (Fundação e apoio ao Desenvolvimento Tecnológico de Engenharia), recurso este vindo de projeto de pesquisa fomentado pela INVESTCO/ ANEEL - Agência Nacional de Energia Elétrica. Ela foi recebida com as seguintes características: 16 bits de resolução radiométrica e fusionada com 0,5 metros de resolução espacial. No total, o sensor opera com 4 bandas, que se distribuem nas seguintes faixas do espectro: 
450-510 $\mathrm{nm}$ (blue)

510-580 nm (green)

655-690 nm (red)

780-920 nm (near IR)

Nesta Dissertação fora usada uma única cena do satélite GEOEYE, cena esta que engloba grande parte do município de Lajeado. Tal material utilizado para a classificação é ilustrado na Figura 4.3 no seu respectivo canal Red (Vermelho), Green (Verde) e Blue (Azul) (RGB). 


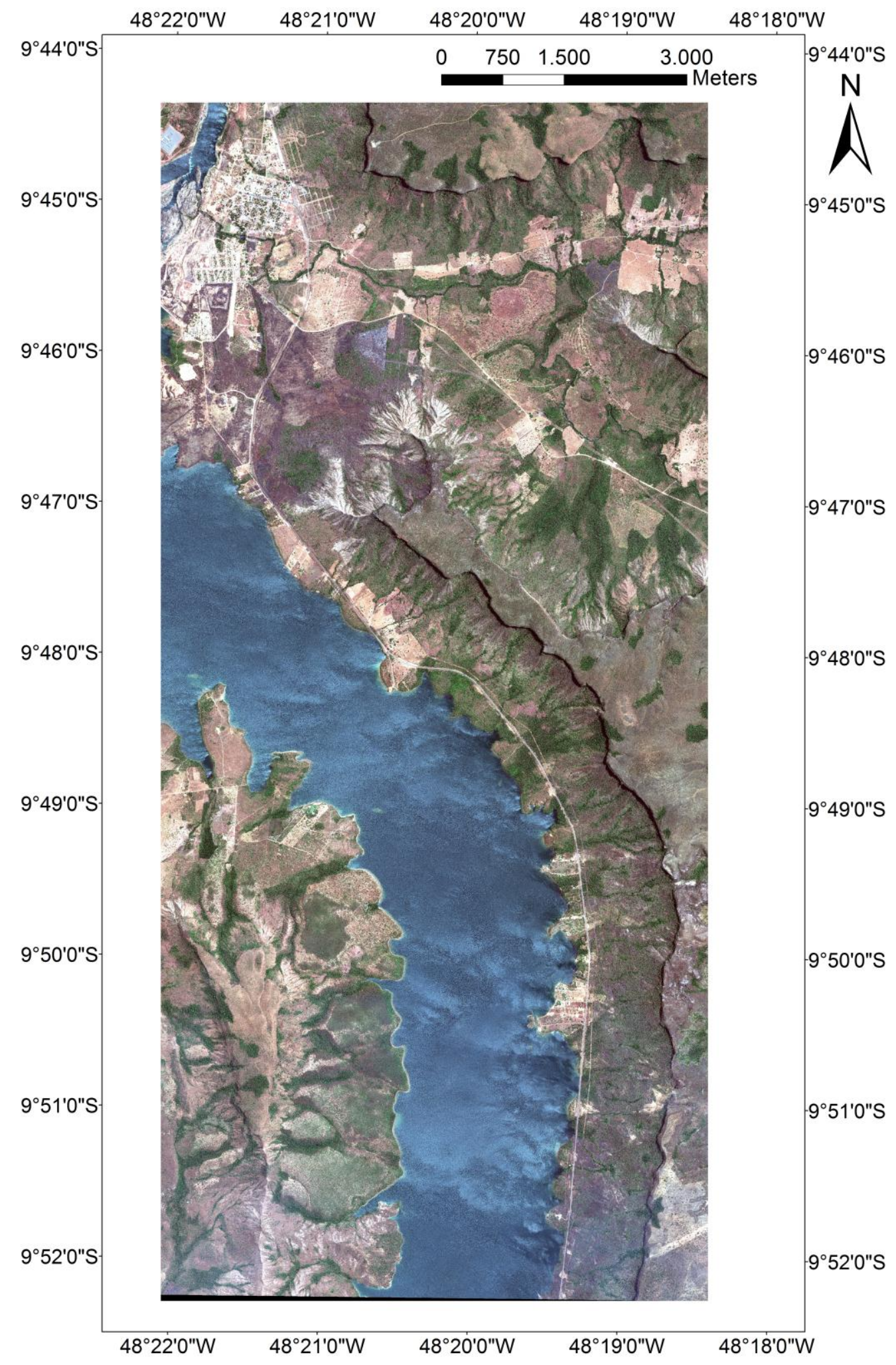

Figura 4.3 - Imagem GEOEYE utilizada para os processos de classificação aqui ilustradas pelas bandas RGB. 
Foi utilizado o software Envi 4.8, que realiza classificação SVM pixel a pixel e utiliza o método "um contra um" para resolver o problema da classificação multiclasses. Os layouts das classificações foram gerados no software ArcGis 10 . Foram também tiradas fotos em nível de campo para complementar o trabalho.

\subsection{METODOLOGIA}

A proposta metodológica deste trabalho consiste em uma classificação em imagens de satélite utilizando o algoritmo SVM e gerando-se uma avaliação de seus resultados. A classificação, para este trabalho, visa à confecção de um mapa temático dos tipos de cobertura do solo verificados na represa de Lajeado.

As classes de cobertura do solo foram estabelecidas segundo hierarquização proposta pelo IBGE (2006) e com algumas adaptações presentes em CORINE (Coordination of Information of Environment) no trabalho de Bossard et al. (2000). Estas adaptações visaram a incrementar algumas classes de cobertura do solo que, apesar de não existem na hierarquia proposta pelo IBGE (2006), foram constatadas na área e devem ser devidamente discriminadas. As classes de cobertura do solo neste trabalho seguem, portanto, a estrutura hierárquica do IBGE (2006) com algumas adaptações que foram baseadas em sua semelhança com a hierarquia de CORINE, permitindo assim a implementação de classes de cobertura do solo explicadas no relato de Bossard et al. (2000). Esta adaptação é mostrada na Figura 4.4, que destaca em azul a hierarquia do IBGE (2006) como base e as adaptações de CORINE em verde. 


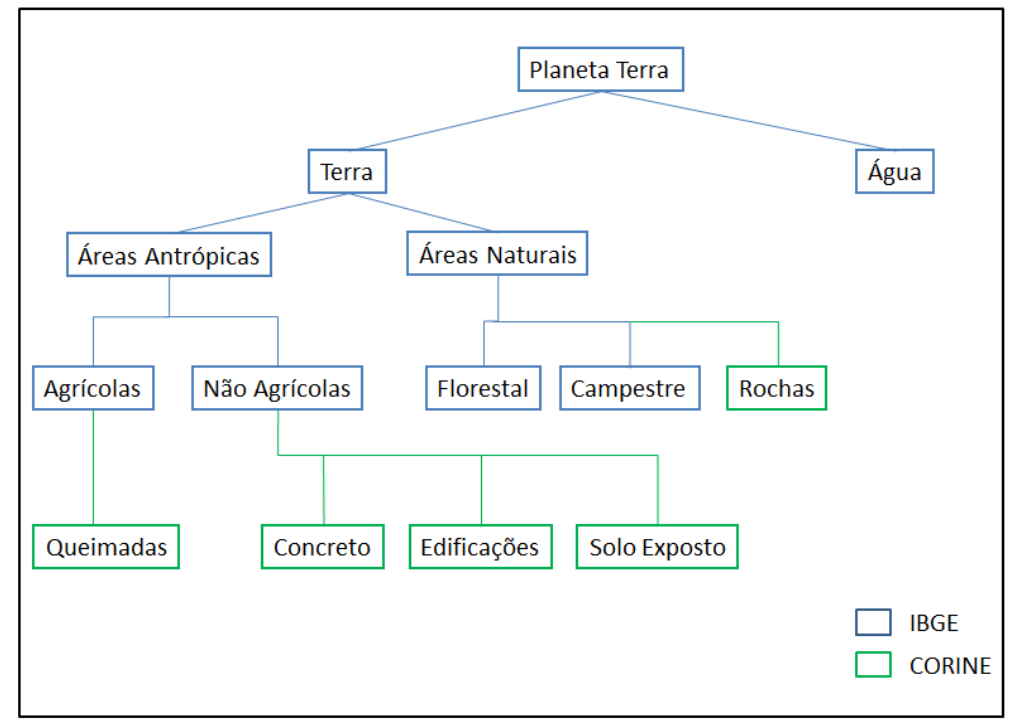

Figura 4.4 - Hierarquia de classes utilizada, que tem como base a proposta do IBGE (2006) e possui adaptações de CORINE (2000).

Logo, as classes automaticamente identificadas no processamento das imagens foram: Água, Florestal, Campestre, Rochas, Queimadas, Solo Exposto, Concreto e Edificações. A descrição de cada uma destas classes de cobertura presentes na imagem GEOEYE e comprovadas por trabalho de campo encontra-se na seção a seguir.

\subsubsection{Classes de cobertura do solo}

Foram então definidas as seguintes classes de cobertura do solo:

-Água: consiste basicamente no reservatório propriamente dito da represa e em alguns cursos d'água no trecho terrestre, cursos estes que são exemplificados pela imagem GEOEYE na Figura 4.6 (a). A Figura 4.5 (a) ilustra a água do reservatório e no canto superior direito está a barragem da usina, enquanto as Figuras 4.5 (b) e (c) ilustram a represa e um curso d'água em nível de campo. 


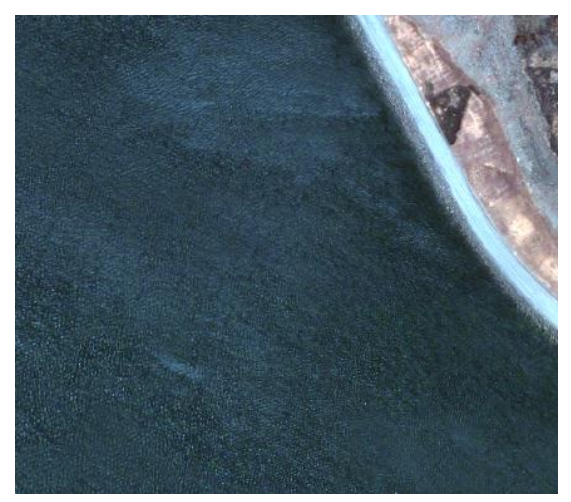

(a)

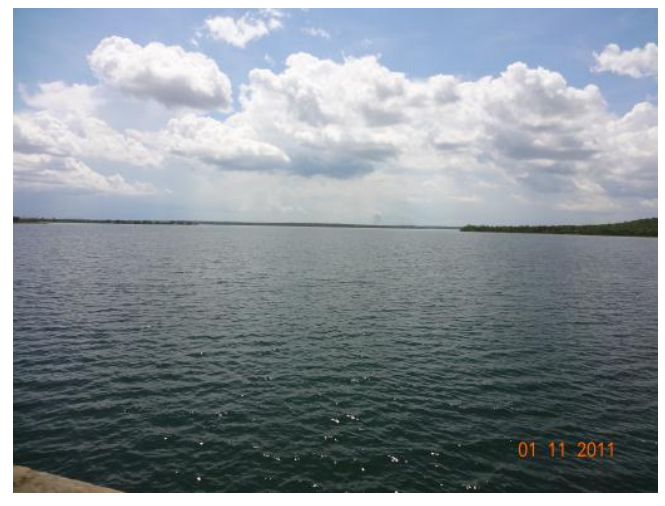

(b)

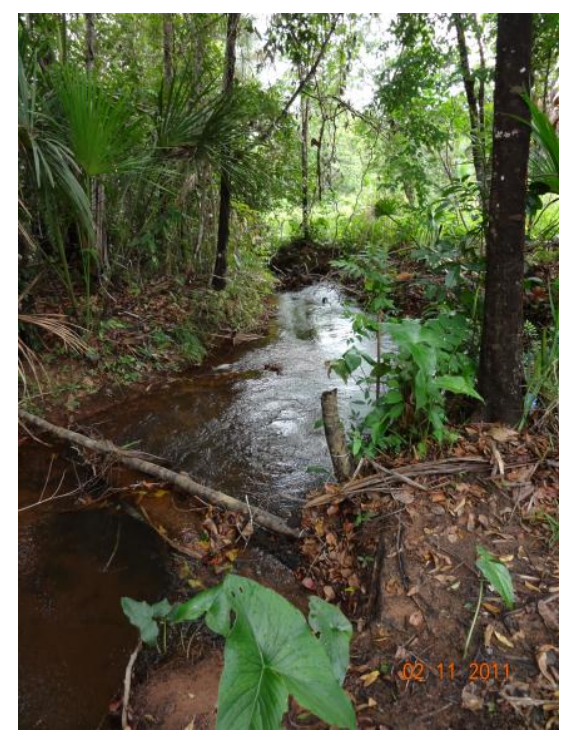

(c)

Figura 4.5 - Exemplo da classe Água na imagem (a), ilustrada em nível de campo pelo reservatório da hidrelétrica (b) e por um curso d'água (c). 
- Florestal e Campestre: a vegetação consiste em áreas não alteradas pelo homem, exemplificada pela Figura 4.6. Nesta Figura encontram-se os diferentes tipos de vegetação presentes na área de estudo, que variam quanto ao seu estrato. A classe Florestal consiste em árvores propriamente ditas e a classe Campestre em vegetação rasteira (gramíneas), típica de campos. Estas duas classes são exemplificadas na Figura 4.6 pela imagem GEOEYE (a) (também há nesta Figura um exemplo da classe Água representado por corpo hídrico) e em nível de campo a classe Florestal (b) e Campestre (c).

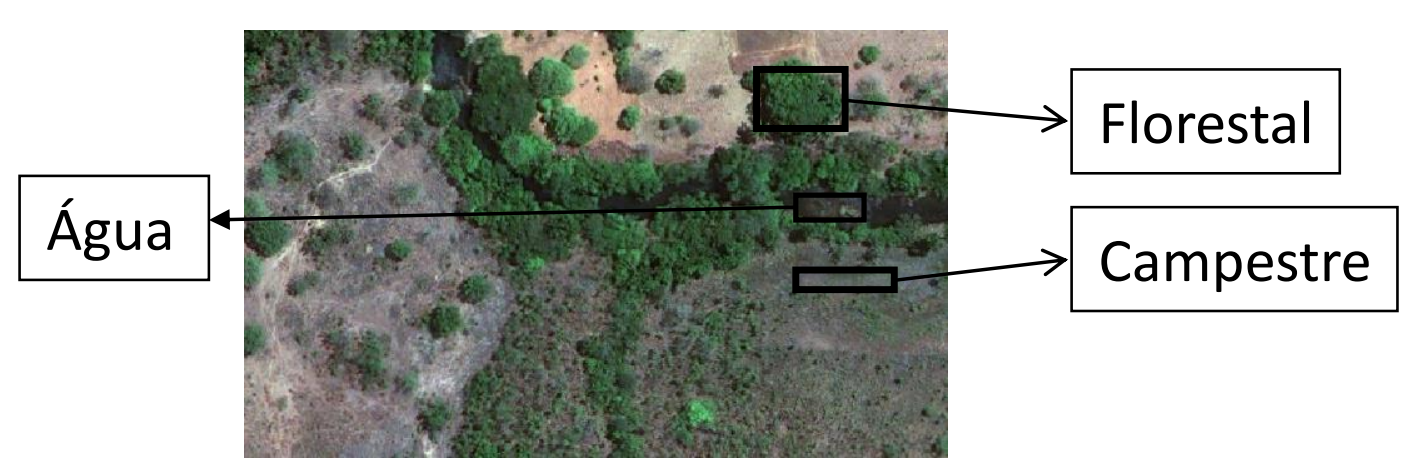

(a)

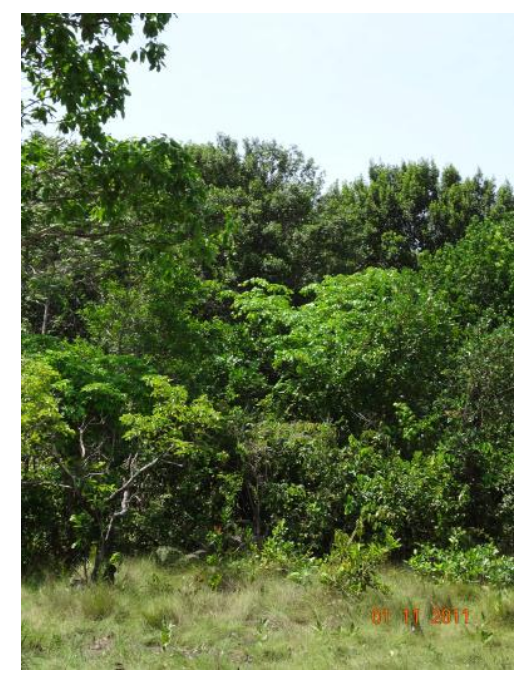

(b) 


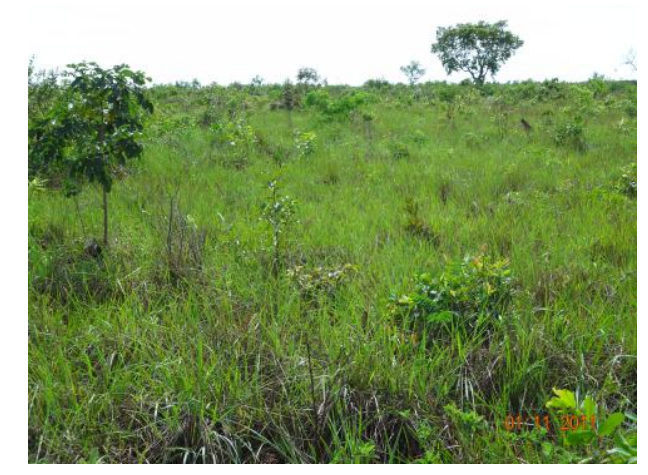

(c)

Figura 4.6 - Exemplo das classes Florestal e Campestre na imagem (a), que mostradas em campo são vegetação arbórea (b) e rasteira (c), respectivamente. A classe Água também é exemplificada por um curso d'água (a).

- Edificações: consiste em construções existentes na área urbana. Neste caso, a descrição de CORINE define Edificações como uma área impermeável não densa, ausente de prédios e não pertencente a aglomerados urbanos. A Figura 4.7 mostra a classe Edificações na imagem GEOEYE (a) e em campo (b), que é representada basicamente por casas.

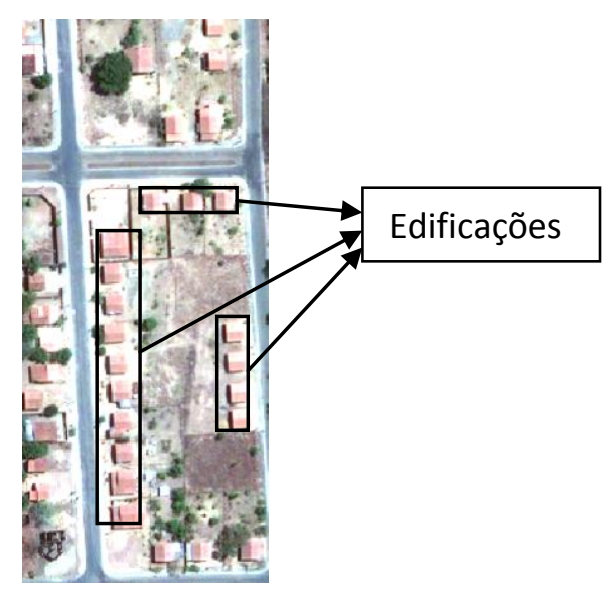

(a) 


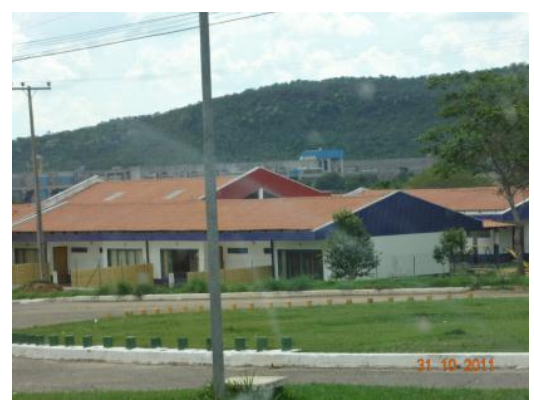

(b)

Figura 4.7 - Exemplo da classe Edificações na imagem (a) e em campo (b), consistindo basicamente em casas não situadas em aglomerados urbanos.

- Rochas: Locais em que diversas rochas encontram-se expostas por fatores naturais, constituindo um elemento geológico sem interferências do Homem na região. Esta classe é mostrada pela Figura 4.8 na imagem de satélite (a) e em campo (b).

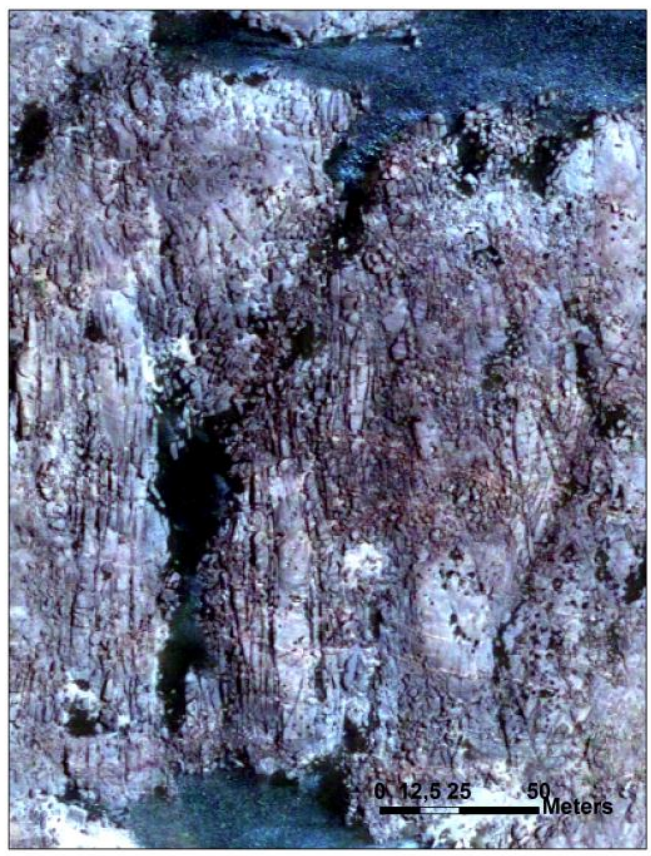

(a) 


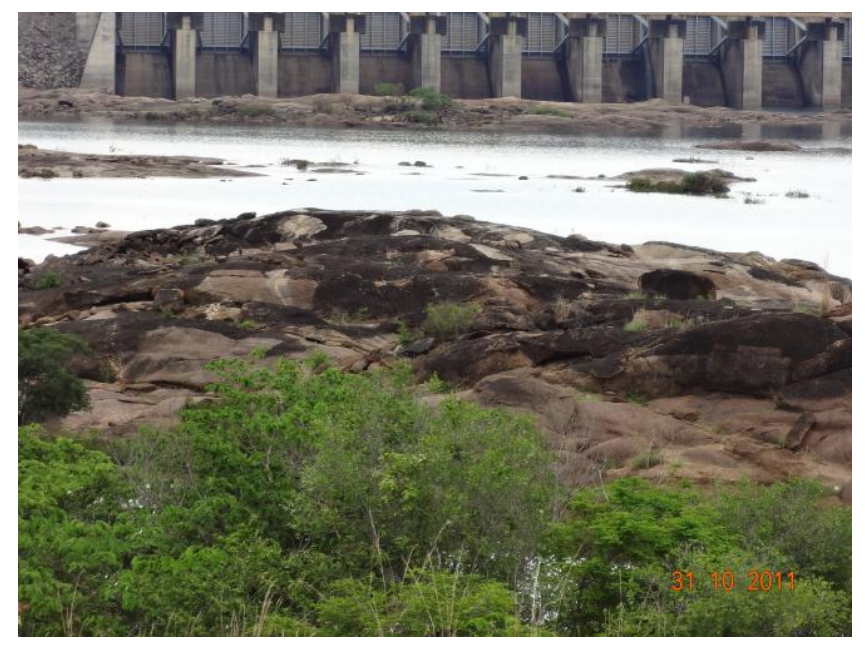

(b)

Figura 4.8 - Exemplo da classe Rochas na imagem (a) e em campo (b).

- Solo Exposto: consiste em vias de transporte não pavimentadas e em locais em que houve alteração do ambiente natural e a vegetação foi retirada. Esta classe é devidamente exemplificada pela Figura 4.9 na imagem GEOEYE da área de estudo (a) e em nível de campo como retirada de vegetação (b) e estradas não pavimentadas (c). A classe Solo Exposto pode indicar a presença de futuros empreendimentos a serem instalados sobre os locais (BOSSARD et al., 2000), como novas propriedades ou vias de transporte a serem possivelmente pavimentadas. Tanto pela imagem GEOEYE quanto pelas atividades em campo verificou-se que a classe Solo Exposto não é relacionada ao período entre safra de áreas agrícolas.

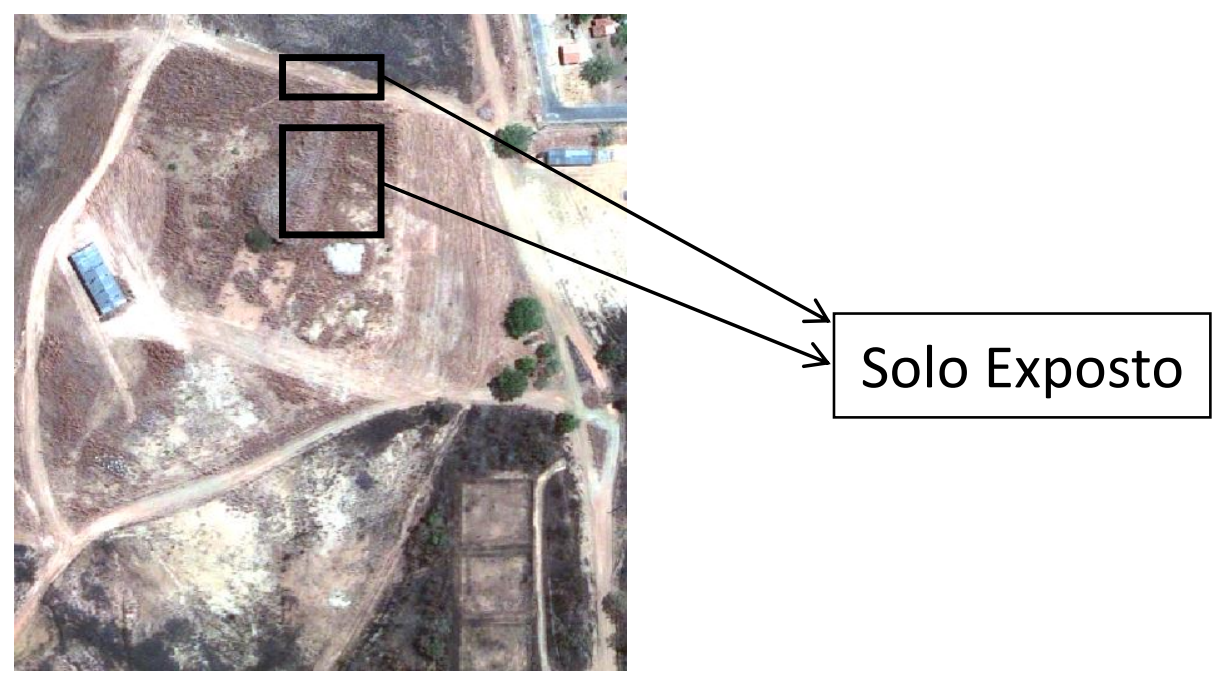

(a) 


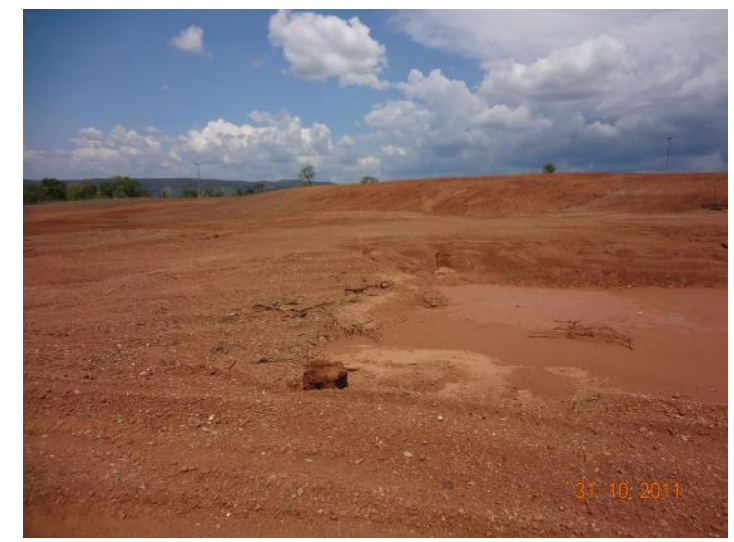

(b)

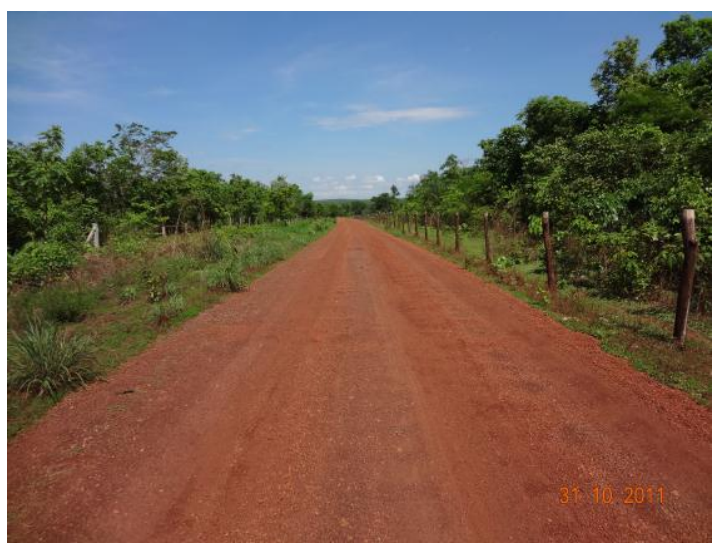

(c)

Figura 4.9 - Exemplo da classe Solo Exposto na imagem GEOEYE (a) e em nível de campo como área desprovida de vegetação (b) e rodovia não-pavimentada (c), consistindo em áreas antrópicas não cobertas por vegetação.

- Queimadas: Exemplificadas pela Figura 4.10, a represa de Lajeado apresenta áreas sem vegetação retratando locais que sofreram incêndios. Nestas áreas, a origem da queimada ocorreu pelos habitantes locais, a fim de exercer alguma forma de uso futuro do solo. Constatou-se que os moradores do entorno da represa são extremamente humildes, sendo que a falta de informação e de recursos os levam queimar determinados locais para permitir que dali seja retirado o seu sustento ou parte dele. 


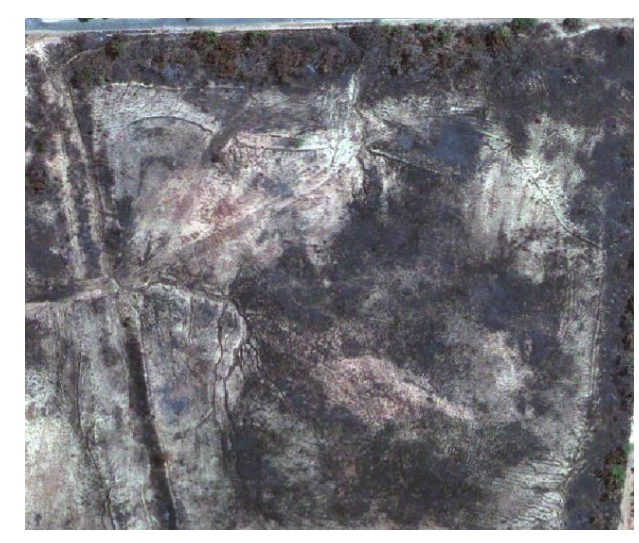

(a)

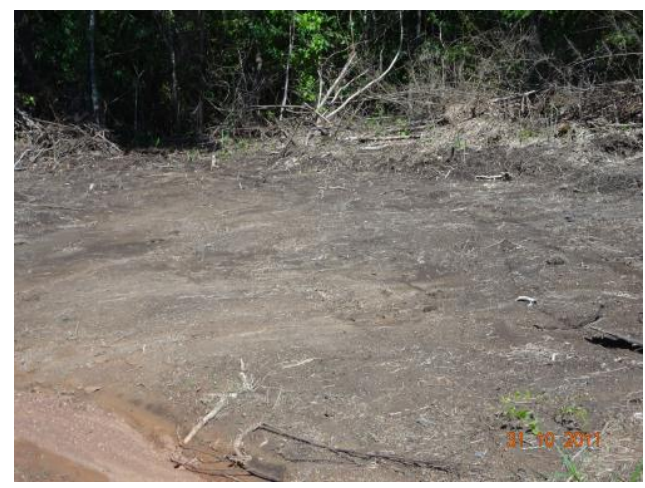

(b)

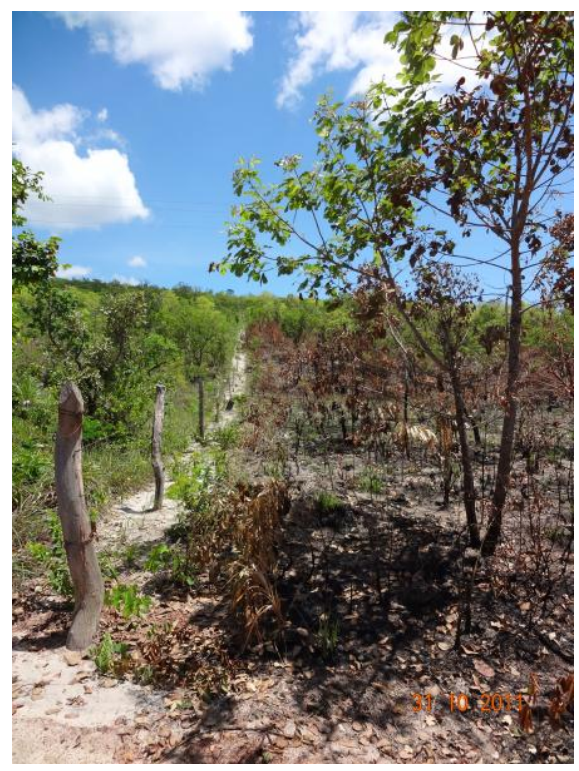

(c)

Figura 4.10 - Exemplo da classe Queimadas na imagem (a) e em campo (b); (c), representando locais desprovidos de vegetação mas com coloração mais escura devido à ocorrência de queimadas. 
- Concreto: áreas urbanas que apresentam alguma forma de pavimento em sua cobertura. As rodovias pavimentadas cuja ocorrência na imagem GEOEYE é mostrada na Figura 4.9 (b) e em nível de campo na Figura 4.9 (c) consistem em um bom exemplo da presença da classe Concreto na área de estudo.

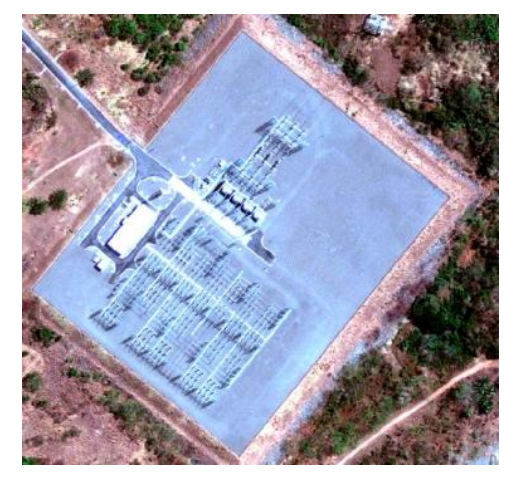

(a)

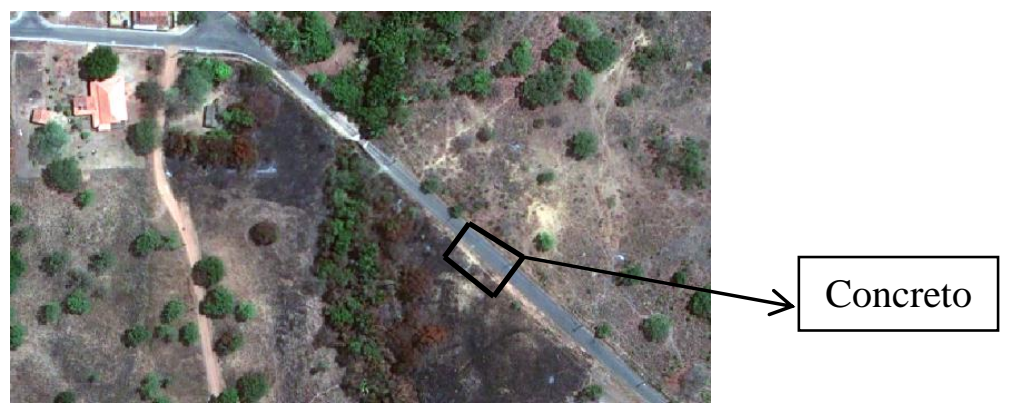

(b)

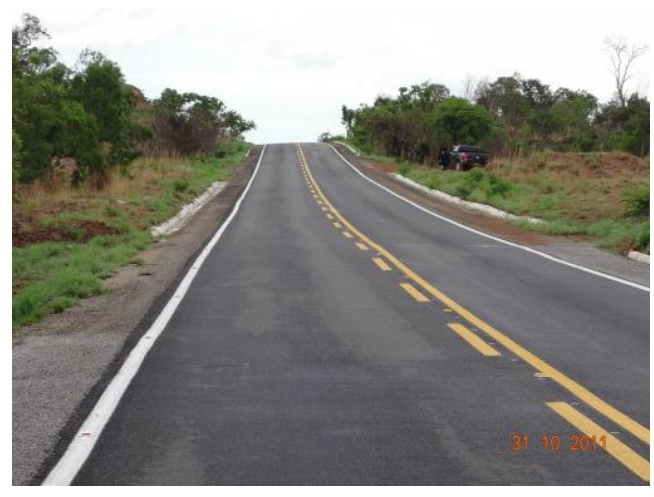

(c)

Figura 4.11 - Exemplos da classe Concreto na área de estudo, que englobam este material sobre a construções (a) e rodovias (b), sendo mostrada sua ocorrência em campo (c). 


\subsubsection{Processamento das imagens}

Para treinamento do método de classificação SVM, realizou-se para cada classe o processo de amostragem no software Envi 4.8. Como a imagem adquirida possui tamanho considerável em termos de memória, cerca de $3 \mathrm{~GB}$, o processamento da mesma necessitou de divisão da imagem em partes iguais através do comando Dice Image do software Erdas 2011. As partes foram então devidamente classificadas e mosaicadas no Envi 4.8, constituindo assim o mapa temático da área de estudo.

O único pré-processamento realizado foi o georreferenciamento com base em um mosaico já feito pela fornecedora da imagem. Já no processo de classificação do algoritmo SVM, utilizou-se a função Kernel RBF (eq. (10)), cujos parâmetros a serem calibrados são o $C$ e $\circ Y$. Os testes foram realizados por meio de combinações do parâmetro de penalização $C$, nos valores de $2^{-5} ; 2^{1} ; 2^{5} ; 100 ; 2^{10}$; e $2^{15}$; e com o parâmetro $Y$ da função nos valores de $2^{-10} ; 2^{-5} ; 2^{-2} ; 2^{0} ;$ e $2^{3}$.

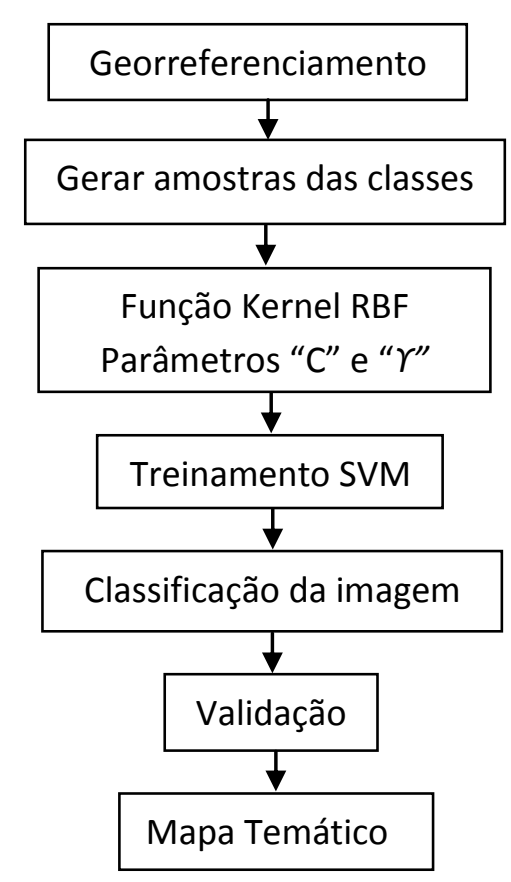

Figura 4.3 - Fluxograma do processo de classificação utilizando algoritmo SVM. 
A validação da classificação obtida neste experimento foi feita por meio da construção de uma matriz de confusão utilizando-se amostras diferentes das que foram utilizadas para o treinamento do algoritmo. Essas amostras independentes servem como dados de referência para uma determinada classe, sendo que sua incorreta classificação implica em um erro que é contabilizado na matriz de confusão. Esta matriz realiza a quantificação dos erros e acertos gerados pelo processamento da imagem.

A acurácia da classificação foi também avaliada por interpretação visual, ou análise qualitativa. Esta avaliação identificou erros na classificação não explicitados pela matriz de confusão, sendo que estes erros foram devidamente verificados por atividade de campo.

\subsubsection{Fluxograma do trabalho}

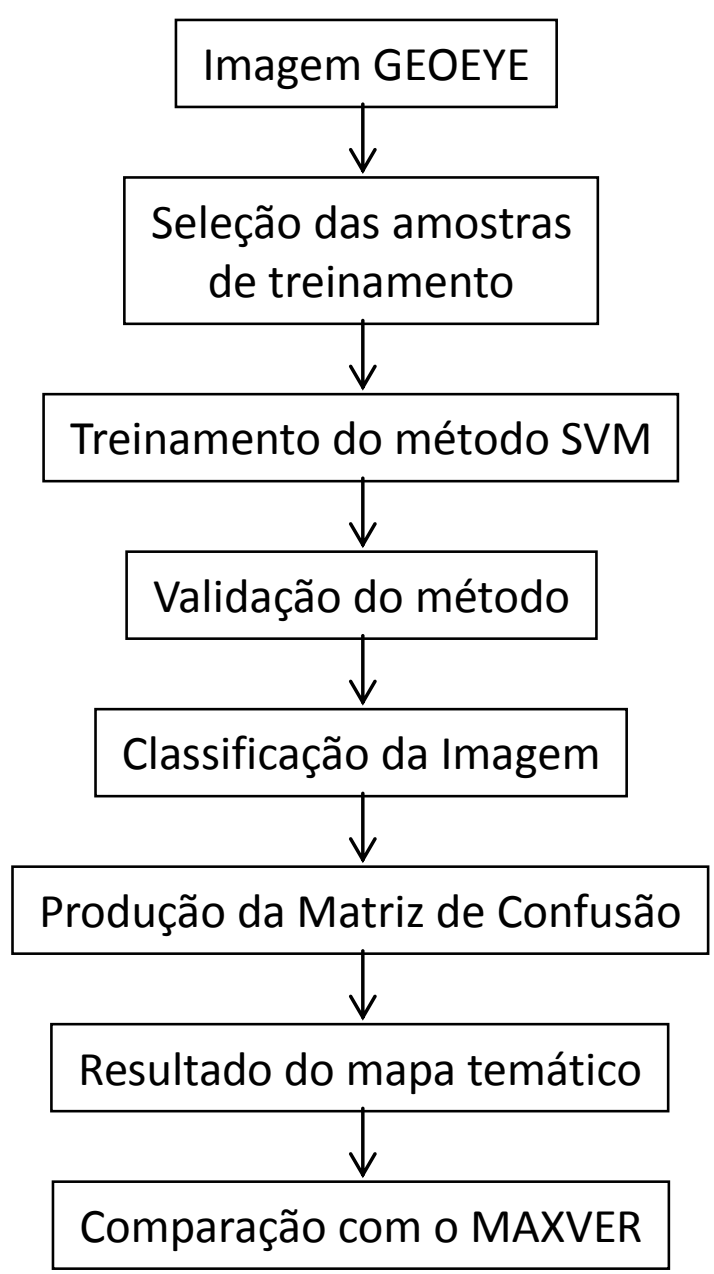

Figura 4.4 - Metodologia geral do trabalho. 
Acerca de cada item do fluxograma:

- Imagem GEOEYE: material de estudo a qual será aplicado o processo de classificação;

- Seleção de amostras de treinamento: processo de amostragem, que consiste na interação entre o analista e o classificador SVM;

- Treinamento do SVM: processo a qual o algoritmo, a partir das amostras, realiza o treinamento e gera um modelo;

- Validação do método: avalia a acurácia dos modelos obtidos pela Validação Cruzada a partir dos valores de exatidão global e índice de Kappa;

- Classificação da imagem: é obtida a imagem classificada que apresentar os índices de avaliação mais favoráveis ao processo de classificação;

- Produção da Matriz de Confusão: este avaliador de acurácia da imagem classificada é mostrado, sendo possível evidenciar em números os erros existentes no modelo obtido;

- Resultado do mapa temático: o mapa de cobertura do solo é confeccionado e mostrado, bem como as áreas que abrangem cada classe;

- Comparação com o MAXVER: são comparados os resultados obtidos pelos classificadores MAXVER e SVM, onde são avaliadas suas respectivas acurácias e os erros quantitativos e qualitativos presentes nos seus mapas temáticos; 


\section{RESULTADOS E DISCUSSÃO}

\subsection{SIMILARIDADE ENTRE CLASSES}

O índice de Jeffries-Matusita indicou que os seguintes pares de classes de cobertura do solo apresentam similaridade espectral: Campestre com Queimadas; Solo Exposto com Edificações; e Campestre com Solo Exposto.

Estas similaridades indicadas pelo índice alertaram que uma provável ocorrência de confusão entre tais pares de classes pode ocorrer no processo de classificação. A Classe Campestre, como a própria hierarquia de classes adotada neste trabalho evidencia, pertence a áreas naturais, sendo, portanto, a única que, segundo o índice, podia gerar erros significativos no mapa temático final da área, pois seria confundida com alvos que indicam antropização do local representados pelas classes Solo Exposto e Queimadas.

Logo, apesar de o índice de Jeffries-Matusita sugerir a unificação destes pares de classes, optou-se por mantê-las distintas entre si, pois apresentam diferentes níveis de informação acerca da cobertura do solo, tornando importante o seu monitoramento.

\subsection{CALIBRAÇÃO DE PARÂMETROS DO CLASSIFICADOR SVM E SEUS RESULTADOS}

O método da validação cruzada mostrou que o algoritmo SVM ficou calibrado quando os coeficientes $C$ e $Y$ foram iguais a 100 e $2^{-5}$, respectivamente. Com estes valores aplicados na classificação do algoritmo SVM, o resultado do mapa temático obtido da área de estudo encontra-se na Figura 5.1. O mapa apresenta alguns erros presentes na classificação, como indicar a presença de corpos hídricos (coloração azul) em regiões que apresentam sombreamento, apontar Rochas em locais que possuem Concreto e indicar Edificações (casas) em locais que apresentam a classe Solo Exposto. Maiores detalhes sobre os erros estão escritos na seção 5.3. 


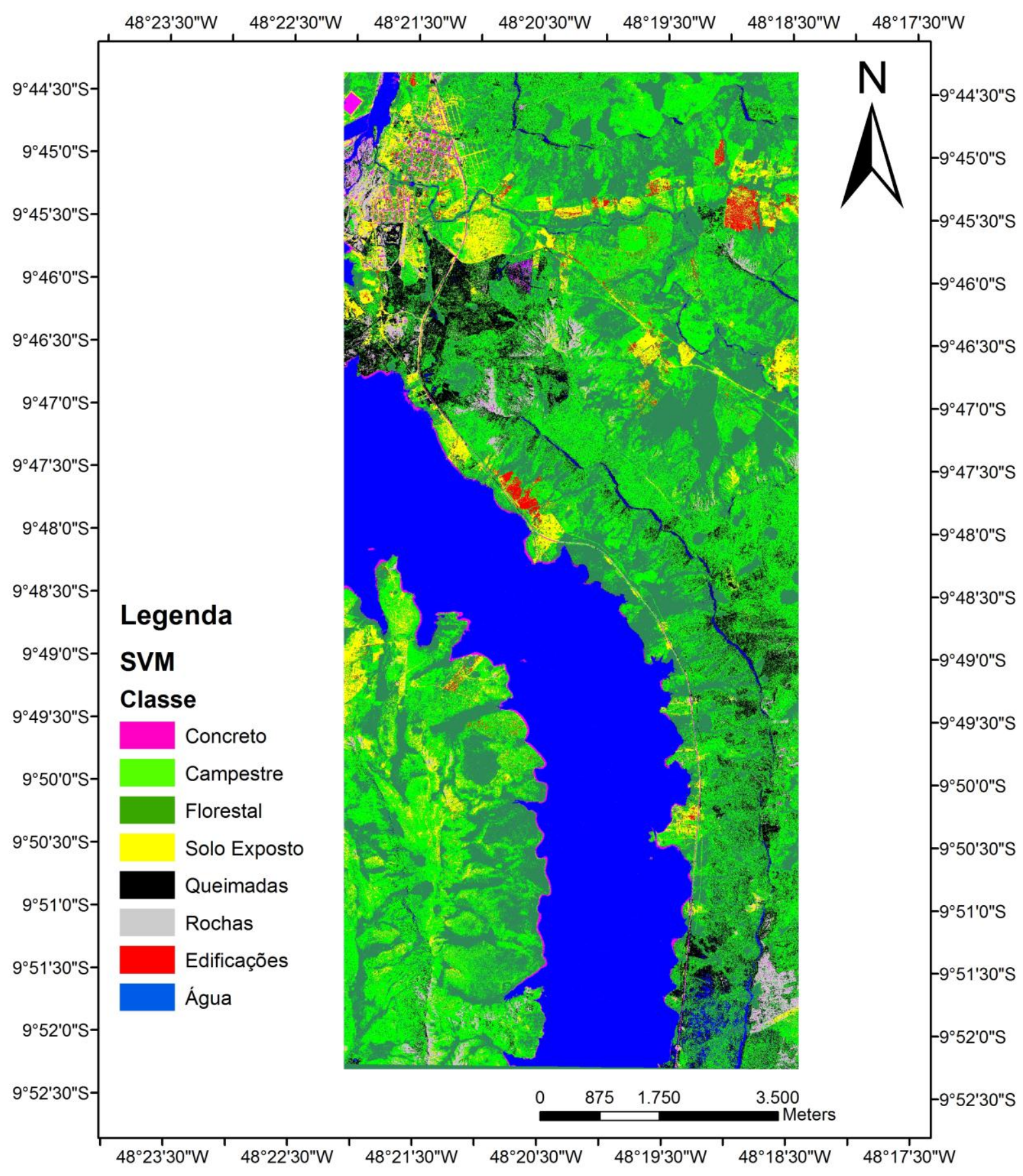

Figura 5.1 - Resultado da classificação SVM para a área de estudo.

Os dados acerca de cada classe encontram-se na Tabela 3. Evidenciou-se o domínio das classes que compreendem áreas naturais no local, especificamente o 
domínio de vegetação (classes Florestal e Campestre) e Água, que compreendem aproximadamente $82 \%$ do local estudado. Este dado sugere, a princípio, que a área de estudo encontra-se em situação ambientalmente favorável, pois consiste nas proximidades da cidade de Lajeado. $O$ fato de algumas áreas antropizadas localizarem-se nas margens da represa, entretanto, não é uma situação favorável à preservação da mesma.

Segundo o mapa temático obtido, uma classe que talvez mereça atenção por parte dos gestores é a Queimadas, que está associada à incêndios. A classe apresentou uma extensão de aproximadamente 783 ha, sugerindo que a área de estudo pode estar sendo foco de novos desmatamentos por parte da população local. Entretanto, este dado deve ser cuidadosamente avaliado, pois a classe Queimadas apresentou alguma confusão com a sombra de árvores e, conforme o índice de Jeffries-Matusita já indicou, pode também apresentar alguma confusão também com a classe Campestre, que compreende uma área natural. Caso as queimadas sejam diagnosticadas, os gestores deverão providenciar medidas que contenham esta prática, como mostrar à população local alguns métodos sustentáveis de uso da terra para sua subsistência.

Tabela 1 - Dimensão das classes de cobertura do solo para o algoritmo SVM.

\begin{tabular}{ccc}
\hline Classe & Pixels & Área (ha) \\
\hline Agua & $23,54 \%$ & 2306,45 \\
Florestal & $25,94 \%$ & 2541,48 \\
Campestre & $32,49 \%$ & 3183,39 \\
Rochas & $2,57 \%$ & 252,18 \\
Concreto & $0,86 \%$ & 84,24 \\
Solo Exposto & $5,49 \%$ & 538,03 \\
Queimadas & $7,99 \%$ & 783,65 \\
Edificações & $1,12 \%$ & 109,84 \\
\hline
\end{tabular}

A soma das áreas das classes que abrangem a antropização do local equivale a $15,47 \%$ da área, sugerindo, conforme já mencionado, boa preservação ambiental. Entretanto, este cenário deve ser mantido e controlado, pois a presença da represa estimula a geração de empregos, de lazer e de turismo, que são 
possíveis ameaças para a qualidade tanto da represa quanto do meio ambiente, estimulando assim novas instalações.

Em uma avaliação qualitativa da classificação notou-se que a classe Edificações ficou superestimada. Apesar disso, grande parte dos seus erros de comissão, segundo observação qualitativa do resultado, gerou erros de omissão para a classe Solo Exposto, o que acabou não distorcendo as informações sobre a extensão das áreas antropizadas.

Outra constatação qualitativa foi que, pela Figura 5.1, parece existir um corpo hídrico no mesmo sentido da represa e a leste da mesma. Constatou-se assim um erro na classificação, pois avaliando-se a imagem GEOEYE notou-se que este trecho classificado como Água é na verdade um sombreamento decorrente da topografia local.

Todavia, em relação à conservação da represa, ainda não é possível obter um diagnóstico final, pois apenas uma cena foi usada nesta Dissertação, não sendo abrangida toda a área da represa de Lajeado. O diagnóstico deve ser concluído quando o local por inteiro for processado, não se restringindo apenas à área imageada por apenas uma cena do satélite GEOEYE, que não cobre toda a extensão da represa.

O percentual total das classes antrópicas deve sofrer diminuição proporcional em relação à represa quando esta for avaliada como um todo, pois a área de estudo desta Dissertação (uma única cena do satélite GEOEYE) incluiu a cidade de Lajeado. Entretanto, a cena já classificada deve mesmo no futuro continuar apresentando a maior parte dos trechos urbanos, pois o avanço de suas áreas costuma ocorrer nas proximidades da cidade.

\subsection{ACURÁCIA DA CLASSIFICAÇÃO OBTIDA}

Verificando-se a qualidade da classificação gerada pela validação do algoritmo SVM, a Matriz de Confusão mostrada na Tabela 4 mostrou uma alta acurácia do processo: a Exatidão Global foi equivalente a 86,1114\% e o índice de Kappa igual a 0,8390. 
Tabela 2 - Matriz de Confusão por pixels (a) e em porcentagem (b) para a classificação obtida com o algoritmo SVM.

\begin{tabular}{|c|c|c|c|c|c|c|c|c|c|c|}
\hline Classe & Agua & Floresta & Campestre & Rochas & Edificações & Solo_exposto Queimadas & Concreto & Total \\
\hline Agua & 5186 & 0 & 0 & 0 & 9 & 0 & 132 & 3 & 5330 \\
\hline Floresta & 0 & 4455 & 0 & 0 & 0 & 0 & 0 & 0 & 4455 \\
\hline Campestre & 9 & 0 & 2319 & 142 & 84 & 1 & 533 & 0 & 3088 \\
\hline Rochas & 0 & 0 & 0 & 4785 & 25 & 918 & 0 & 294 & 6022 \\
\hline Edificações & 0 & 0 & 0 & 0 & 1904 & 362 & 0 & 0 & 2266 \\
\hline Solo_exposto & 0 & 0 & 0 & 0 & 249 & 6165 & 0 & 0 & 6414 \\
\hline Queimadas & 44 & 0 & 648 & 585 & 0 & 5 & 4301 & 0 & 5583 \\
\hline Concreto & 798 & 0 & 0 & 818 & 29 & 3 & 0 & 6170 & 7818 \\
\hline Total & 6037 & 4455 & 2967 & 6330 & 2300 & 7454 & 4966 & 6467 & 40976 \\
\hline
\end{tabular}

(a)

\begin{tabular}{|c|c|c|c|c|c|c|c|c|c|c|}
\hline Classe & Agua & Floresta & Campestre & Rochas & Edificações & Solo_exposto & Queimadas & Concreto & Total \\
\hline Agua & 85.90 & 0.00 & 0.00 & 0.00 & 0.39 & 0.00 & 2.66 & 0.05 & 13.01 \\
\hline Floresta & 0.00 & 100.00 & 0.00 & 0.00 & 0.00 & 0.00 & 0.00 & 0.00 & 10.87 \\
\hline Campestre & 0.15 & 0.00 & 78.16 & 2.24 & 3.65 & 0.01 & 10.73 & 0.00 & 7.54 \\
\hline Rochas & 0.00 & 0.00 & 0.00 & 75.59 & 1.09 & 12.32 & 0.00 & 4.55 & 14.70 \\
\hline Edificações & 0.00 & 0.00 & 0.00 & 0.00 & 82.78 & 4.86 & 0.00 & 0.00 & 5.53 \\
\hline Solo_exposto & 0.00 & 0.00 & 0.00 & 0.00 & 10.83 & 82.71 & 0.00 & 0.00 & 15.65 \\
\hline Queimadas & 0.73 & 0.00 & 21.84 & 9.24 & 0.00 & 0.07 & 86.61 & 0.00 & 13.63 \\
\hline Concreto & 13.22 & 0.00 & 0.00 & 12.92 & 1.26 & 0.04 & 0.00 & 95.41 & 19.08 \\
\hline Total & 100.00 & 100.00 & 100.00 & 100.00 & 100.00 & 100.00 & 100.00 & 100.00 & 100.00 \\
\hline
\end{tabular}

(b)

A relativa alta acurácia pode ser explicada pela ausência de um mapa referência, pois uma avaliação qualitativa já é capaz de verificar que o modelo possui mais erros do que os registrados pela Matriz de Confusão.

Nesta Dissertação, algumas amostras foram coletadas de maneira aleatória estratificada simples para se testar o resultado da classificação, sendo que as mesmas não totalizam sequer $0,03 \%$ da área de estudo. Caso houvesse um mapa referência, os índices de acurácia aqui calculados certamente seriam mais baixos e estimariam melhor a propagação de erros a qual este estudo pode gerar.

Entretanto, o custo para se obter um mapa referência por inteiro é significativamente elevado, sendo que para extrair informações mais específicas sobre a área de estudo o analista pode fazer uso da interpretação visual, uma vez que a imagem trabalhada possui alta resolução espacial.

A inspeção visual pode verificar, por exemplo, se uma área classificada como Queimadas no mapa temático gerado não é na verdade a sombra de árvores 
existentes na classe Florestal. Tal inspeção pode ser feita analiticamente, ou seja, simplesmente abrindo-se a imagem de satélite e verificando-se visualmente o que aconteceu no local em que o mapa temático identificou uma presença da classe Queimadas.

Pela Matriz de Confusão, percebeu-se que as classes cuja acurácia ficou abaixo de $85 \%$ foram Campestre, Rochas, Edificações e Solo Exposto. Os erros de classificação apresentados nestas classes devem ser criticamente avaliados, pois evidenciam confusão entre áreas naturais e áreas antrópicas e vice-versa.

No caso do algoritmo confundir as classes Edificações com Solo Exposto, o gestor da represa não é tão prejudicado no processo de monitoramento, pois ambas são áreas antrópicas e a classe Edificações possui formato espacial bem definido, geralmente retangular. A Figura 5.2 mostra um exemplo de acerto (a) e um exemplo de erro (b) da classe Edificações, que foi confundido com Solo Exposto. A avaliação analítica para diagnosticar estes erros envolvendo a classe Edificações é facilmente realizada: basta notar altas concentrações uniformes e contínuas da classe Edificações (Figura 5.2 (b)) para perceber que na realidade são áreas desprovidas de vegetação, ou seja, classe Solo Exposto.

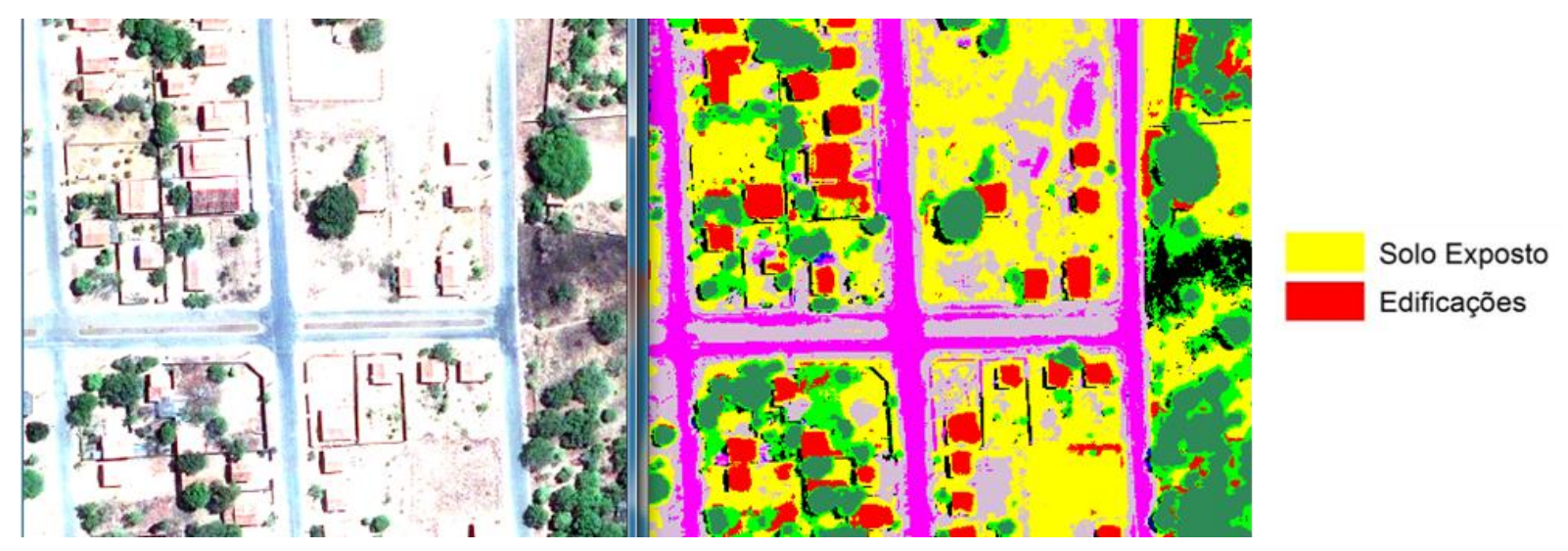

(a) 


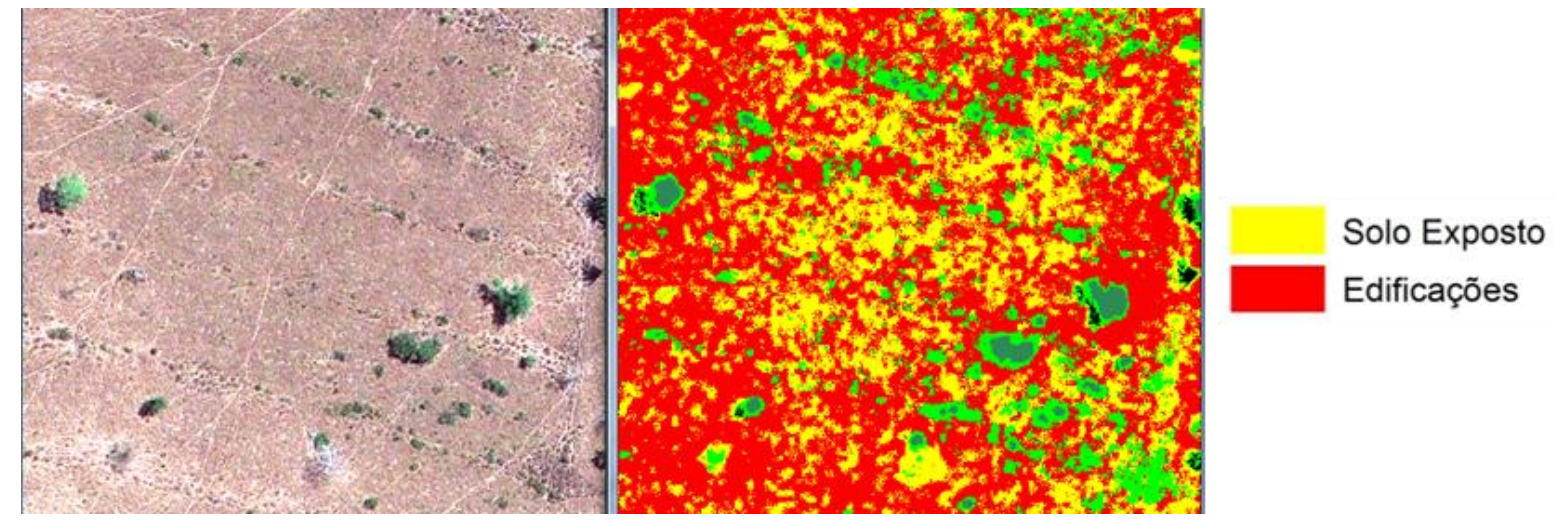

(b)

Figura 5.2 - Confusão entre as classes Edificações e Solo Exposto. Exemplo de acerto na identificação de casas (a) e de erro de comissão para Edificações e omissão para Solo Exposto (b).

No caso da confusão envolvendo a classe Rochas, que teve parte de sua área indicada como Concreto, a confusão é rapidamente notada pelo contexto espacial (Figura 5.3) da área, pois não existe concreto espalhado aleatoriamente e em pequenos blocos ao longo de rochas.

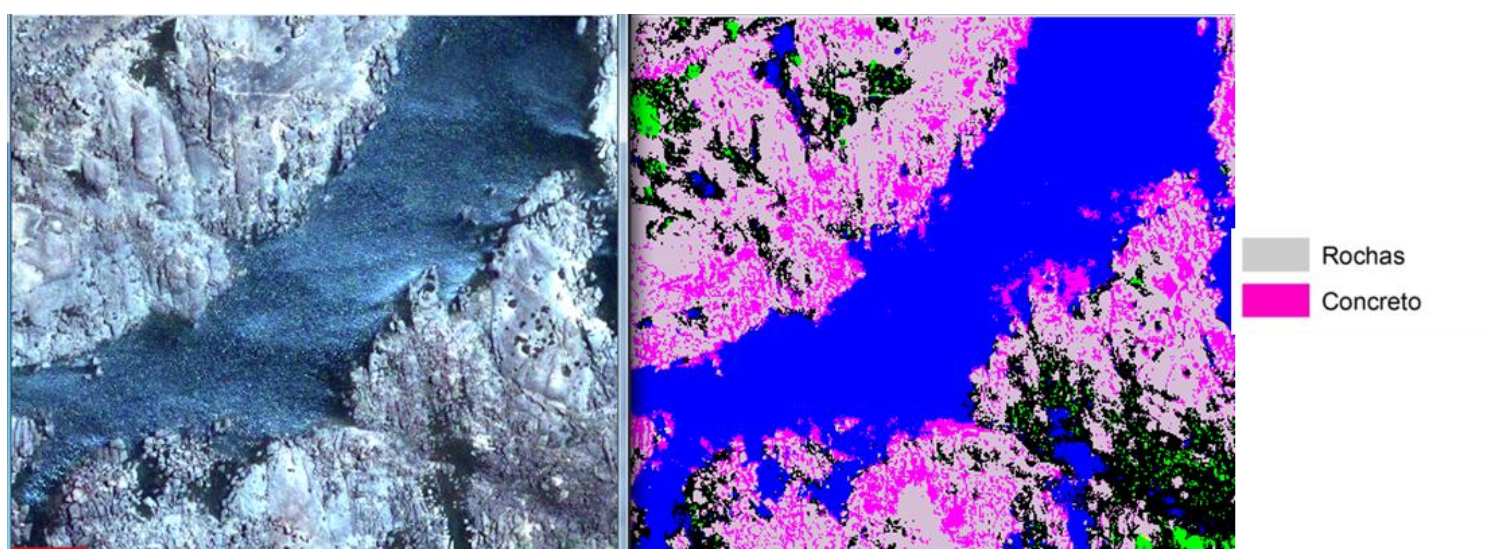

Figura 5.3 - Exemplo de erro de comissão para a classe Concreto e omissão para a classe Rochas.

A situação inversa, comissão de Rochas e omissão de Concreto, também é facilmente percebida pelo contexto espacial. As rodovias pavimentadas apresentaram certas descontinuidades. Apesar disto, tais descontinuidades são facilmente distinguíveis e não atrapalham a identificação de rodovias e pavimentos por parte do analista, como mostra a Figura 5.3. Em relação a estas duas classes, a semelhança espectral entre elas já foi notada por Stein, Van der Meer e Gorte 
(1999), que notaram a semelhança da assinatura espectral devido aos minerais presentes em afloramentos rochosos que são utilizados na fabricação de concreto.
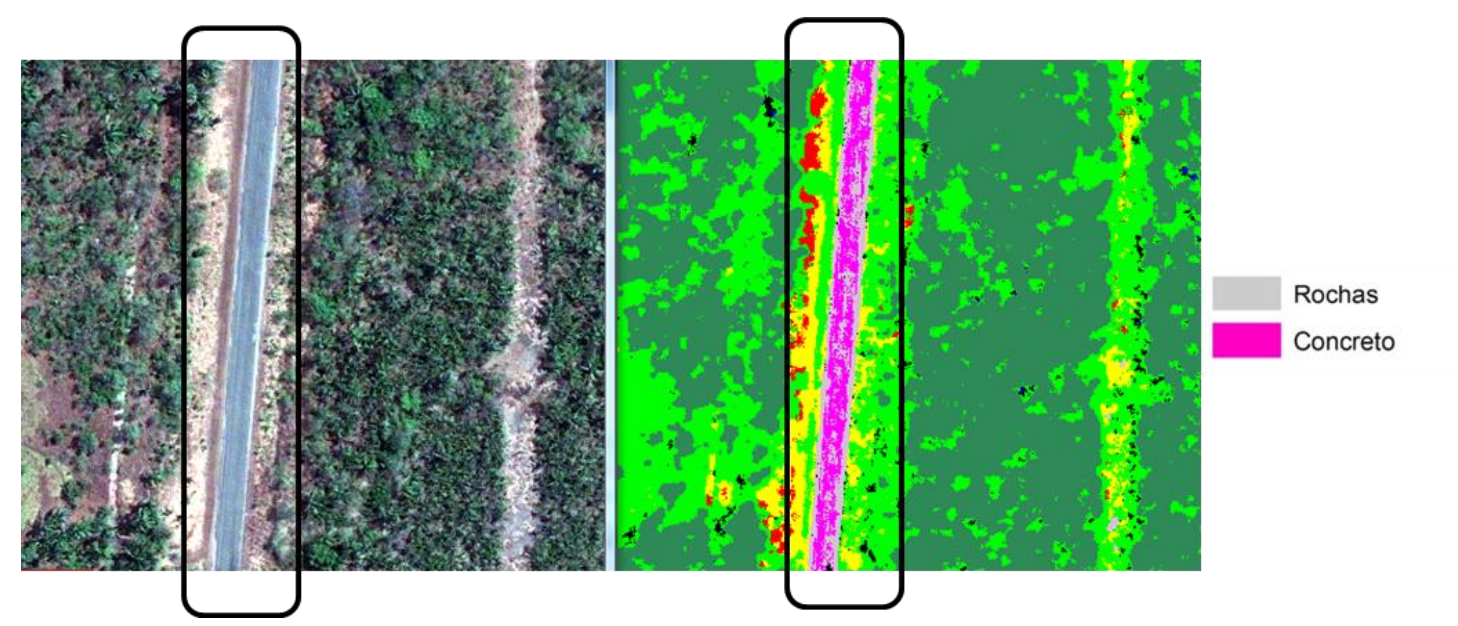

Figura 5.4 - Exemplo de confusão entre as classes Rochas (erro de comissão) e Concreto (erro de omissão), que são facilmente notáveis.

Em relação à classe Solo Exposto, indicada pela Matriz de Confusão com erros em relação à classe Rochas, os erros não foram facilmente encontrados. Foi necessário então localizar as amostras de teste, verificando-se que elas sobrepuseram pequenas áreas que facilmente são diagnosticadas como Solo Exposto devido ao contexto e extensão a qual os erros de comissão da classe Rochas se encontraram. Estes erros de comissão da classe Rochas e omissão da classe Solo Exposto são mostrados na Figura 5.5, bem como a localização de uma amostra de teste desta classe de áreas antrópicas.

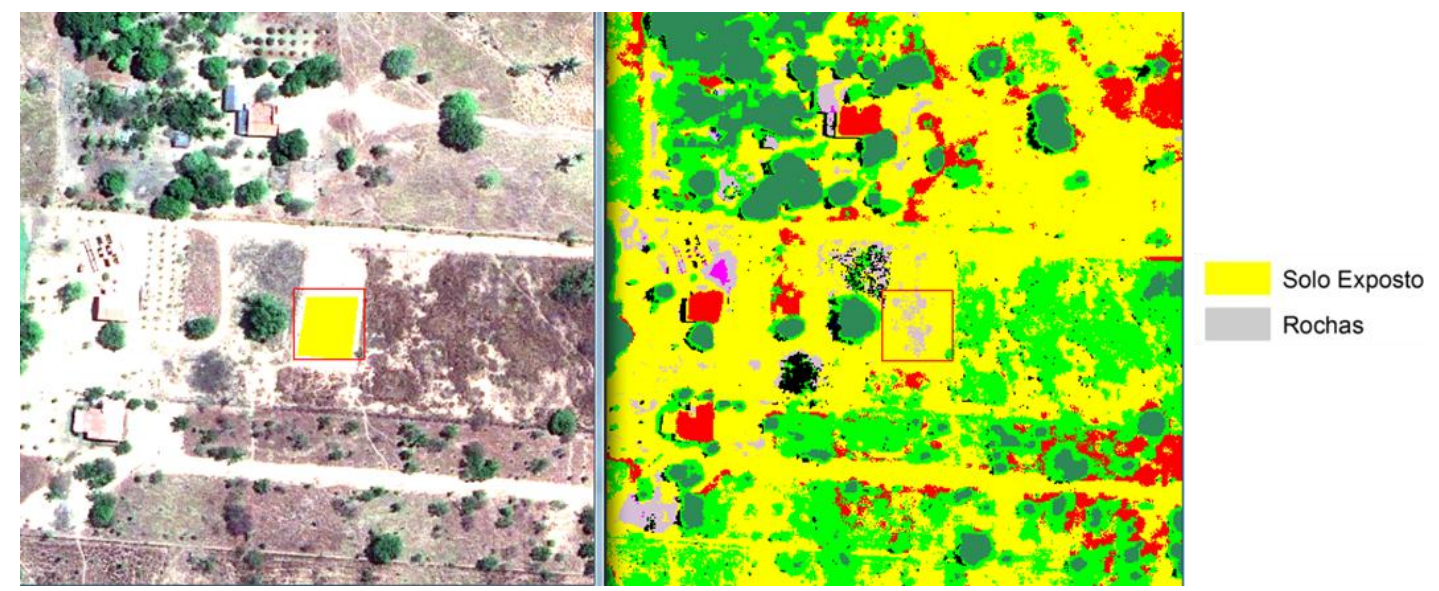

Figura 5.5 - Exemplo de amostra de teste da classe Solo Exposto que sobrepôs pequenas áreas classificadas como Rochas. 
Durante 0 ato de procurar visualmente os citados erros de comissão da classe rochas exemplificados na Figura 5.5, entretanto, notou-se visualmente um dado não constatado pela Matriz de Confusão: a classe Rochas gerou erros de omissão para a classe Queimadas, conforme mostra a Figura 5.6. Ressalta-se que o exemplo da Figura 5.6 não foi visitado em campo devido à dificuldade de acesso ao local, mas a interpretação visual e contexto da imagem permitem inferir os citados erros entre as classes Rochas e Queimadas.

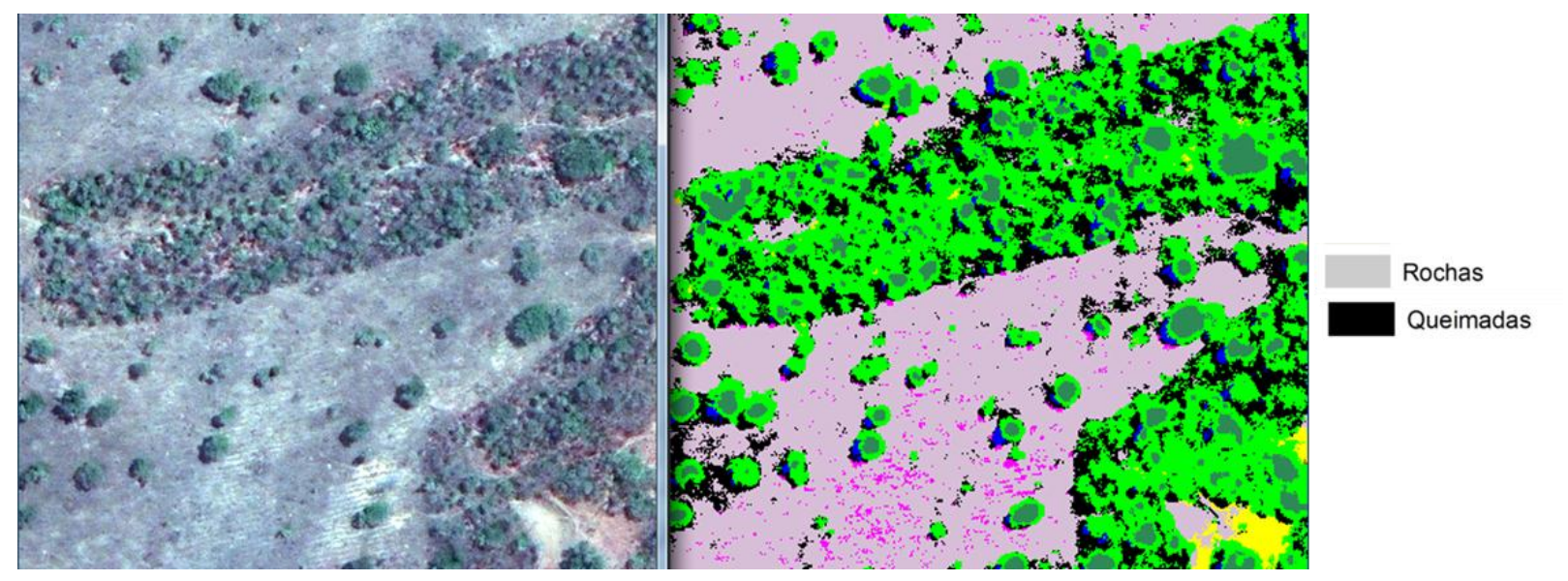

Figura 5.6 - Exemplo de confusão não detectada pela Matriz de Confusão, envolvendo as classes Rochas e Queimadas. Neste caso, as áreas classificadas como Rochas (Comissão) deveriam ter sido rotuladas como Queimadas (Omissão).

Verificou-se, portanto, que as estatísticas da classe Rochas não foram muito precisas. Conforme já discutido e mostrado na Figura 5.6, os erros de comissão desta classe geraram erros de comissão para a classe Queimadas, fazendo com que a extensão das Rochas fique superestimada segundo a classificação obtida.

A classe Campestre teve parte significativa de seus erros associados à classe Queimadas, confirmando a previsão do índice de Jeffries-Matusita. Neste caso, o gestor deve se atentar, pois a confusão ocorreu entre uma área natural e uma antrópica que não são facilmente perceptíveis analiticamente. Apesar de parte dos erros de comissão da classe Queimadas estar associado à sombra das árvores (o que é facilmente notado por inspeção visual, uma vez que a classe Florestal foi a única que apresentou acurácia excelente), todas as regiões classificadas com este rótulo de antropismo devem ser cuidadosamente verificadas para certificar sua 
ocorrência. A Figura 5.7 mostra um exemplo em que deveria predominar a classe Campestre (a) e a Figura 5.8 um exemplo em que deveria predominar a classe Queimadas.

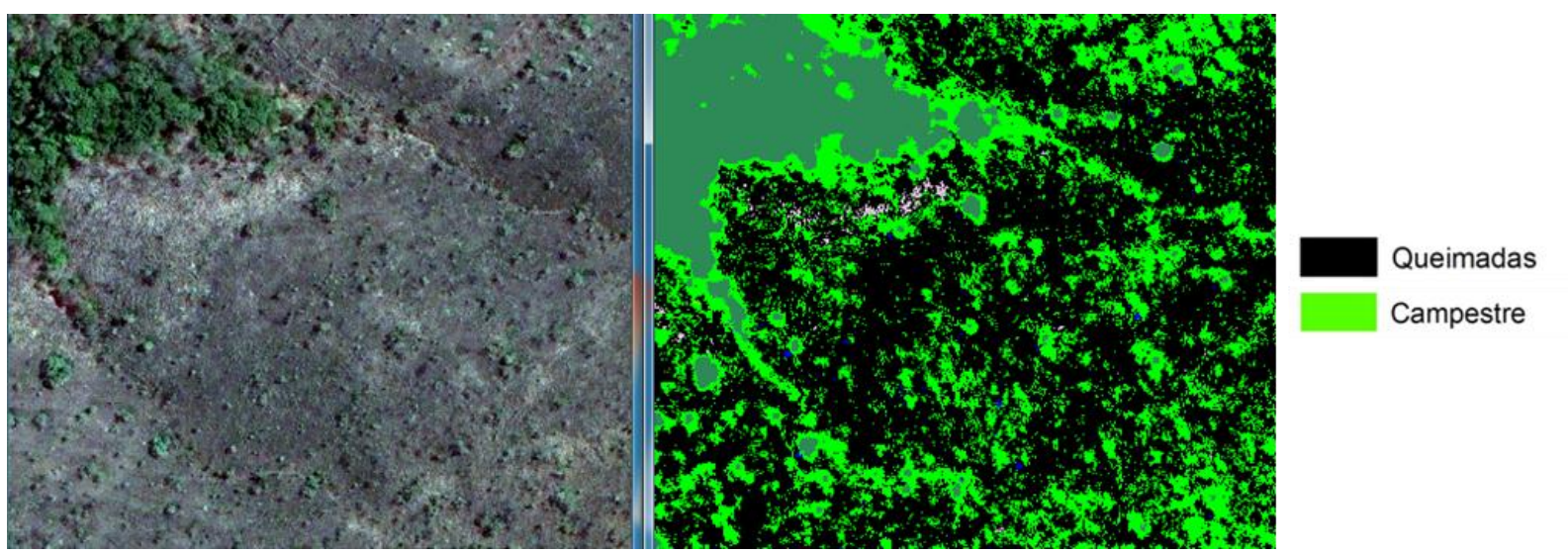

Figura 5.7 - Confusão entre as classes Queimadas e Campestre, que não são facilmente notáveis. Neste exemplo, as áreas da classe Queimadas deveriam pertencer à classe Campestre.

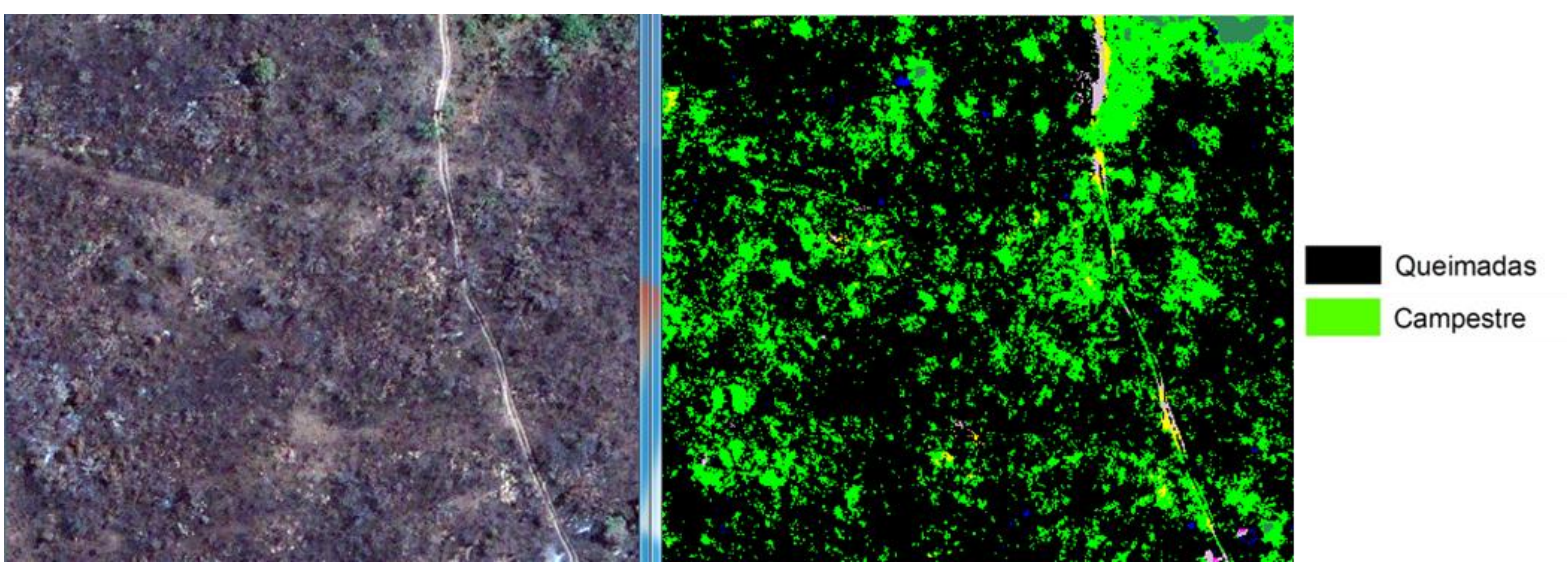

Figura 5.8 - Áreas da classe Queimadas que erroneamente foram classificadas como Campestre.

Avaliando-se qualitativamente, notou-se que as classes com uma acurácia não significativa foram Campestre, Rochas, Edificações e Queimadas. Os erros das classes Rochas e Edificações, porém, são facilmente percebidos devido ao contexto espacial a qual as mesmas foram erroneamente inseridas. Logo, apesar de não se destacar na Matriz de Confusão, considerou-se que a única classe que não fora bem mapeada pelo algoritmo SVM foi Queimadas e, com acurácia parcialmente satisfatória, Campestre. Ambas merecem alguma atenção por parte do gestor da represa, devendo o mesmo apresentar um olhar crítico para a presença das mesmas. A classe Queimadas mostrou-se menos precisa porque a classe 
Campestre geralmente acompanha a classe Florestal, única que teve acurácia considerada excelente. Já a classe Queimadas não apresenta uma contextualização específica (a população local não possui muitos critérios para promover a queimada de algumas regiões), sendo geralmente acompanhada por pequenas estradas nas áreas onde efetivamente ocorre, que só são detectadas qualitativamente pela imagem GEOEYE (vide Figura 5.8).

Atividades de campo mostraram que a classe Queimadas é originada por incêndios locais. Notou-se, portanto, que uma grande ameaça à conservação da represa reside nas atividades da comunidade local, que é extremamente humilde e carente de informações e infra-estrutura adequada para exercerem suas atividades básicas. Os moradores fazem uso da queimada como um recurso para ocupar o solo, degradando o meio ambiente. As queimadas mostraram-se intensas e sem qualquer meio eficaz de controle, sendo necessária a implementação de políticas que mostrem aos habitantes uma maneira mais racional de se fazer uso do solo. Como exemplo da presença descontrolada de incêndios na área de estudo, foi fotografada (Figura 5.9) uma queimada próxima à rodovia que liga Palmas à cidade de Lajeado.

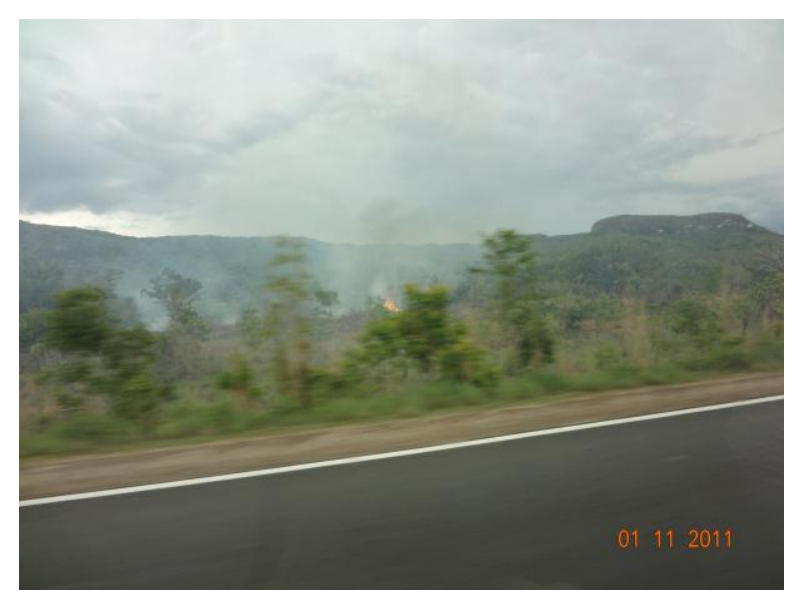

Figura 5.9 - Habitantes locais praticando a queimada em um local próximo à rodovia que liga Palmas a Lajeado.

Outra observação importante feita em campo ocorreu em um local que fora diagnosticado com incêndios pela imagem GEOEYE. Este local, ilustrado pela Figura 5.10 (a) com presença de incêndios segundo a imagem de satélite de 2010, foi visitado em 2011 e devidamente registrado pela Figura 5.10 (b). Notou-se que o 
morador do local fez uso da queimada em sua terra para que ali fossem implantados plantios devidamente protegidos por uma cerca. O uso do solo nesta área cercada não pode ser especificado, mas a cerca comprovou alguma proteção à terra conferida por aquele que retém sua posse.

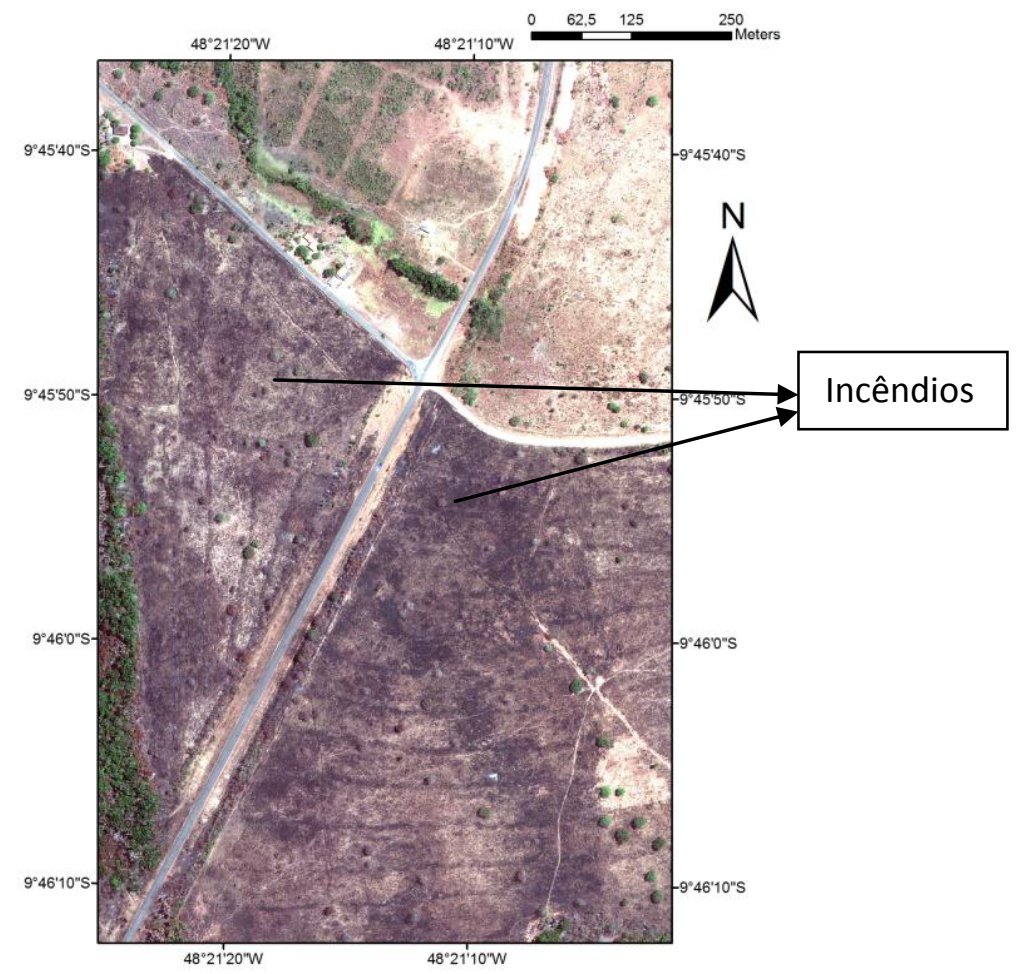

(a)

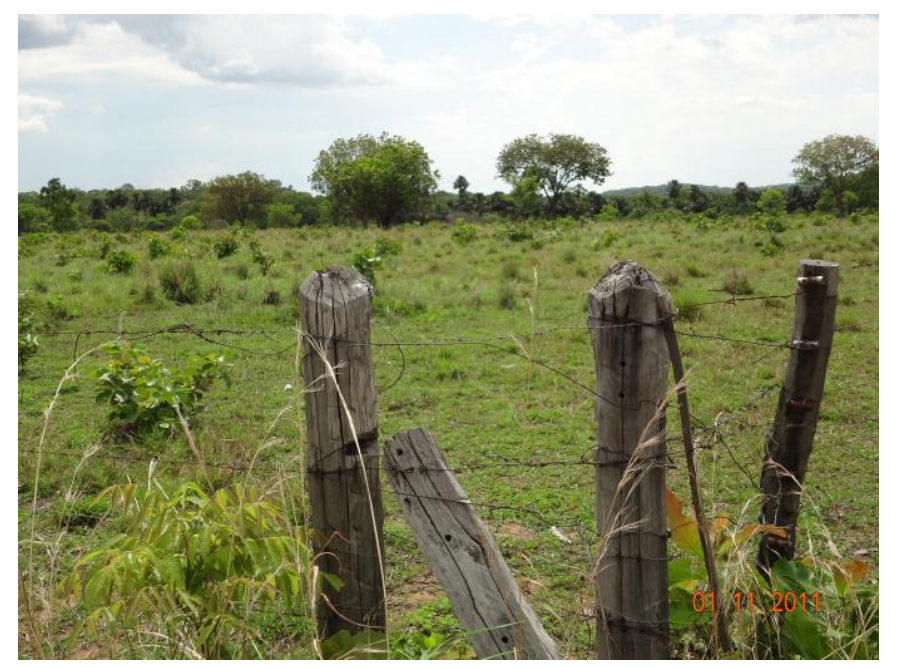

(b)

Figura 5.10 - A presença de queimadas mostradas pela imagem GEOEYE de 2010 (a) e o mesmo local como pastagem em 2011 (b). 
No processo de classificação, outros erros que, apesar de não significativos, também foram qualitativamente diagnosticados, são os relacionados ao processo de identificação das classes Água e Queimadas. A presença de água em regiões contornadas por áreas antrópicas inexiste, sendo muitas vezes desnecessário qualquer interpretação visual, conforme ilustra a Figura 5.11(a) para avaliar a presença de um corpo d'água na região. No caso de um curso d'água como o de um córrego, que na área de estudo (imagem GEOEYE) encontra-se rodeado por vegetação, é facilmente perceptível a incorreta indicação de interferência humana (Figura 5.11 (b)), pois esta interferência na superfície terrestre não existe sobre corpos d'água.
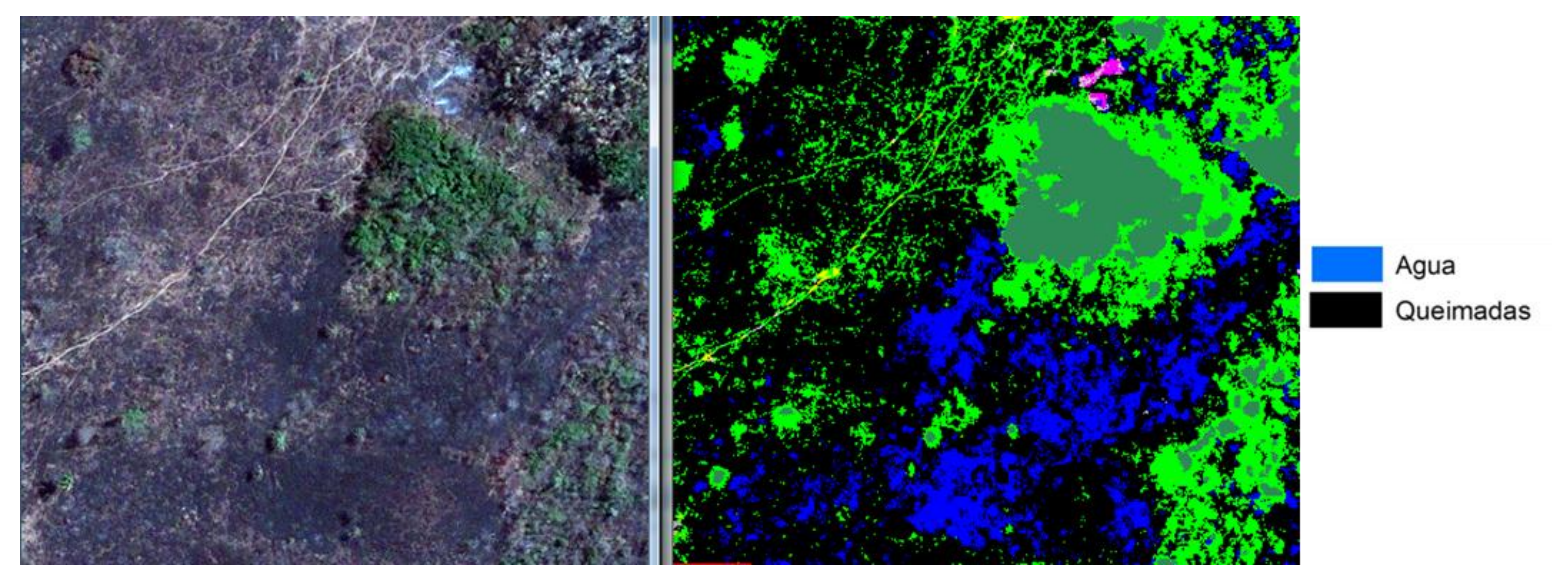

(a)
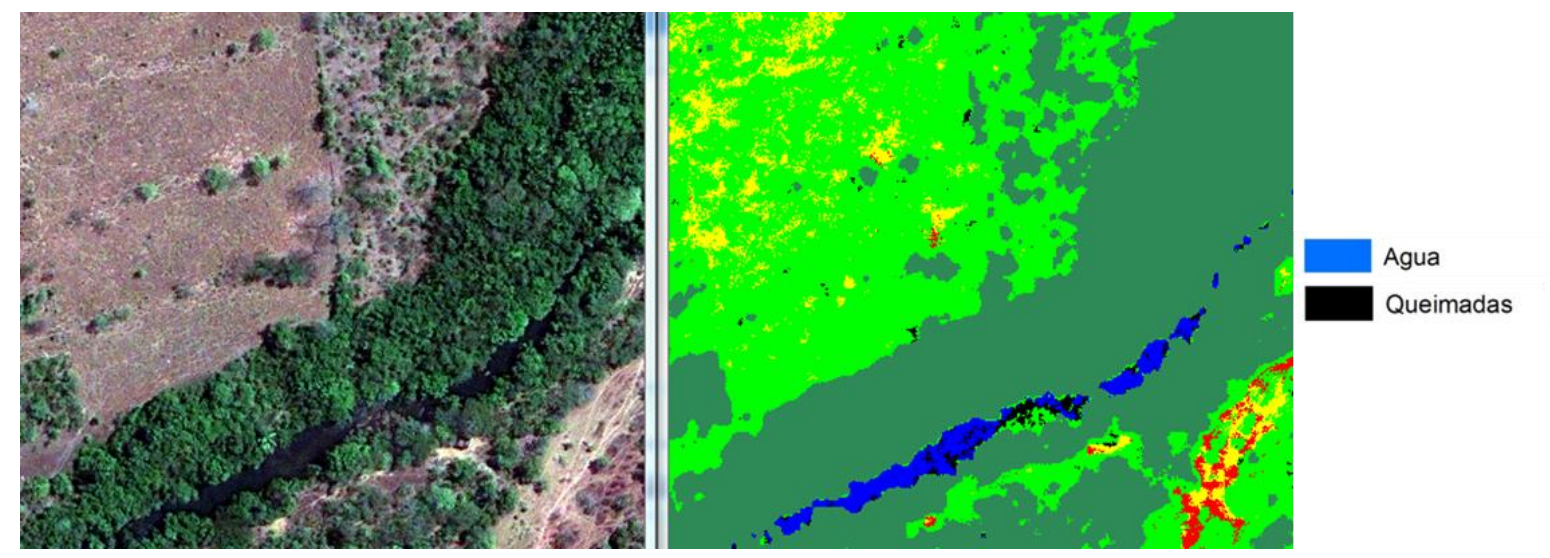

(b)

Figura 5.11 - Falsa presença de um corpo d'água próximo à regiões de Queimadas (a); Incorreta indicação de antropismo próximo ou no domínio cursos d'água (b). 


\subsection{COMPARAÇÃO ENTRE OS CLASSIFICADORES SVM E MAXVER}

A classificação do algoritmo MAXVER também apresentou índices de acurácia elevados. Seus valores foram praticamente iguais aos apresentados pelo classificador SVM, pois a Exatidão Global e o índice de Kappa foram iguais a, respectivamente, $86,0064 \%$ e 0,8385 . A Figura 5.12 mostra o mapeamento das classes segundo o MAXVER e a Tabela 5 mostra a Matriz de Confusão da classificação. 


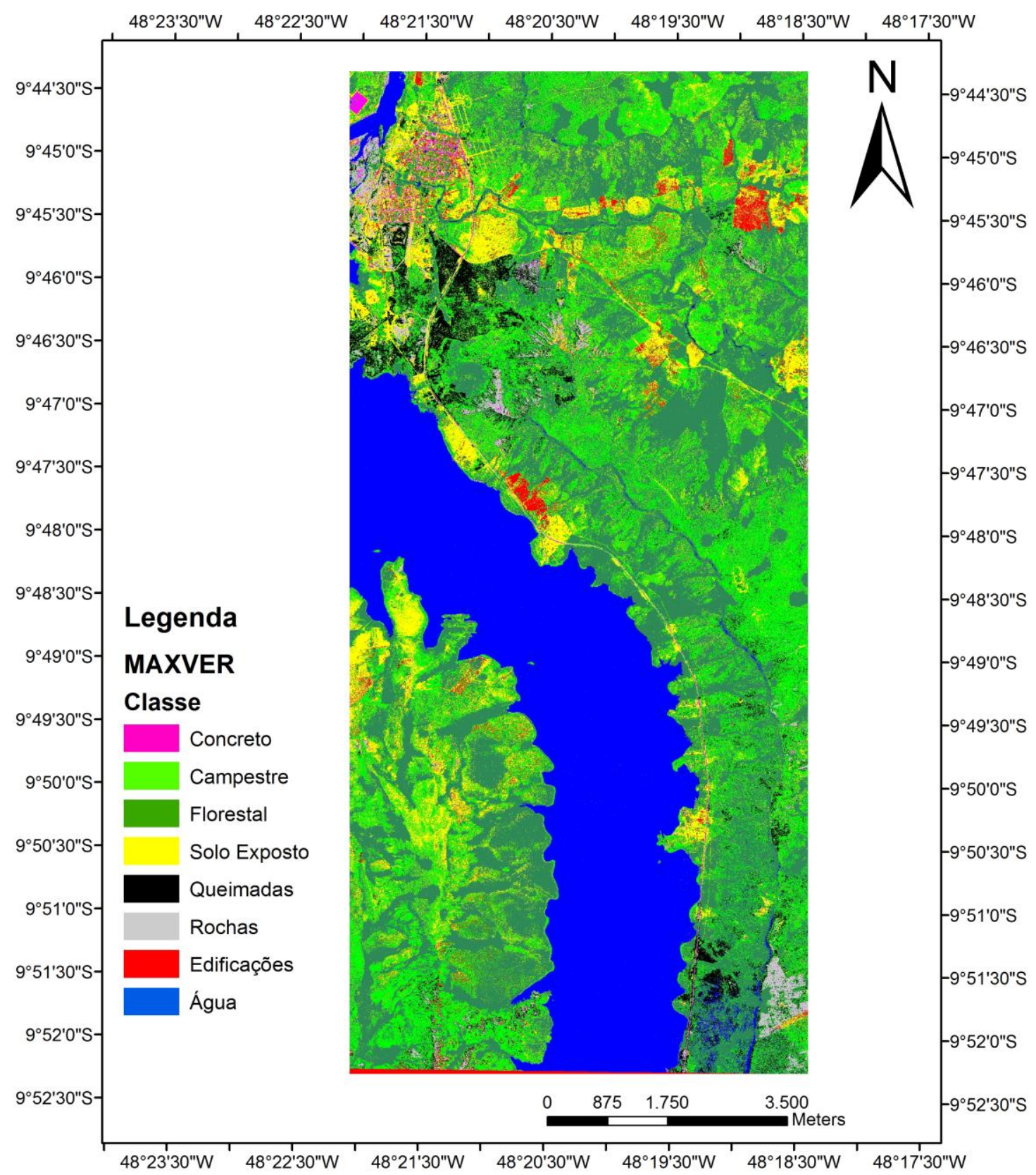

Figura 5.12 - Resultado da classificação MAXVER para a área amostrada. 
Tabela 3 - Matriz de Confusão em pixels (a) e em porcentagem (b) para a classificação obtida com o algoritmo MAXVER.

\begin{tabular}{|c|c|c|c|c|c|c|c|c|c|}
\hline Classe & Agua & Floresta & Campestre & Rochas & Edificaç̃̃es & Solo_exposto & Queimadas & Concreto & Total \\
\hline Agua & 5711 & 0 & 0 & 0 & 0 & 0 & 22 & 12 & 5745 \\
\hline Floresta & 0 & 4455 & 9 & 0 & 1 & 0 & 15 & 1 & 4481 \\
\hline Campestre & 138 & 0 & 2864 & 417 & 12 & 0 & 833 & 97 & 4361 \\
\hline Rochas & 30 & 0 & 0 & 4875 & 15 & 1382 & 5 & 540 & 6847 \\
\hline Edificações & 0 & 0 & 0 & 0 & 2104 & 737 & 0 & 10 & 2851 \\
\hline Solo_exposto & 0 & 0 & 79 & 0 & 168 & 5335 & 0 & 0 & 5582 \\
\hline Queimadas & 131 & 0 & 15 & 465 & 0 & 0 & 4091 & 0 & 4702 \\
\hline Concreto & 27 & 0 & 0 & 573 & 0 & 0 & 0 & 5807 & 6407 \\
\hline Total & 6037 & 4455 & 2967 & 6330 & 2300 & 7454 & 4966 & 6467 & 40976 \\
\hline
\end{tabular}

(a)

\begin{tabular}{|c|c|c|c|c|c|c|c|c|c|}
\hline Classe & Agua & Floresta & Campestre & Rochas & Edificações & Solo_exposto & Queimadas & Concreto & Total \\
\hline Agua & 94.60 & 0.00 & 0.00 & 0.00 & 0.00 & 0.00 & 0.44 & 0.19 & 14.02 \\
\hline Floresta & 0.00 & 100.00 & 0.30 & 0.00 & 0.04 & 0.00 & 0.30 & 0.02 & 10.94 \\
\hline Campestre & 2.29 & 0.00 & 96.53 & 6.59 & 0.52 & 0.00 & 16.77 & 1.50 & 10.64 \\
\hline Rochas & 0.50 & 0.00 & 0.00 & 77.01 & 0.65 & 18.54 & 0.10 & 8.35 & 16.71 \\
\hline Edificações & 0.00 & 0.00 & 0.00 & 0.00 & 91.48 & 9.89 & 0.00 & 0.15 & 6.96 \\
\hline Solo_exposto & 0.00 & 0.00 & 2.66 & 0.00 & 7.30 & 71.57 & 0.00 & 0.00 & 13.62 \\
\hline Queimadas & 2.17 & 0.00 & 0.51 & 7.35 & 0.00 & 0.00 & 82.38 & 0.00 & 11.48 \\
\hline Concreto & 0.45 & 0.00 & 0.00 & 9.05 & 0.00 & 0.00 & 0.00 & 89.79 & 15.64 \\
\hline Total & 100.00 & 100.00 & 100.00 & 100.00 & 100.00 & 100.00 & 100.00 & 100.00 & 100.00 \\
\hline
\end{tabular}

(b)

Pela Matriz de Confusão, as classes com menor acurácia foram Rochas, Solo Exposto e Queimadas. A Figura 5.13 mostra um exemplo em que a classe Rochas foi, segundo a Matriz, significativamente confundida com Campestre, Queimadas e Concreto. Tais erros, entretanto, são facilmente distinguíveis por avaliação visual, pois como Rochas e Concreto possuem correlação significativa, nota-se qual a verdadeira classe predominante para este caso. 


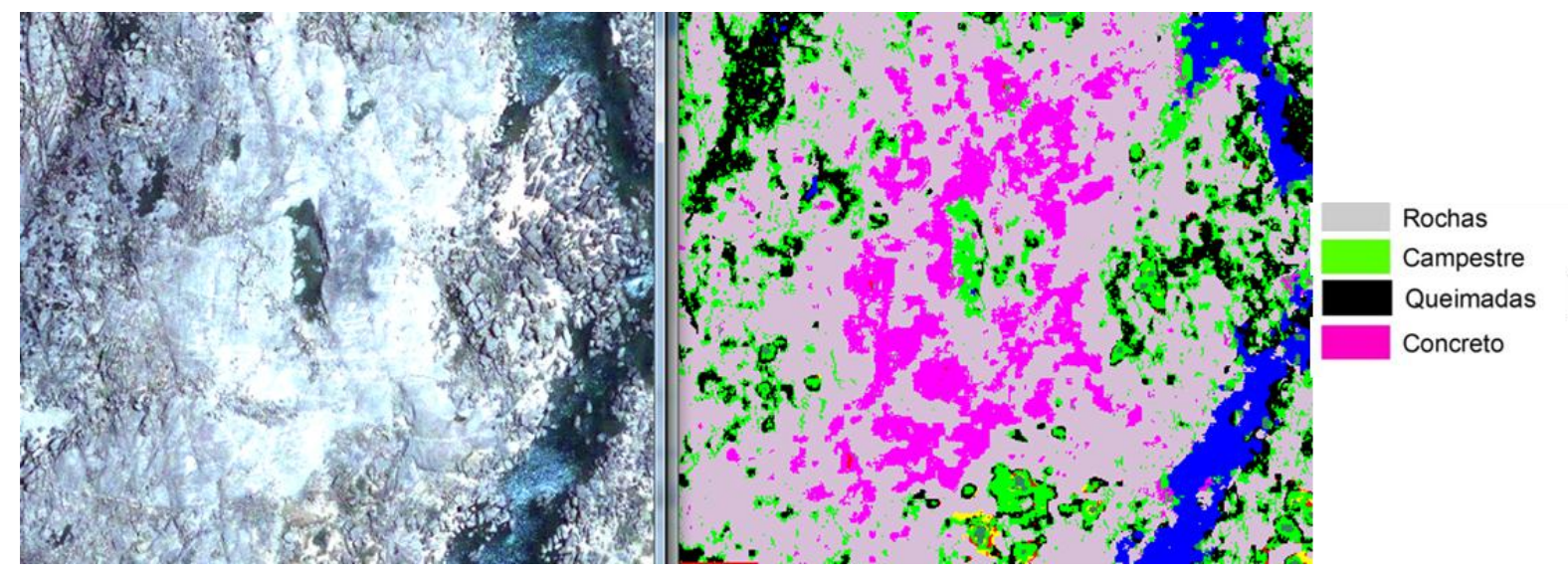

Figura 5.13 - Confusões envolvendo a classe Rochas, que são facilmente notáveis.

Os erros de comissão de Rochas que geraram omissão para Solo Exposto foram altamente similares aos ocorrentes no SVM. Para detectar estes erros visualmente, foi necessário localizar as amostras de teste da classe Solo Exposto, conforme já ilustrado pela Figura 5.5 da seção anterior. No caso do MAXVER, porém, a ocorrência foi altamente semelhante, mas com uma quantidade maior de pixels erroneamente classificados.

Novamente os erros presentes na classe Queimadas confirmaram a previsão do índice de Jeffries-Matusita. A confusão entre esta e a classe Campestre é exemplificada pela Figura 5.14, em que é facilmente perceptível qual é a dominante. No caso da Figura 5.14, nota-se que no local predomina a classe Queimadas.

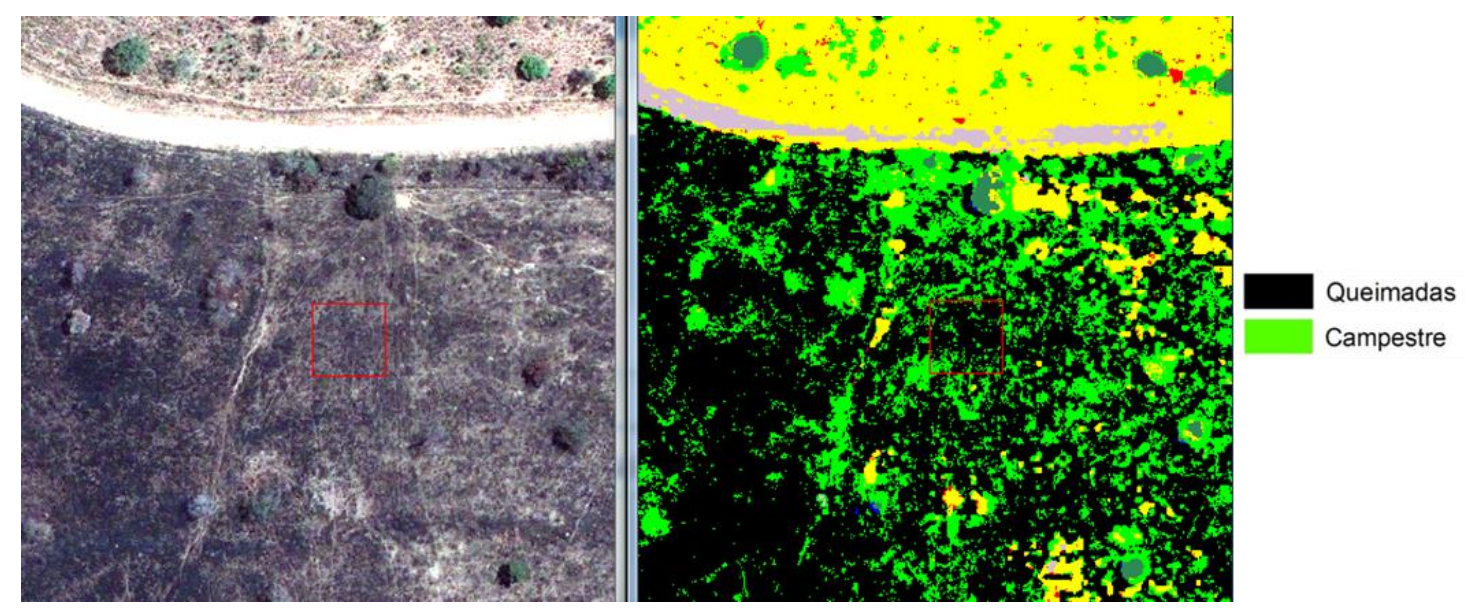

Figura 5.14 - Confusão entre as classes Campestre e Queimadas, sendo que elas apresentaram, respectivamente, erros de comissão e de omissão. 
A comparação entre os dois classificadores mostrou que seus resultados foram parecidos. Logo, o classificador MAXVER gerou erros similares aos apresentados pelo SVM. A Tabela 6 mostra as estatísticas das classes mapeadas pelo MAXVER, evidenciando que Florestal, Campestre, Solo Exposto, Queimadas e Edificações apresentaram diferenças significativas quanto à sua extensão em relação aos resultados do SVM.

Tabela 4 - Dimensão das classes de cobertura do solo ao longo da região amostrada para o algoritmo MAXVER.

\begin{tabular}{ccc}
\hline Classe & Pixels & Área (ha) \\
\hline Agua & $23,04 \%$ & 2257,76 \\
Florestal & $32,93 \%$ & 3227,31 \\
Campestre & $23,99 \%$ & 2351,54 \\
Rochas & $2,03 \%$ & 198,62 \\
Concreto & $0,30 \%$ & 29,40 \\
Solo Exposto & $10,77 \%$ & 1055,41 \\
Queimadas & $4,47 \%$ & 437,95 \\
Edificações & $2,46 \%$ & 241,27 \\
\hline
\end{tabular}

A classe Florestal foi muito bem mapeada pelo SVM, mas o mapeamento desta pelo MAXVER foi maior. Este último identificou a presença de árvores em áreas de sombra, como mostra a Figura 5.15. A presença de sombras é uma adversidade para a classificação em imagens, mas como a mesma não foi explicitada nas hierarquias de classes propostas tanto pelo IBGE quanto por CORINE, inexistiu a sua presença neste trabalho.

Ainda analisando a Figura 5.15, fica evidente também que os resultados do classificador SVM mostraram uma extensão maior para a classe Campestre do que no MAXVER. 


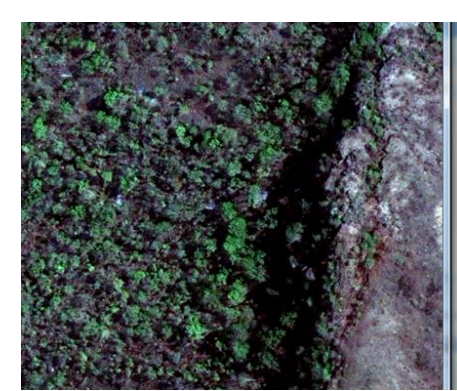

Imagem

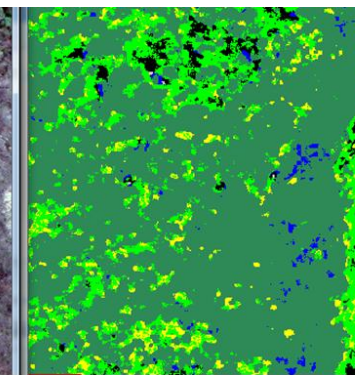

MAXVER

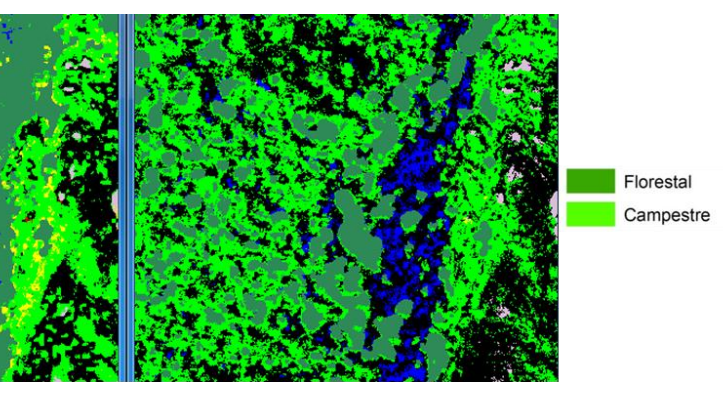

SVM

Figura 5.15 - Comparativamente, o MAXVER classificou maior quantidade de árvores (Florestal) e o SVM maior quantidade de vegetação rasteira (Campestre). Além disto, o MAXVER classificou como predominantemente Florestal as áreas sombreadas.

Já Figura 5.16 exemplifica que o SVM mapeou melhor as classes Solo Exposto e Campestre. Esta área foi verificada em campo e é mostrada na Figura 5.16 (b), que comprova a presença de ambas as classes. A Figura 5.16 reforça um exemplo de uma classificação com maior acurácia obtida para as classes Campestre e Solo Exposto segundo resultados do SVM, pois os resultados do MAXVER indicaram praticamente a presença de solo exposto. Além disto, o trabalho de campo sugeriu que a presença das classes Campestre e Solo Exposto na classificação SVM pode indicar a pastagem como tipo de uso do solo.

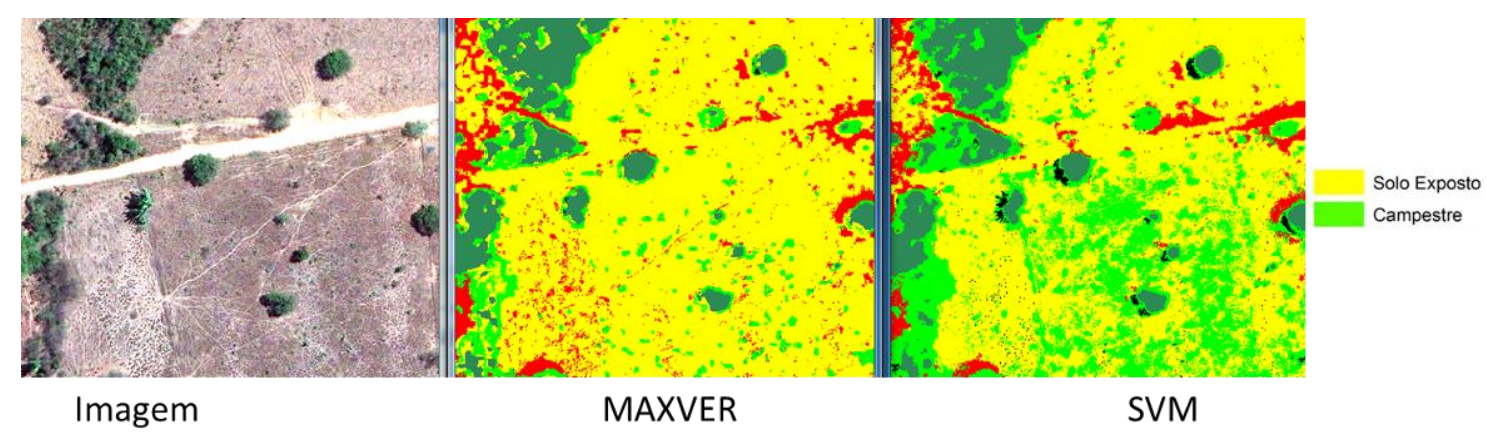

(a) 


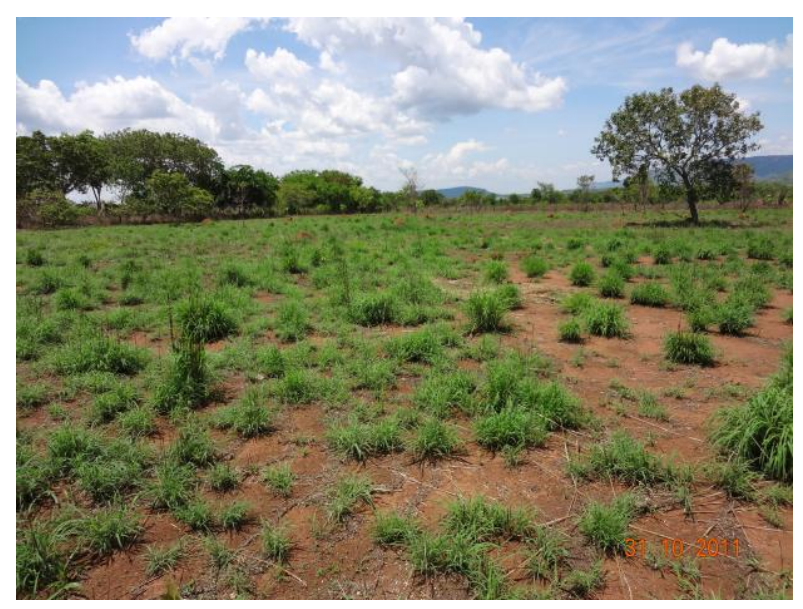

(b)

Figura 5.16 - Exemplo de uma maior acurácia na classificação de Campestre e Solo Exposto pelo classificador SVM visto pela imagem e seus mapas temáticos (a) e comprovado em nível de campo (b).

As classes Campestre e Queimadas também geraram divergências entre os classificadores. A Figura 5.17 mostra que o MAXVER mapeou com maior acurácia a classe Queimadas quando a mesma possui erros de comissão associados à erros de omissão da classe Campestre. Tais erros de comissão de Queimadas foram mais significativos na classificação SVM, justificando a diferença observada entre as extensões desta classe segundo os resultados do SVM e MAXVER. No caso da Figura 5.17, a classe Queimadas no SVM ficou mais superestimada que no MAXVER.

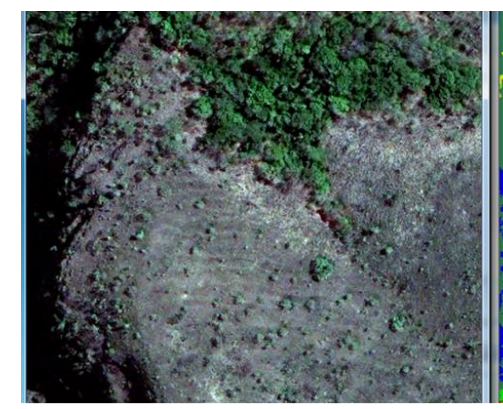

Imagem

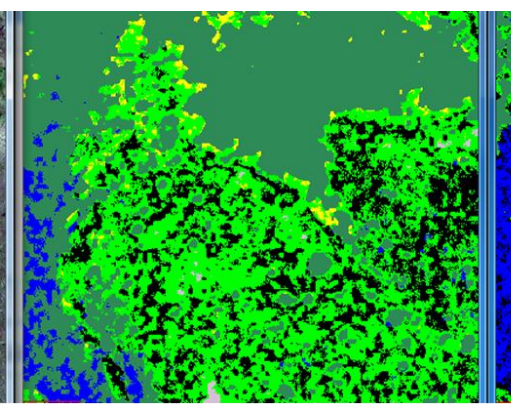

MAXVER

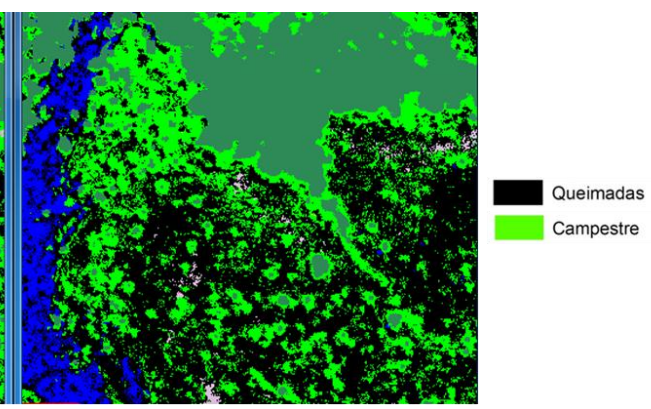

SVM

Figura 5.17 - Classificador MAXVER obteve maior acurácia no mapeamento da classe Queimadas. Neste exemplo, a classe Queimadas está mais superestimada nos resultados do SVM do que nos resultados do MAXVER. 
Os exemplos mostrados nas Figuras 5.16 e 5.17 permitiram inferir que a classe Campestre fora mapeada com maior acurácia pelo SVM quando próxima a regiões classificadas como Solo Exposto e pelo MAXVER quando associadas a erros de comissão da classe Queimadas, o que geralmente ocorre em áreas preservadas.

A classe Edificações, que apresentou erros de comissão nos resultados gerados pelo SVM, ficou ainda mais superestimada pelo MAXVER. A Figura 5.18 mostra a diferença obtida para esta classe segundo os resultados do MAXVER e do SVM.

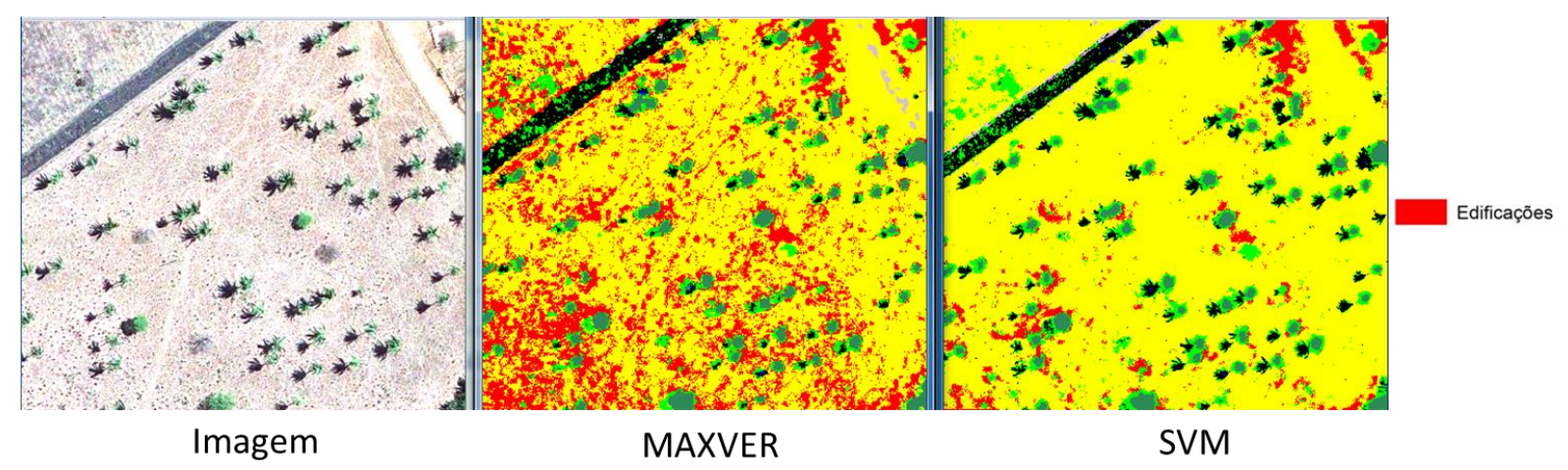

Figura 5.18 - Erros de comissão para a classe Edificações foi menor nos resultados do SVM que nos resultados do MAXVER.

Em uma avaliação qualitativa, o SVM foi considerado superior ao MAXVER no mapeamento das classes Solo Exposto e Edificações. Já o MAXVER foi considerado superior ao SVM no mapeamento das classes Florestal e Queimadas.

Avaliou-se que o SVM detectou melhor regiões que apresentam vegetação rasteira, apesar dos erros de omissão que este gerou devido à comissão da classe Queimadas. Justifica-se esta constatação porque quando a presença de Solo Exposto na classificação MAXVER é incorreta, o verdadeiro contexto da imagem é perdido. Na classificação SVM, a presença da classe Campestre, apesar dos erros de omissão, geralmente vem acompanhada das classes Florestal e Queimadas, esta última com erros de comissão.

Já o mapeamento de vegetação arbórea foi mais preciso pelo MAXVER, que não confundiu seu sombreamento com corpos hídricos ou Queimadas, conforme ocorrido pela classificação do SVM. 
Como avaliação geral, os dois resultados foram parecidos. O SVM, entretanto, contextualizou melhor suas classes no espaço, conforme exemplificam as Figuras 5.19 a 5.21. Para este classificador, portanto, apenas a classe Queimadas não foi bem mapeada.

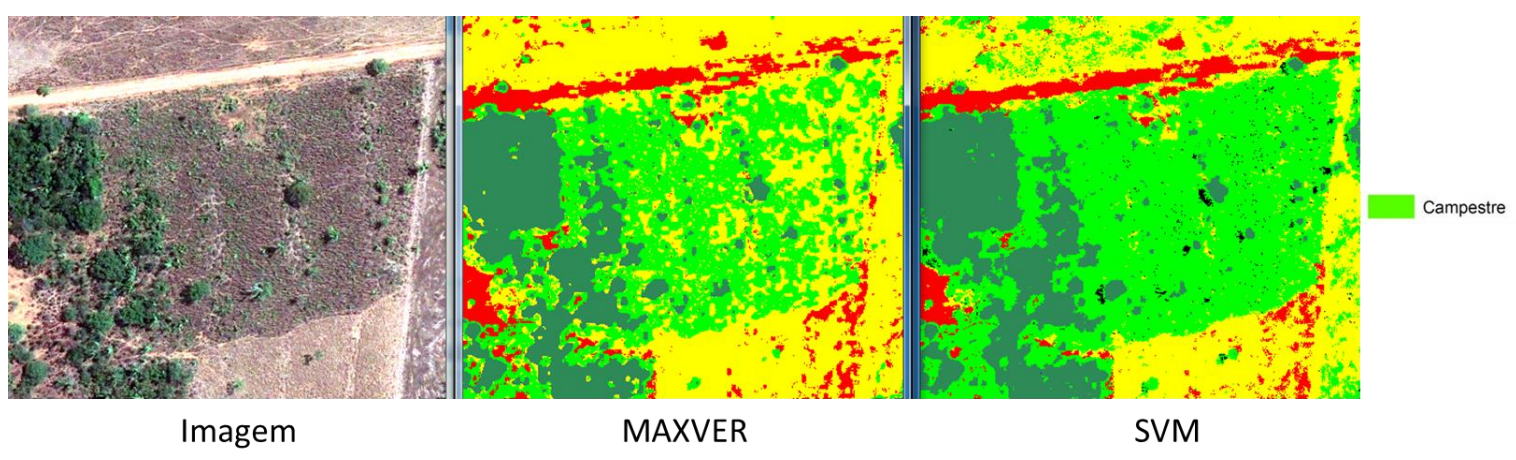

(a)

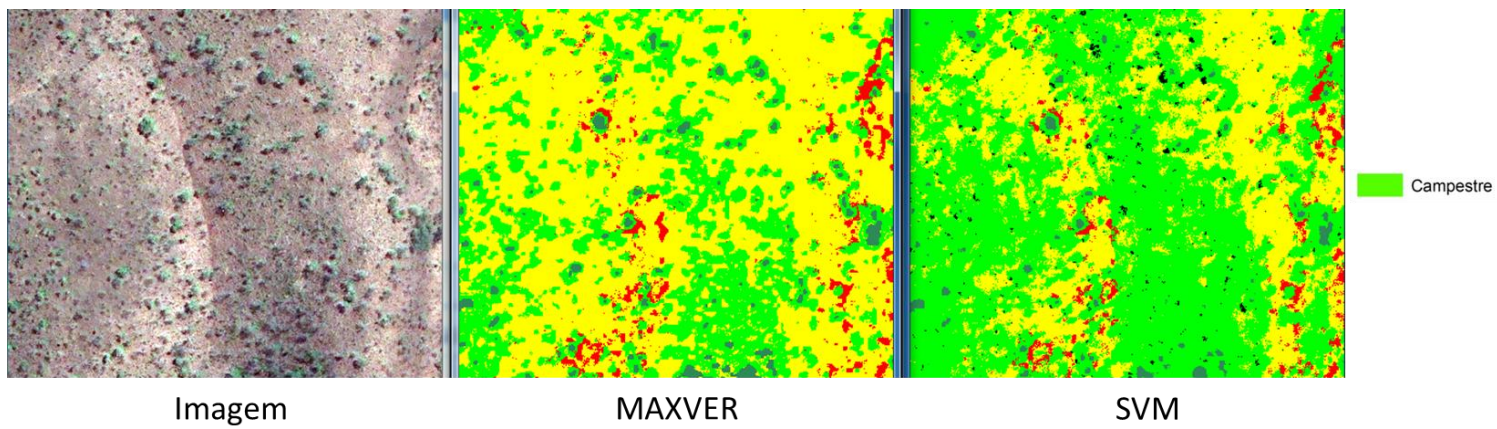

(b)

Figura 5.19 (a) e (b) - A classe Campestre obteve maior acurácia quando classificada pelo SVM.

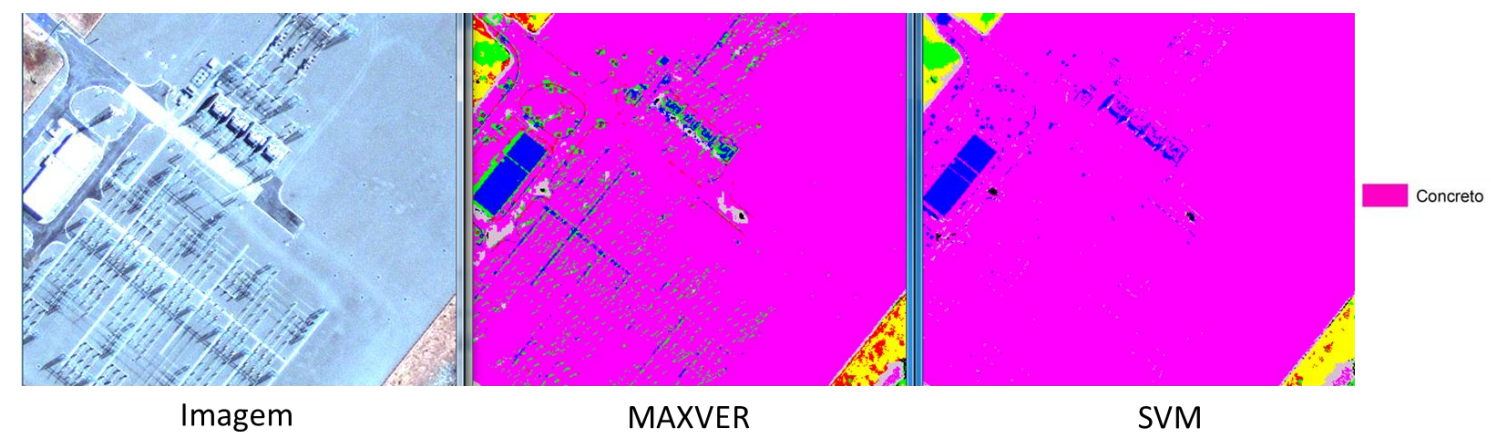

Figura 5.20 - A classe Concreto obteve maior acurácia quando classificada pelo SVM. 


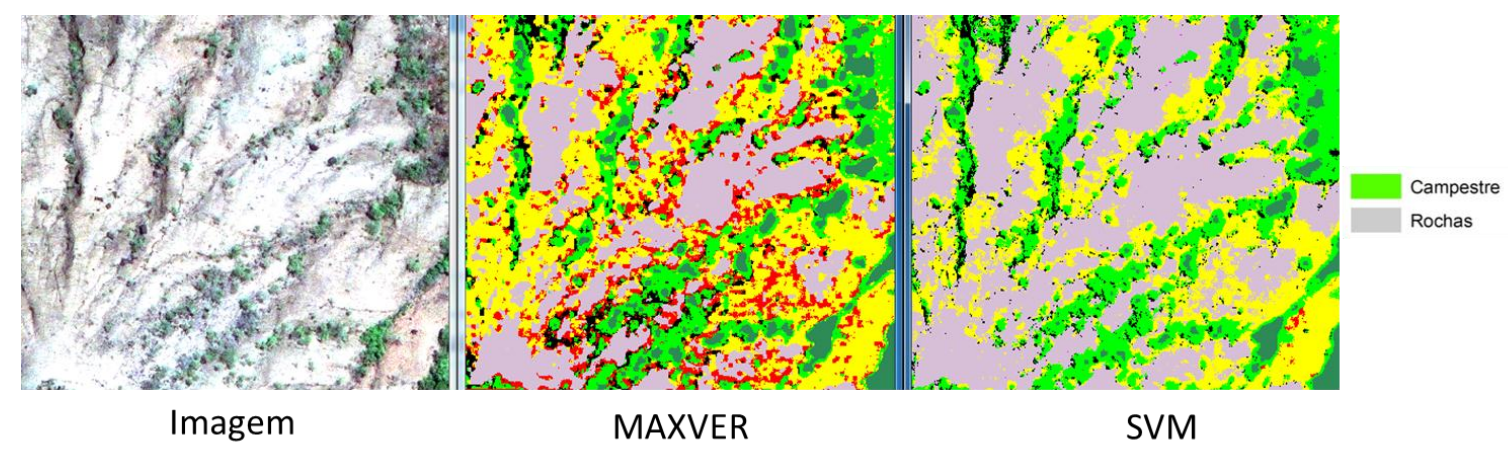

Figura 5.21 - As classes Campestre e Rochas obtiveram maior acurácia e apresentaram melhor contextualização quando classificadas pelo SVM.

Os trabalhos de campo constataram uma curiosidade acerca da classe Rochas para o sensor a bordo do satélite GEOEYE. Ao visitar a área mostrada pela figura 5.21, verificou-se que a cobertura classificada como Rochas é na verdade Campestre, conforme mostra a Figura 5.22 (a). Tal erro, contudo, fora considerado sutil, pois ao observar o perfil do solo, ilustrado na Figura 5.22 (b), verificou-se que as rochas encontram-se logo abaixo das gramíneas. A amenidade do erro reside no fato de que, para os classificadores SVM e MAXVER, cujos resultados são mostrados na Figura 5.21, predominou no sensor GEOEYE o espectro da classe Rochas, que encontra-se logo abaixo das gramíneas (classe Campestre), conforme comprova a Figura 5.22 (b).

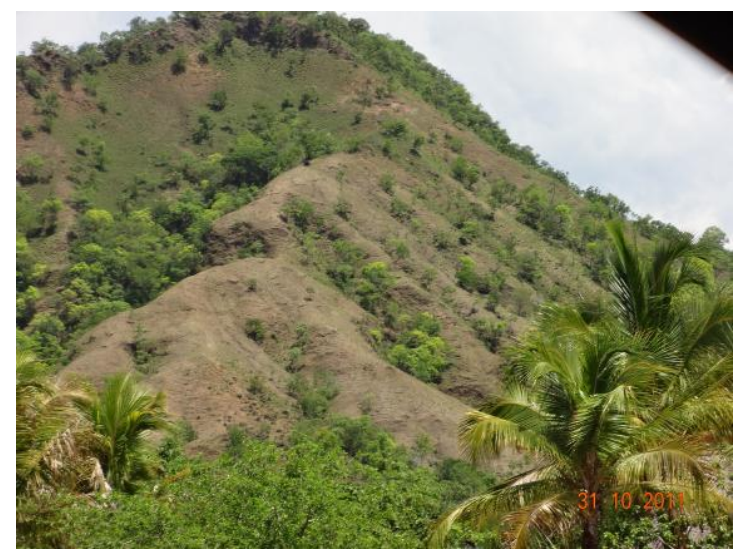

(a) 


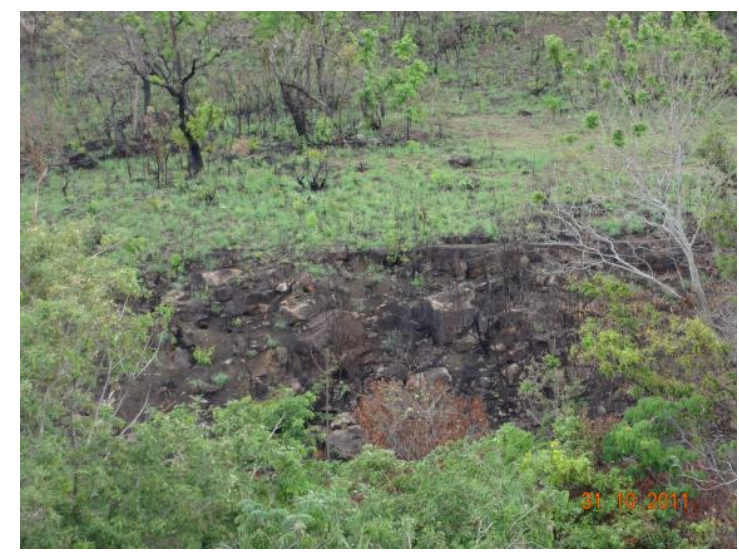

(b)

Figura 5.22 - Locais classificados como Rochas são, na verdade, gramíneas (a) que germinaram logo acima de uma camada de rochas (b). A predominância do espectro da classe Rochas no sensor GEOEYE prevaleceu na classificação, que fora mostrada na Figura 5.21.

Para um bom mapeamento da represa, portanto, ambos algoritmos geraram bons resultados. Apesar da classe Queimadas não ter apresentado um mapeamento adequado pelo SVM, a verificação de sua ocorrência pode ser auxiliada através dos resultados obtidos pelo MAXVER.

O SVM, apesar de considerado mais satisfatório em seus resultados, não diferiu significativamente do tradicional MAXVER. Tal fato pode ser explicado pelo tamanho das amostras, que como já retratado por Mather e Koch (2011), resultados bons são possíveis de ser obtidos pelo SVM já a partir de pequenas amostras. Para amostras maiores, o diferencial do SVM perante o MAXVER ocorre quando é utilizado um grande espaço dimensional de atributos (PAL; MATHER, 2005), sendo que nesta Dissertação as quatro bandas do satélite não permitiram esta situação.

Foody e Marthur (2006) evidenciaram que uma das grandes vantagens do SVM encontra-se na sua capacidade de obter uma boa classificação a partir de pequenas amostras, sendo o ênfase do algoritmo neste caso a separação de classes, não sua descrição. Pal e Mather (2005) alertaram que o SVM é significativamente superior ao MAXVER quando a dimensão do espaço amostral é grande, o que confunde o MAXVER devido ao Hughes Effect, sendo esta também uma constatação feita por Oommen et al. (2008).

Amostras grandes aproximam as classes do seu comportamento normalpadrão, comportamento de classes este assumido pela classificação do MAXVER (MATHER, 2004) e que gera resultados mais satisfatórios. Logo, uma insuficiência 
na quantidade amostrada de cada classe pode restringir a atuação deste tradicional algoritmo (OOMMEN et al., 2008). Apesar disto, caso as amostras aumentem significativamente, os support vectors mais adequados para gerarem uma boa classificação podem ser incluídos no treinamento e aprimorar ainda mais a classificação deste algoritmo (OOMMEN et al., 2008).

Logo, o uso do SVM pode ser justificado em relação ao MAXVER por ser mais robusto. O SVM não apresenta grandes restrições ao processo de amostragem, uma vez que pequenas amostras já geram bons resultados (MATHER; $\mathrm{KOCH}, 2011$ ) e grandes amostras aumentam a probabilidade de inclusão de support vectors mais adequados na delimitação da função discriminante de classes (OOMMEN et al., 2008). Além disto, o SVM pode ser empregado na classificação de imagens multiespectrais (OOMMEN et al., 2008; PAL; MATHER, 2005).

Deve-se ressaltar que o algoritmo MAXVER, apesar dos altos valores de acurácia, que neste trabalho foram ligeiramente menores que os obtidos pelo SVM, possui custos computacionais e tempo de processamento significativamente menores. Esta velocidade na geração de resultados o torna uma boa opção para se ter uma idéia preliminar sobre o mapa temático do local caso o analista se disponha a coletar amostras significativas, que consistem no maior custo deste algoritmo. 


\section{CONCLUSÕES}

Verificou-se que o SVM é um algoritmo adequado para a classificação automática em imagens de satélite de alta resolução para a gestão de hidrelétricas, pois os resultados gerais obtiveram alta acurácia e a única classe que apresentou confusões mais significativas foi Queimadas.

Foi possível verificar pelo mapeamento da cobertura do solo a localização dos principais focos de antropização a qual a represa de Lajeado está sujeita. A Lajeado EDP poderá, portanto, acompanhar o dinamismo da cobertura do solo através de imagens do mesmo sensor mas obtidas em época diferente. Como a imagem aqui analisada é de 2010, pode-se aplicar um mesmo estudo, caso haja recursos, em uma imagem de 2011 ou até mesmo em imagens de anos anteriores deste sensor.

O mapa temático obtido pelo processo de classificação mostrou que na data a qual a imagem foi adquirida a represa de Lajeado encontrou-se em um estado de preservação ambiental ainda satisfatório. Porém, como a conclusão da inundação da represa ocorreu em 2002, devem-se tomar as devidas precauções para que a expansão de áreas antrópicas não apresente proporções elevadas de crescimento e quantidades inadmissíveis de incêndios, sendo que os recursos demonstrados nesta Dissertação auxiliam nesta gestão.

A classificação obtida pelo SVM só não gerou resultado satisfatório para a classe Queimadas. As regiões rotuladas como tal devem ser devidamente avaliadas pelo analista, sendo que os resultados desta classe obtidos pelo MAXVER podem auxiliar na identificação da presença efetiva da mesma. Esta foi a única classe em que, comparativamente, o MAXVER gerou significativamente melhores resultados em relação ao SVM, visto que este último espacialmente contextualizou de maneira mais adequada as demais classes de cobertura do solo.

Logo, a identificação automática de atividades antrópicas pode auxiliar o mapeamento e, caso uma imagem de outra data do mesmo local seja adquirida, o monitoramento da dinâmica da expansão urbana nas proximidades da represa. Esta expansão já é esperada tanto pelo fato de a usina hidrelétrica atrair novas atividades econômicas ao longo de suas proximidades quanto pela existência de um estímulo ao turismo a qual agências vêm promovendo em virtude de atividades de lazer que 
uma represa pode proporcionar à população. Neste cenário, a classificação de imagens mostrou-se uma ferramenta adequada ao mapeamento de represas hidrelétricas quando se aplica o algoritmo SVM em imagens de alta resolução, reforçando assim o Sensoriamento Remoto como uma ferramenta útil no monitoramento e gestão ambiental.

Os trabalhos de campo mostraram-se úteis para o processo de classificação de imagens. Tornaram possíveis algumas constatações interessantes que, apesar de não influir diretamente no processo de classificação em si, foram de grande auxílio na avaliação da acurácia do algoritmo e levantamento de informações da área. Verificou-se pelo trabalho de campo que na imagem GEOEYE o espectro de rochas pode prevalecer sobre o de gramíneas que cresceram sobre sua superfície. Além disto, uma constatação de suma importância foi a de que os incêndios são os principais ameaçadores da qualidade ambiental do entorno da represa, sendo esta ameaça uma consequência das condições precárias de sobrevivência a qual a população local ficou imposta.

As classificações feitas neste trabalho foram feitas pixel por pixel. Como a imagem analisada possui alta resolução, sugere-se que uma classificação orientada a objeto seja implementada e seus resultados devidamente avaliados para se verificar as eventuais diferenças. Este tipo de classificação não é implementado pelo software Envi 4.8, logo, outras ferramentas devem ser buscadas para que uma classificação SVM orientada a objeto possa ser realizada. 


\section{REFERÊNCIAS BIBLIOGRÁFICAS}

ALMEIDA, C. M.; SOUZA, I. M.; ALVES, C. D.; PINHO, C.M.D.; FEITOSA, R. Q. Métodos Cognitivos de Classificação Aplicados a Imagens QuickBird para a Detecção de Áreas Residenciais Homogêneas. Revista Brasileira de Cartografia, v. 1, n. 61, p. 1-12, 2009.

ALMEIDA, W.S.; SOUZA, N.M.; CARVALHO, J.C. Produção de mapas de zonas homólogas de relevo e de uso do solo, a partir de dados de modelos numéricos de terreno e de imagem Quick Bird, como passos intermediários em um diagnóstico da susceptibilidade à erosão, no entorno da usina hidrelétrica Corumbá IV (GO). In: SIMPÓSIO BRASILEIRO DE SENSORIAMENTO REMOTO, 14, 2009, Natal - Brasil. Anais ... São José dos Campos: INPE, 25 a 30 de abril de 2009. p. 5563-5570.

ANDERBERG, M. R. Cluster Analysis For Applications. Em Probability and Mathematical Statistics, vol 19, Academic Press, Inc., USA, NY - New York, 1973.

ASSAD, E.D.; SANO, E. E. Sistemas de informações geográficas: aplicações na agricultura. Planaltina: EMBRAPA - CPAC, 1998. $434 \mathrm{p}$.

BERNARDI, H.V.F.; DZEZEJ, M.; CARVALHO, L.M.T.; ARCEBI JÚNIOR, F.W. Classificação digital do uso do solo comparando os métodos "pixel a pixel" e orientada ao objeto em imagem QuickBird. In: SIMPÓSIO BRASILEIRO DE SENSORIAMENTO REMOTO, 13, 2007, Florianópolis - Brasil. Anais... São José dos Campos: INPE, 21 a 26 de abril de 2007. p. 5595-5602.

BEZERRA, H.S.; SANO, E.E.; FERREIRA, L.G. Desempenho do satélite SinoBrasileiro de recursos terrestres CBERS-2 no mapeamento da cobertura da terra no Distrito Federal, Brasil. Revista Brasileira de Geofísica, São Paulo, v. 25, n. 2, p. 171-185, 2007.

BLANZ, V., SCHÖLKOPF, B., BÜLTHOF, H., BURGES, C., VAPNIK, V. and VETTER, T. Comparison of view-based object recognition algorithms using realistic 3d models. In VON DER MALSBURG, C.; VON SEELEN, W.; VORBRÜGGEN, J. C.; SENDHOFF, B. Artificial Neural Networks-ICANN'96. Berlin: Springer Lecture Notes in Computer Science, Vol. 1112. 1996. p. $251-256$.

BLASCHKE, T. Object based image analysis for remote sensing. ISPRS Journal of Photogrammetry \& Remote Sensing, v. 65, n. 1, p. 2-16, ago 2010.

BOLFE, E.L.; PEREIRA, R.S.; AZAMBUJA MADRUGA, P.R.; FONSECA, E.L. Avaliação da Classificação Digital de Povoamentos Florestais em Imagens de Satélite Através de Índices de Acurácia. R. Árvore, Viçosa - MG, v.28, n. 1, p. 85-90, 2004. 
BORGES, S.V.; SILVA, N.M. Análise da Influência do reservatório de Manso, na Marginal Oeste, Chapada dos Guimarães - MT. Engenharia Ambiental - Espírito Santo do Pinhal, v. 5, n. 3, p. 017-035, set/dez 2008.

BOSSARD, M.; FERANEC, J.; OTAHEL, J. CORINE land cover technical guide Addendum 2000. Technical Report, n. 40, European Environment Agency, 2000.

BURGES, C. A tutorial on support vector machines for pattern recognition. Data Mining and Knowledge Discovery, v.2, n.2, p. 121-167, 1998.

CABRAL, J. B. P. Utilização de técnicas de segmentação e correlação de Sperman em Imagens TM para o Estudo da Concentração de Sedimentos em Suspensão no Reservatório de Barra Bonita - São Paulo - Brasil. Geofocus - Revista Internacional de Ciência y Tecnologia de la Informacion Geográfica., Madrid- España, n. 3, p. 235267, 2003.

CALDERANO FILHO, B. 2009; ANDRADE, A.G.; POLIVANOV, H.; GUERRA, A.J.T.; RAMALHO FILHO, A. Diagnóstico geoambiental da área do entorno do reservatório da usina hidrelétrica de Tombos, para fins de recuperação de áreas degradadas. Caminhos de Geografia, Uberlândia - MG, v. 10, n. 29, p. 118 - 134, Mar/2009.

CAMPBELL, J. B. Introduction to Remote Sensing. New York: Guildford Press, 2008. $626 \mathrm{p}$.

CASTANO, R.; MAZZONI, D.; TANG, N.; DOGGET, T.; CHIEN, S.; GREELEY, R.; CICHY, B.; DAVIES, A. Learnig Classifiers for Science Event Detection in Remote Sensing Imagery. In. ISAIRAS 2005 CONFERENCE, Munich, Germany, Proceedings... Munich, ESA SP-603, from September 5 to 8, 2005. Disponível em: http://trs-new.jpl.nasa.gov/dspace/bitstream/2014/37464/1/05-2146.pdf

CHEN, Z.; CURRAN, P.J.; HANSOM, J.D. Derivative Reflectance Spectroscopy to Estimate Suspended Sediment Concentration. Remote Sensing of Environment, v. 40, n. 1, p. $67-77,1992$.

CONG, P.; HOWART, P. J. An assessment of some factors influencing multispectral land-cover classification. Photogrammetric Engineering and Remote Sensing. Bethesda, v. 56, n. 5, p. 597-603, 1990.

CONGALTON, R. G. A review of assessing the accuracy of classifications of remotely sensed data. Remote Sensing of Environment. v. 37, p. 35-46, 1991.

CORTES, C.; VAPNIK, V. Support vector networks. Machine Learning, v. 20, n. 3, p. 273-297, 1995.

DAVIDE, A. C. et al. Restauração de matas ciliares. Informe Agropecuário, Belo Horizonte, v.21, n.207, p.65- 74, 2000.

DTREG. <http://www.dtreg.com/svm.htm>. Acesso em: 6 de junho de 2011. 
DUTRA, G.C.; DAVIDE, A.C.; CARVALHO, L.M.T.; BOTELHO, S.A. Modelo de estratificação de áreas visando à recuperação da área no entorno da Usina Hidrelétrica do Funil (Rio Grande) - MG. In: SIMPÓSIO BRASILEIRO DE SENSORIAMENTO REMOTO, 13, 2007, Florianópolis - Brasil. Anais ... São José dos Campos: INPE, 21 a 26 de abril de 2007. p. 2533-2539.

DUTTA, S.; SHARMA, S.A.; KHERA, A.P.; AJAI, YADAV, M.; HOODA, R.S.; MOTHIKUMAR, K.E.; MANCHANDA, M.L. Accuracy assessment in cotton acreage estimation using Indian remote sensing satellite data. Jornal of Photogrammetry and Remote Sensing, v.49, n.6, p. 21-26, 1994.

EMPRESA DE PESQUISA ENERGÉTICA. Estudos do Plano Decenal de Expansão do Setor Elétrico - Estudos da Expansão da Transmissão - Análise dos Sistemas Regionais: Subsistema Norte Ciclo 2006-2015. Relatório Técnico, 2005. Disponível em:

http://www.epe.gov.br/Transmissao/Documents/Estudos 10/PDEE TRANSMISSAO NORTE.pdf

FLORENZANO, T. G. Imagens de satélite para estudos ambientais. São Paulo: Oficina de Textos. 2002. p. 42-54.

FOODY, G. M.; MARTHUR, A. The use of small training sets containing mixed pixels for accurate hard image classification: Training on mixed spectral responses for classification by a SVM. Remote Sensing of Environment, n. 103, p. 197 -189, 2006.

FREIRE, N.C.F.; PACHECO, A.P. Aspectos da detecção de áreas de risco à desertificação na região de Xingó. In: SIMPÓSIO BRASILEIRO DE SENSORIAMENTO REMOTO, 12, 2005, Goiânia - Brasil. Anais ... São José dos Campos: INPE, 16 a 21 de abril de 2005. p. 525-532.

GIGANDET, X.; CUADRA, M. B.; POINTET, A.; CAMMOUN, L.; CALOZ, R.; THIRAN, J. Region-based satellite image classification: method and validation. Image Processing, v. 3. p. 832-835, 2005.

GONÇALVES, L. FONSECA, A.M.; CAETANO, M. Exploração de imagens de alta resolução do satélite Ikonos. In: ENCONTRO DE UTILIZADORES DE INFORMAÇÃO GEOGRÁFICA (ESIG 2001), 6., Lisboa, 2001. Anais... Lisboa, Série Comunicação, 2001. 22p.

GONZALES, R.C.; WOODS, R.E. Processamento de Imagens Digitais. São Paulo, Brasil: Edgard Blucher. 2000.

GRANEMANN, E. A revolução do conhecimento. Infogeo. n.40, p.32-33, 2006.

GUALTIERI, J. and CROMP, R. Support vector machines for hyperspectral remote sensing classification. In: AIPR WORKSHOP, 27, 1998, Washington, D. C. Proceedings of SPIE... The International Society for Optical Engineering 3584, 
October 14 to 16 in 1998, p. 221-232. Disponível em: http://citeseerx.ist.psu.edu/viewdoc/download?doi=10.1.1.27.838\&rep=rep1\&type=pdf.

GUNAL, S.; EDIZKAN, R. Subspace based feature selection for pattern recognition. Information Sciences. v. 178, n.19, p. 3716-3726, 2008.

HAYAKAWA, E.H.; COUTO, E.V.; SOUZA FILHO, E.E.; PRADO, B.R.; PAULA, P.F. Análise temporal da planície de inundação do alto do Rio Paraná (região de Porto Rico - PR) através de dados de Sensoriamento Remoto. Bol. geogr., Maringá, v. 28, n. 1, p. 115-126, 2010.

HEROLD, M.; GARDNER, M.; ROBERTS, D. Spectral Resolution Requirements for Mapping Urban Areas. IEEE Transactions on Geoscience and Remote Sensing, v. 41, n. 9, p. 1907-1919, 2003.

HOFMANN, T.; SCHOLKOPF, B.; SMOLA, A. J. Kernel methods in machine learning. The Annals of Statistics, v. 36, n. 3, p. 1171-1220, 2008.

HSU, C.W.; CHANG, C.C; LIN, C.J. A Practical Guide to Support Vector Classification. Department of Computer Science, National Taiwan University, 2010. (Technical report).

HSU C.-W. and C.-J. LIN, A comparison of methods for multiclass support vector machines. IEEE Transactions Neural Networks, v. 13, n. 2, p. 415-425, Mar. 2002.

HUSON, D. SVM. In: Algorithms in bioinformatics II. SoSe'07: Center for Bioinformatics Tübingen, June 27, 2007. Disponível em: <http://ab.inf.unituebingen.de/teaching/ss07/albi2/script/svm.pdf/view?searchterm $>$. Acesso em: 6 de junho de 2011.

INSTITUTO BRASILEIRO DE GEOGRAFIA E ESTATÍSTICA. Manual Técnico de Uso da Terra. Rio de Janeiro: Manuais Técnicos em Geociências, n.7. 2006. 91p.

ITT Visual Informations Solutions. ENVI 4.8 Help. Boulder, 2010.

IWAI, O. K.; QUINTANILHA, J. A. Utilização de imagens de satélite como ferramenta de auxílio ao planejamento urbano. Revista de Geografía Norte Grande, v. 12, n. 34, p.65-82, Dez. 2005.

JARDINI, M. G. M. ; JARDINI, J. A.; MAGRINI, L. C.; CRISPINO, F.; QUINTANILHA, J. A.; PINFARE, J. C.; SILVA, L. R. Monitoring system for hydroelectric reservoir using high resolution satellite images. In: IEEE Trondheim PowerTech 2011, 2011, Trondheim. IEEE Trondheim PowerTech 2011, 2011.

JENSEN, J. R. Introductory Digital Image Processing. United States of America: Prentice-Hall, 1986. 379p. 
KNEIB, E. C.; SILVA, P. C. M. Caracterização de empreendimentos geradores de viagens: contribuição conceitual à análise de seus impactos no uso, ocupação e valorização do solo urbano. In: CONGRESSO DE PESQUISA E ENSINO EM TRANSPORTES, 18, 2004, Florianópolis - Brasil. Anais... Rio de Janeiro: ANPET, 8 a 12 de novembro de 2004. p. 77-80.

KOPONEN, S., PULLIAINEN, J., KALLIO, K., HALLIKAINEN, M. Lake water quality classification with airbone hyperspectral spectrometer and simulated Meris data. Remote Sensing of Environment, v. 79, n. 1, p. 51-59. 2002.

KOPPEN, W. Climatologia: Um Estudio de los Climasde la Tierra. Version de Pedro R. Henrichs. Mexico, Fondo de Cultura Economica, 1948. 479p.

KÖRTING, T. S. Classificação de Imagens por Regiões. São José dos Campos, 2006. Disponível em <http://www.dpi.inpe.br/ tkorting/projects/isoseg/material.pdf> Acesso em 8 de julho de 2011.

LANG, S. Object-based image analysis for remote sensing applications: modelling reality - dealing with complexity. In. BLASCHKE, T.; LANG, S.; HAY, G. J. Editors , Object Based Image Analysis. Springer, Heidelberg. Berlin: New York, 2008. p. 3 28.

LILLESAND, T.M., KIEFER, R.W. Remote sensing and image interpretation. New York: John Miley \& Sons, Inc., 1987. 721p.

LIZARAZO, I. SVM-based segmentation and classification of remotely sensed data. International Journal of Remote Sensing. v. 29, n. 24, p. 7277 - 7283, 2008.

LOCH, C., KIRCHNER, F. F. Imagem de satélite na atualização cadastral. In: SIMPÓSIO BRASILEIRO DE SENSORIAMENTO REMOTO, 5., Natal, 1988. Anais... São José dos Campos: INPE, 1988, v. 1, p. 3-6.

LORENA, A.C.; CARVALHO, A.C.P.L.F. Uma Introdução às Support Vector Machines. RITA, v. 14, n. 2, p. $43-67,2007$.

LOSEKANN, L.; OLIVEIRA, A. Supply Security in the Brazilian Electricity Sector. International Association for Energy Economics (IAEE) Energy Forum. ${ }^{\text {rd }}$ Quarter, $p$. $19-22,2008$.

LU, D.; WENG, Q. A survey of image classification methods and techniques for improving classification performance. International Journal of Remote Sensing, v. 28, n. 5, p. $823-870,2007$.

MA, Z.; REDMOND, R. L. Tau coefficient for accuracy assessment of classification of remote sensing data. Photogrametric Engineering and Remote Sensing, v. 61, n. 4, p. 435-439, 1995. 
MATHER, P. M. A computationally-efficient maximum-likelihood classifier employing prior probabilities for remotely-sensed data. International Journal of Remote Sensing, v. 6 : n. 2, p. 369 - 376, 1985.

MATHER, P. M.; KOCH, M. Computer Processing of Remotely Sensed Images: an Introduction. 4 ${ }^{\mathrm{a}}$ ed. John Wiley \& Sons, Chichester, 2011. Disponível em $<$ http://books.google.com.br/books?id=GWhvDMNh1hAC\&printsec=frontcover\&dq=m ather+computer+sensing\&hl=pt-BR\&ei=LICmTuvGAs-

tgQfazakK\&sa=X\&oi=book result\&ct=result\&resnum $=1 \& \mathrm{ved}=0 \mathrm{CDgQ6AEwAA \# v=0n}$ epage\&q=mather\%20computer\%20sensing\&f=false $>$ Acesso em 25 de outubro de 2011.

MOREIRA, M. A. Déficit hídrico na cultura do trigo e o impacto na resposta espectral e em parâmetros agronômicos. 1997. 142p. Tese (Doutorado) - Escola Superior de Agricultura Luiz de Queiroz, Universidade de São Paulo, Piracicaba, 1997.

MOREIRA, M. A. Fundamentos do sensoriamento remoto e metodologias de aplicação. 2. ed. Viçosa: UFV, 2003.

MOUAT, D. A., MAHIN, G. G., LANCASTER, J. Remote Sensing techniques in the analysis of change detection. Geocarto International, v. 8, n. 2, p. 39-50, 1993.

MURTHA, P.A. Remote sensing and vegetation damage: a theory for detection and assessment. Photogrammetric Engineering and Remote Sensing. v. 44, n. 9, p. 1147-1158, 1978.

NASCIMENTO, M. C.; SOARES, V. P.; RIBEIRO, C. A. A. S.; SILVA, E. Uso do geoprocessamento na identificação de conflito de uso da terra em áreas de preservação permanente na bacia hidrográfica do Rio Alegre, Espírito Santo. Ciência Florestal, v. 15, n. 2, p. 207-220, 2005.

NASCIMENTO, R.F.F.; ALCÂNTARA, E.H.; STECH, J.L.; KAMPEL, M. Uso de dados MERIS/ENVISAT em águas interiores. In. ALCÂNTARA, E.H.; NOVO, E. M. L de M. STECH, J.L. Novas Tecnologias para o Monitoramento e Estudo de Reservatórios Hidrelétricos e Grandes Lagos. Rio de Janeiro: Ed. Parêntese, 2011. p $81-118$.

NOERNBERG, M. A.; CALTABIANO, A.C.V.; FERREIRA, E.M.V.M. GONÇALVEZ JÚNIOR, J.D.C.; DORIA, C.R.C. Relação entre Profundidade Secchi e Fator de Reflectância da Água de Ambientes Aquáticos lênticos em Cachoeira Paulista, SP. In: SIMPÓSIO BRASILEIRO DE SENSORIAMENTO REMOTO, 08, 1996, Salvador Brasil. Anais ... São José dos Campos: INPE, 14 a 19 de abril de 1996. p. 933-939

NOVO, Evelyn M. L. M. Sensoriamento Remoto - Princípios e Aplicações. São Paulo, Brasil: Edgard Blucher. 2008. 372p. 
OOMMEN, T.; MISRA, D.; TWARAKAVI, N. K. C.; PRAKASH, A.; SAHOO, B.; BANDOPADHYAY, S. An Objective Analysis of Support Vector Machine Based Classification for Remote Sensing. Math Geosci, v. 40, p. 409 424, 2008.

OSUNA, E., FREUND, R.; GIROSI, F. Training support vector machines: an application to face detection. In IEEE CONFERENCE ON COMPUTER VISION AND PATTERN RECOGNITION, 1997 Puerto Rico. Proceedings..., Puerto Rico: CVPR, 17 a 19 de junho de 1997, p. $130-136$.

PADILHA, R. C. B. L. A., KURKDJIAN, M. L. N. O. Aplicação da técnica de segmentação em imagens HRV/SPOT para a discriminação dos vazios urbanos. In: SIMPÓSIO BRASILEIRO DE SENSORIAMENTO REMOTO, 08, 1996, Salvador Brasil. Anais ... São José dos Campos: INPE, 14 a 19 de abril de 1996. p. 241-246

PAL, M.; MATHER, P. Assessment of the effectiveness of support vector machines for hyperspectral data. Future Generation Computer Systems, v. 20, n. 7, p. 12151225, 2004.

PAL, M. e MATHER, P.M. Support vector machines for classification in remote sensing. International Journal of Remote Sensing v. 26, n. 5, p. 1007-1011, 10 March 2005.

PEIXOTO, R.H., P.B. Efeitos da implantação do reservatório da Usina Hidrelétrica Luis Eduardo Magalhães sobre a qualidade da água do Rio Tocantins. 2007. Tese (Doutorado). Universidade Federal do Rio de Janeiro, Rio de Janeiro, 2007.

PEREIRA VLR. 2002. A Limnologia e o gerenciamento integrado do reservatório da Usina Hidrelétrica Luis Eduardo Magalhães - UHE Lajeado Tocantins. 2002. 262 p. Tese (Doutorado). Universidade Estadual de São Paulo, São Paulo, 2002.

PEREIRA FILHO, W.; STRASSBURGER, L.; BARBOSA, C. C. F. Caracterização Espectral do Reservatório de Ita - Sul do Brasil. In: SIMPÓSIO BRASILEIRO DE SENSORIAMENTO REMOTO, 11, 2003, Belo Horizonte - Brasil. Anais ... São José dos Campos: INPE, 05 a 10 de abril de 2003. p. 2555-2559.

PINHO, C. M. D.; FEITOSA, F. F.; KUX, H. Classificação automática de cobertura do solo urbano em imagem IKONOS: Comparação entre a abordagem pixel-a-pixel e orientada a objetos In: SIMPÓSIO BRASILEIRO DE SENSORIAMENTO REMOTO, 12, 2005, Goiânia - Brasil. Anais ... São José dos Campos: INPE, 16 a 21 de abril de 2005. p. $4217-4224$

REIS, R. S.; NOVO, E. M. L. M.; ESPÍNDOLA, E. L. G.; SEVERI, W. Uso de Imagens Landsat e Dados de Campo para Avaliar a Distribuição Espacial de Material em Suspensão em Reservatórios do Semi-Árido Brasileiro. In: SIMPÓSIO BRASILEIRO DE SENSORIAMENTO REMOTO, 11, 2003, Belo Horizonte - Brasil. Anais ... São José dos Campos: INPE, 05 a 10 de abril de 2003. p. 2569-2577 
RICHARDS, J.A.; JIA, X. Remote Sensing Digital Image Analysis: An

Introduction, 3aㅡ ed. New York: Ed. Springer-Verlag, 1999. p. 273-274

RODRIGUEZ, A. C. M. Mapeamento Multitemporal do uso e cobertura do solo do município de São Sebastião-SP, utilizando técnicas de segmentação e classificação de imagens TMLandsat e HRV-SPOT. São José dos Campos: INPE, 2000. 94p.

ROSA, R.; BRITO. J.L.S.; LIMA. E.F.; SIQUEIRA, C.A.; MACEDO, D. Elaboração de uma Base Cartográfica e Criação de um Banco de Dados Georreferenciados da Bacia do rio Araguari - MG. In: LIMA, S.C.; SANTOS, R.J. Gestão Ambiental da Bacia do Rio Araguari - rumo ao desenvolvimento sustentável. Uberlândia, Universidade Federal de Uberlândia - Instituto de Geografia. Brasília: CNPq, 2004. p. $69-88$.

SACHS, I. Estratégias de Transição para o Século XXI. São Paulo: Studio Nobel, 1993.

SCHOWENGERDT, R. A. On the estimation of spatial-spectral mixing with classifier likelihood functions. Pattern Recognition Letters, v. 17, n. 13, p.1379-1387, Nov. 1996.

SCHOWENGERDT, R. A. Remote Sensing - Models and Methods for Image Processing, 3a ed. United States of America: Academic Press, 2007. 515p.

SHAHSHAHANI, B. M.; LANDGREBE, D. A. The Effect of Unlabeled Samples in Reducing the Small Sample Size Problem and Mitigating the Hughes Phenomenon. IEE Transactions on Geosciences and Remote Sensing, v. 32, n. 5, p. 1087-1095, 1994.

SILVA, J. R. L. Dinâmica de cianobactérias e cianotoxinas em um braço do reservatório da Usina Hidrelétrica Luís Eduardo Magalhães e suas implicações para o abastecimento público de Palmas-TO. 2009. Dissertação (Mestrado). Universidade Federal do Rio Grande do Sul, Porto Alegre, 2009.

SILVA, O. F.; NOVO, E.; KRUG, T. Distribuição Espaço-temporal dos Totais Sólidos em Suspensão do Reservatório Tucurui/PA Através de Dados in situ e TM-Landsat. In: SIMPÓSIO BRASILEIRO DE SENSORIAMENTO REMOTO, 08, 1996, Salvador Brasil. Anais ... São José dos Campos: INPE, 14 a 19 de abril de 1996. p. 387-392.

SINGH, A. Digital change detection techniques using remotely sensed data. International Journal of Remote Sensing, v. 10, p. 989-1003, 1989.

SKOLE, D.L., CHOMENTOWSKI, W.H., SALAS, W.A., NOBRE, A.D. Physical and Human Dimensions of Deforestation in Amazonia. Bioscience, v. 44, n. 5, p. 314322, 1993. 
SONG, M.; CIVCO, D. Road Extraction Using SVM and Image Segmentation. Photogrammetric Engineering \& Remote Sensing, v. 70, n. 12, p. 1365-1371, December 2004.

SOUSA, B.F.S.; TEIXEIRA, A.S.; SILVA, F.A.T.F. Classificação de bioma caatinga usando Support Vector Machines (SVM). In: SIMPÓSIO BRASILEIRO DE SENSORIAMENTO REMOTO, 14, 2009, Natal - Brasil. Anais... São José dos Campos: INPE, 25 a 30 de abril de 2009. p. 7917-7924.

SOUSA, M.A.; RIBEIRO, R.J.C.; CARNEIRO, P.J.R. Aplicações do sensoriamento remoto e do geoprocessamento. Estudo de caso: bacia do rio do Sono, TO - Brasil. In: SIMPÓSIO BRASILEIRO DE SENSORIAMENTO REMOTO, 14, 2009, Natal Brasil. Anais... José dos Campos: INPE, 25 a 30 de abril de 2009. p. 2241-2248.

SOUSA JÚNIOR, W. C. Geoprocessamento aplicado à determinação de parâmetros de alagamento do reservatório da usina hidrelétrica de Serra da Mesa, Minaçu, Goiás. In: SIMPÓSIO BRASILEIRO DE SENSORIAMENTO REMOTO, 09, 1998, Santos - Brasil. Anais... José dos Campos: INPE, 11 a 18 de setembro de 1998. p. 695-700.

STEIN, A.;VAN DER MEER, F.; GORTE, B. Spatial Statistics for Remote Sensing. Netherlands: Kluwer Academic Publishers, 1999. 284p.

STORY, M.; CONGALTON, R.G. Accuracy assessment: a user's perspective. Photogrammetric Engineering and Remote Sensing, v. 52, p. 397-399, 1986.

TANAKA, S; SUGIMURA, T. A new frontier of remote sensing from IKONOS images. International Journal of Remote Sensing. v. 22, n.1, p. 1-5, 2001

TUNDISI J. E. M. Indicadores da qualidade da bacia hidrográfica para gestão integrada dos recursos hídricos. Estudo de caso: Bacia hidrográfica do Médio Tocantins. 2006. 152 p. Tese (Doutorado) - Universidade Federal de São Carlos, São Carlos, 2006.

TZOTSOS, A. A Support Vector Machine Approach For Object Based Image Analysis. 2006. Disponível em < http://www.isprs.org/proceedings/XXXVl/4C42/Papers/09 Automated\%20classification\%20Generic\%20aspects/OBIA2006 Tz otsos.pdf > Acesso em 17 de outubro de 2011.

VAPNIK, V. N. The Nature of Statistical Learning Theory. New York: SpringerVerlag, 1995.

Vapnik, V. N.; Chervonenkis, A. Y. On the uniform convergence of relative frequencies of events to their probabilities. Theory of Probability and its Applications, v. 16, n. 2, p. 283-305, 1971. 
WIJAYA, A.; MARPU, P.R.; GLOAGUEN, R. Geostatistical Texture Classification of Trophical Rainforest in Indonesia. In 5th ISPRS International Symposium on Spatial Data Quality, 2007.

WORLD RESOURCES INSTITUTE. World Resources 2000-2001: people and ecosystems: the fraying web of life. Oxford: Elsevier Science, 2000. 389p.

ZITZKE, V.A. A rede sociotécnica da Usina Hidrelétrica do Lajeado (TO) e os reassentamentos rurais das famílias atingidas. 2007. 316 p. Tese (Doutorado) Universidade Federal de Santa Catarina, Florianópolis, 2007. 